NBER WORKING PAPER SERIES

\title{
SCALE VERSUS SCOPE IN THE DIFFUSION OF NEW TECHNOLOGY: EVIDENCE FROM THE FARM TRACTOR
}

\author{
Daniel P. Gross \\ Working Paper 24125 \\ http://www.nber.org/papers/w24125 \\ NATIONAL BUREAU OF ECONOMIC RESEARCH \\ 1050 Massachusetts Avenue \\ Cambridge, MA 02138 \\ December 2017
}

I am grateful to Barry Eichengreen for his support throughout all stages of this project. I also thank Dominick Bartelme, Carola Binder, Susan Carter, Brad DeLong, Alex Field, Joel Mokyr, Petra Moser, Alan Olmstead, Paul Rhode, Daniel Robert, Richard Sutch, Noam Yuchtman, and especially Marty Olney for encouragement and helpful comments, as well as participants in the BEHL Economic History Lunch, All-UC Hundred Flowers conference, and NBER DAE Summer Institute meetings. I am grateful to Richard Sutch for sharing data on hybrid corn diffusion from the USDA Agricultural Statistics. I thank the Berkeley Economic History Lab and All-UC Group in Economic History for financial support. This research was additionally supported by NSF Graduate Research Fellowship Grant No. DGE-1106400 and an EHA Graduate Fellowship. The views expressed herein are those of the author and do not necessarily reflect the views of the National Bureau of Economic Research. All errors are my own.

NBER working papers are circulated for discussion and comment purposes. They have not been peer-reviewed or been subject to the review by the NBER Board of Directors that accompanies official NBER publications.

(C) 2017 by Daniel P. Gross. All rights reserved. Short sections of text, not to exceed two paragraphs, may be quoted without explicit permission provided that full credit, including () notice, is given to the source. 
Scale versus Scope in the Diffusion of New Technology: Evidence from the Farm Tractor Daniel P. Gross

NBER Working Paper No. 24125

December 2017

JEL No. N52,O13,O32,O33,Q16

\begin{abstract}
$\underline{\text { ABSTRACT }}$
Using the farm tractor as a case study, I show that lags in technology diffusion arise along two distinct margins, which I term scale and scope. Though tractors are now used in nearly every agricultural field operation and in the production of nearly all crops, they first developed with much more limited application. Early diffusion was accordingly rapid in these narrower applications, but limited in scope until tractor technology generalized. The sequence of diffusion is consistent with a model of $R \& D$ in specific-versus general-purpose attributes and with other historical examples, suggesting that the key to understanding technology diffusion lies not only in explaining the number of different users, but also in explaining the number of different uses.
\end{abstract}

Daniel P. Gross

Harvard Business School

Soldiers Field

Boston, MA 02163

and NBER

dgross@ hbs.edu 
Technology diffusion is widely viewed as a leading explanation for productivity growth and productivity differences across industries, firms, and geographic regions. For example, it is frequently argued that facilitating the diffusion of modern production technologies to manufacturing and agriculture in developing countries is a key to lifting incomes and breaking a cycle of poverty. More generally, diffusion is typically viewed as the fastest path to the technology frontier. Research on technology diffusion has made significant inroads in explaining variation in its scale, treating as fixed the total potential market. Considerably less attention has been paid to changes in scope the set of potential applications, and thus the size of the market itself - despite that this extensive margin is one of the principal dimensions along which technologies spread. ${ }^{1}$

This paper shows that the historical diffusion of farm tractors - a technology which revolutionized twentieth-century crop production and is a fixture in modern agriculture - was the result of not only an increasing number of users, but also a growing number of uses. The tractor first developed for narrow applications with existing complementary equipment, exogenously high demand, and lower R\&D costs, and initial diffusion was accordingly rapid for these applications, but otherwise limited in scope. Only later did tractor technology become sufficiently general for its diffusion to be broadbased and pervasive. This pattern of expanding scope is consistent with other historical examples and with economic theory, which suggests that in this context, R\&D will naturally progress from specific- to general-purpose variants of an innovation, and that these technical advances will (i) drive the development of additional complementary technologies, and (ii) and directly translate to an increasing scope of diffusion. Lags in diffusion can therefore be the result of holdups and market failures in R\&D that stymie the generalization of existing technology.

The paper opens by reviewing the history of the farm tractor. Here it is useful to first clarify what the tractor is: farm tractors are vehicles that tow and power the agricultural implements that do the day-to-day work of plowing, planting, cultivating, and harvesting crops. Though now used in nearly every agricultural field operation and in the production of nearly all crops, tractors first developed for use in tillage and harvesting grain. Early, fixed-tread models could not navigate row crops without destroying the crop, and this generation of tractor technology was therefore not a candidate to replace draft power on corn-growing farms at any price. By the 1930s, however, a

\footnotetext{
${ }^{1}$ As Griliches (1957) shows, logistic models of technology diffusion are parametrized by (i) when it begins, and (ii) the rate at which it proceeds. These two parameters characterize what I refer to in this paper as "scope" and "scale," respectively. Research on diffusion has overwhelmingly focused attention on the latter, which has been attributed to heterogeneous costs and benefits (Duflo et al. 2008, Suri 2011), fixed costs of adopting an indivisible technology (David 1966, Olmstead 1975), and changes in relative factor prices (Manuelli and Seshadri 2014), as well as to suboptimal decision-making due to credit constraints (Clarke 1991), information spillovers (Conley and Udry 2010, Dupas 2014, Munshi 2004), and individual biases (Duflo et al. 2011).
} 
more versatile, general-purpose design had emerged, making it possible for these farms to "replace their horses and mules with one general-purpose tractor" (Sanders 2009).

The era of the tractor in U.S. agriculture begins in the late 1910s, prior to which diffusion was effectively zero. Using serial numbers and production data from the four major manufacturers of this period, I first verify that fixed-tread models dominated tractor production up until the early 1930s, accounting for 96\% of tractors manufactured from 1917 to 1928 and $91 \%$ through 1932 . During the 1930s, the industry made a near-complete transition to general-purpose models, which comprised over 85\% of units produced between 1933 and 1940 .

I then use county-level data from the U.S. Census of Agriculture to show that the initial wave of tractor diffusion in the 1920s was concentrated in the Wheat Belt states of North Dakota, South Dakota, and Kansas, while a second wave from 1930 to 1940 was concentrated in the Corn Belt states of Iowa, Illinois, and Nebraska. This sequence is plainly visible in maps of wheat versus corn intensity and diffusion (Figure 1). Numerically, I find that county-level diffusion from 1925 to 1930 was 0.4 percentage points greater with every percent of farmland in wheat but did not vary with farmland in corn. From 1930 to 1940, the pattern is precisely reversed, following the introduction of the general-purpose tractor and mechanical corn harvestor; in the 1940s, diffusion rounds out in counties with little of either crop and primarily growing hay. The results are robust to a wide variety of controls, sample restrictions, and definitions of diffusion - establishing that they are not due to changes in farm sizes, local factor prices, financial conditions, dealer networks, New Deal relief, the Dust Bowl, the contemporaneous diffusion of hybrid corn, or other features of Midwest agriculture that might have affected tractor demand in this period.

The question remains as to why the tractor's development followed this sequence. To put structure around this phenomenon, I introduce a model of innovation where a firm develops a technology with application-specific and general-purpose technological attributes, and where the value of the innovation depends on the evolving quality of complementary technologies. The model borrows ideas from the framework developed by Bresnahan and Trajtenberg (1995) to characterize generalpurpose technologies, while endogenizing the path of product development. Intuitively, this model suggests that product features develop in the order in which they are most valuable, implying that new technologies will often first be invented for narrow applications where complements are already available, and only later will they generalize for broader use. However, in this model, firms may be under-incentivized to invest in $R \& D$, especially general-purpose $R \& D$, because they do not internalize the external returns of their R\&D to complementors. 
The narrative record suggests that the leading manufacturers of the era made a late and limited effort to invent a general-purpose model: International Harvester executives invested few resources in its general-purpose R\&D program prior to its first breakthrough and nearly pulled the plug, and Ford had no such program at all. The stakes, however, are not small: the baseline estimates suggest that had early tractor models diffused as quickly to corn-growing regions as to wheat-growing regions, aggregate diffusion in the Midwest would have been $25.7 \%$ greater in 1930 . Back-of-theenvelope calculations suggest this increase would have generated annual labor savings equivalent to $10.2 \%$ of contemporary Midwest agricultural employment - the value of which, inflated to the present, is roughly $1.2 \%$ of current Midwest agricultural GDP.

Tractors have a rich history as the subject of research on technology diffusion. Early contributions focused on fixed costs as a barrier to tractor diffusion (e.g., Ankli 1980), following the tradition of David (1966). Recent research has emphasized the importance of factor price changes and quality improvements to explaining aggregate diffusion (Manuelli and Seshadri 2014), but the literature is missing a crucial part of the story: tractor quality historically varied as much if not more across space as it did over time. Indeed, its significance today is the result of not only its mechanical efficiency, but also its versatility as a source of power in agriculture.

Though tractors are inherently important, the example serves to highlight scope as an economically significant but under-studied margin of technology diffusion: the idea that diffusion may be propelled by expanding capabilities, rather than uniform price or quality changes, is intuitive yet largely overlooked in the literature. A related line of work has introduced the idea of "appropriate technologies" to growth models as an explanation for uneven diffusion (Basu and Weil 1998), and the possibility of a mismatch between technological requirements and local factors of production (Acemoglu and Zilibotti 2001, Caselli and Coleman 2006). Yet in these papers, technologies are fixed, and countries adopt newly appropriate technologies as they develop (e.g., as skilled worker share or capital intensity increases). In the present paper, I instead show that technologies themselves can endogenously evolve from being narrowly to widely appropriate.

An implication of the results is that in addition to studying the population of users, research on diffusion should also focus attention on the firms performing $R \& D$ that increases the scope of existing technologies such that they can be used more broadly. Given the potential presence of externalities that decouple private returns to $R \& D$ from social returns, a second implication is that investment in technological generality may be a high-value target for R\&D policy tools. The results of this paper might also be able to explain previously-documented spatial patterns in technology 
diffusion, such as the evidence from Comin and Hobijn (2004) that technology diffusion "trickles down" from more- to less-developed economies and from Keller (2002) that R\&D spillovers appear to decline with distance: new technology is often first developed in more advanced regions and in many cases would have to be adapted to conform to local conditions, users' needs, and technology standards in other parts of the world in order to penetrate these markets.

The paper is organized as follows. In Section 1, I review the tractor's history through the 1940s. Section 2 describes the data and estimation strategy. Section 3 provides descriptive evidence that tractors diffused in sequence to wheat- and then corn-growing regions of the Midwest. Section 4 formalizes the relationship between crop intensities and tractor diffusion and presents a battery of robustness checks, and Section 5 extends these results. In Section 6, I develop the model, discuss its implications, and relate it to the history and evidence. Section 7 considers the effects of accelerated generalization for Midwest agriculture. Section 8 concludes.

\section{History of the Tractor}

The modern tractor's history begins around 1870 with the invention of the steam tractor, which was in effect little more than a steam engine on wheels. These were equipped with a drawbar for towing portable implements and a belt pulley to power stationary equipment, and were primarily used for plowing and post-harvest threshing, with little portable use beyond tillage. They were also heavy, expensive, and prone to mechanical failure and explosion. Kerosone tractors succeeded steam models around 1890 but were similarly deficient. Given these deficiencies, these early models were never a serious threat to farms' dependence on draft power.

The transition to smaller, lighter-weight, more affordable tractors occurred in the 1910s. The first true commercial success in the tractor industry was the Ford Fordson in 1917, and by all accounts it marked the beginning of the tractor era (Figure 2). By the end of 1918, Ford had overtaken its competitors in sales (Leffingwell 1998), and by the early 1920s, the Fordson accounted for $75 \%$ of tractor sales in the U.S. (Leffingwell 2002). At the time Ford ended production in 1928, it had sold nearly half of all tractors sold in the 1920s (White 2010).

[Figure 2 about here]

The advantages of the Fordson were its size, agility, low price, and the fact that it could be used with existing plows, harrows, and grain combines (Williams 1987). However, its low clearance made 
it impractical for cultivating row crops such as corn or cotton, leading manufacturers to separately develop and sell expensive, standalone cultivators and Corn Belt farms to continue relying heavily on draft power. Contemporary studies found that the diversity of farm operations was one of the key impediments to tractor adoption: fixed-tread tractors could be used for $77 \%$ of field operations in raising common grains, but only $38 \%$ in row crops (Gunlogson 1922), and this same study then noted that "since 4 to 6 horses are required to care properly for the corn crop on operations which cannot be done with the common type of tractor, and since the whole farm can be operated with five or six horses, the investment in a tractor is not justifiable on the basis of economy." Other contemporaries similarly observed that although this class of tractor had become popular in grain production, "the market for tractors in the Corn Belt... has hardly been scratched, for study reveals that only about $6 \%$ of the farms in these six states have tractors, while the other $94 \%$ percent still depend on horses for power" (Iverson 1922), at a time when small grains and corn each comprised about $40 \%$ of total U.S. acreage in field crops (Gunlogson 1922).

The "logical solution" (Iverson 1922) was to design a tractor that could do it all. Despite the known, large potential demand for a general-purpose variant, it was slow to develop. In the words of one International Harvester (IHC) engineer, "there was talk about a new kind of tractor in the industry" at the end of the 1910s, but "no one had such a machine or even much of an idea on how to start building one" (Klancher 2008). Nevertheless, IHC saw the Fordson's deficiencies for row crop production as targets (namely, low ground clearance and wheel placement, Leffingwell 2002), and took the lead in developing a general-purpose model.

The first references to this project in IHC records appear in 1919, but by 1921 executives were unenthusiastic about the costs and lack of progress and voted to pull funding, and the project was saved only by special funding set aside by the firm's president (Klancher 2008). Other leading firms, including Ford, made no such effort at all - such that when IHC broke through with the Farmall in 1925, it quickly overtook the market. The Farmall had high clearance and adjustable-width treads for use in all of plowing, cultivating, and harvesting, with both row crops and small grains. It also had a more powerful engine, a belt pulley to power stationary equipment, and a motor-driven shaft that could power implements (power take-off). In a 1940 testimony to Congress, the vice president of IHC described how "it made possible for the first time the application of tractor power to all field operations," and further stated it "had the greatest usefulness in farming areas where row crops predominate, particularly in the Corn Belt and Cotton Belt," where previous fixed-tread variants "had been of limited utility" (Fowler McCormick, TNEC 1940). 
The Farmall ushered in a new generation of tractor technology as competitors rushed to imitate the Farmall's design and develop their own general-purpose tractors, and it stimulated the invention of additional farm implements to be used with them. John Deere came out with a variant in 1928, and Allis-Chalmers in 1930. Further advances in tractors soon followed: in 1927, Deere invented the power lift for raising implements during turns; in 1931, Caterpillar built the first diesel-engine tractor; in 1932, Allis-Chalmers introduced pneumatic rubber tires that improved fuel efficiency and forward horsepower; and in 1938, Ford introduced the Ferguson three-point hitch for attaching implements, replacing the drawbar. Manufacturers quickly made these features standard, and by the early 1940s the main features of the modern tractor were set.

Production totals confirm the historical narrative. Table 1 shows total output of fixed-tread and row-crop tractors by the most important manufacturers of the era (Ford, IHC, Deere, AllisChalmers), which collectively produced $80 \%$ of all tractors in each of the 1920s and 1930s (White 2010). These production counts are imputed from model-specific serial numbers that uniquely identify each manufactured unit. Serial numbers were gathered from various sources (see table notes), which provided the first and last numbers stamped for each year of production. The sample covers nearly all models manufactured by these firms from 1917 to 1940.

[Table 1 about here]

The table shows a clear transition from fixed-tread to general-purpose tractors between 1917 and 1940. Nearly all units produced from 1917 to 1924 were fixed-tread Fordsons, but following the Farmall's release in 1925, fixed-tread models' share of production began a gradual but permanent decline, as general-purpose purpose models grew from $0 \%$ to over $90 \%$ of all units manufactured by $1940 .^{2}$ This technological transition can also be seen in terms of the windows studied in this paper: from 1925 to 1930, roughly 759,000 fixed-tread tractors were manufactured by these four firms (359,000 by IHC alone), versus 146,000 general-purpose units. In the next decade, from 1931 to $1940,816,000$ general-purpose tractors were produced, as opposed to only 167,000 fixed-tread units. In short, this paper argues that this technological transition is responsible for the ensuing broad-based diffusion of tractors across the U.S. Midwest.

\footnotetext{
${ }^{2}$ Note that although 214 prototype Farmalls were manufactured by IHC in 1924 and given serial numbers, and thus appear in the table for that year, commercial production only began in 1925 .
} 


\section{Previous Research on Tractor Diffusion}

Though a large body of research has studied the historical diffusion of tractors and other agricultural technologies, the importance of changes in scope is absent from this literature. Most research treats the tractor as a product of uniform quality over time and across space and attributes lags in diffusion to fixed costs and economies of scale, credit constraints, or exogenous factor price changes. Even when the existing literature recognizes that "a 'tractor' in 1960 is not the same capital good as a 'tractor' in 1920" (Manuelli and Seshadri 2014), it tends to overlook the fact that tractor quality varied as much or even more in cross-section as it did over time.

David's (1966) study of antebellum reaper adoption introduced the neoclassical threshold model to this literature, asserting that reaper diffusion was driven by increasing farm sizes (scale economies). Olmstead (1975) questioned the assumption of a static, indivisible technology, showing that joint ownership and contract work were common practice and that reapers were improving over time, and suggests that farm size was in fact simultaneous with the adoption decision. Ankli and Olmstead (1981), Clarke (1991), White (2000), and others have nevertheless attempted to calculate adoption thresholds for tractors in order to explain its delayed diffusion, despite the well-known critiques of David's (1966) model. Myers (1921) and Gilbert (1930) lend support to both advocates and critics of the threshold model, acknowledging that "the advantages of a tractor increase with [the] size of the farm" while also pointing out that contract work was common and that tractor adoption led farms to expand: "the ability to do more work with the tractor resulted in an increase in the amount of land worked on nearly one-third of the farms visited" (Gilbert 1930).

Clarke (1991) argues that financial barriers slowed tractor diffusion in Illinois and Iowa in the 1920s and that New Deal relief - rather than changes in farm size, factor prices, or technology was responsible for a surge in diffusion in the 1930s. To support this claim, Clarke first calculates a 1929 adoption threshold of 100 acres for farms in Corn Belt states. Clarke then finds that only about half of the farms above this threshold owned a tractor in 1929, and that this gap narrowed over the subsequent decade. After correlating "underdiffusion" ${ }^{3}$ with farmers' cash holdings and mortgage debt ratios and obtaining coefficients with the expected signs (negative and positive, respectively), she attributes the growth in diffusion to New Deal price supports and lending programs that might have improved Corn Belt farmers' financial positions and borrowing conditions.

Would-be adopters would have had to be credit-constrained for New Deal policies to cause a surge

\footnotetext{
${ }^{3}$ Defined in Clarke (1991) as the fraction of farms above the 100-acre threshold without tractors.
} 
in tractor purchases. Yet farms in North and South Dakota were leading adopters of tractors in the 1920 s, despite the post-WWI collapse in wheat prices and mortgage foreclosure rates near $50 \%$ (Alston 1983, Table 1). White (2000) further notes that "the same farmers that Clarke concluded might not have been able to obtain a loan for a tractor were cheerfully buying automobiles for cash" before 1930: roughly $80 \%$ of farms in Midwest states owned automobiles at that time, compared to only $25 \%$ owning tractors. The difference was not for a lack of manufacturer credit, as both Ford and IHC provided financing to their customers. Given these inconsistencies, the evidence that liquidity constraints can explain diffusion lags in the Corn Belt is questionable, though financing undoubtedly plays an important role in large equipment purchases.

Manuelli and Seshadri (2014) counter the claim that tractor diffusion was inefficiently slow due to market imperfections such as credit constraints with the more traditional argument that exogenous changes in factor prices and improvements in tractor quality over time can rationalize the tractor's allegedly "slow" diffusion. Accounting for the tractor's improving quality over time is an important contribution, yet by modeling aggregate diffusion and ignoring variation in quality across space, it misses a crucial part of the story: tractors hardly diffused to farms growing row crops before the 1930s because they could not replace draft power at any price. Treating the tractor's quality as a unidimensional parameter that follows a secular process over time and using it to explain the scale of diffusion in the aggregate belies the true nature of the problem.

\section{Data and Empirical Strategy}

The paper draws on a panel of 1,059 counties in the U.S. Midwest from 1925 (the earliest date for which county-level diffusion data are available) to 1950, with the baseline sample restricted to the 1,033 counties whose borders were unchanged from 1910 to $1950 .{ }^{4}$ The Midwest led the country in tractor adoption through 1950 and exhibits sufficient spatial variation in diffusion throughout the tractor era to be able to identify its expanding scope. The Midwest also spans the principal

\footnotetext{
${ }^{4}$ The included states are: Illinois, Indiana, Iowa, Kansas, Michigan, Minnesota, Missouri, Nebraska, North Dakota, Ohio, South Dakota, and Wisconsin. Together these states form the East and West North Central Census Divisions. There are 1,059 uniquely defined counties over this period, and 1,033 with static borders. The 26 dropped counties are primarily in North and South Dakota. I forgo Hornbeck's (2010) border adjustment procedure to avoid synthetic observations that piece together fractions of counties under the assumption that county-level variables are evenly dispersed across space. The results are insensitive to this choice. Regression samples are further restricted to counties with data available for all robustness checks: 1,030 counties in 1925-30, 942 counties in 1930-40, and 943 counties in 1940-1950. In all periods, St. Louis County and City are dropped because some data sources do not distinguish between them. The remaining reduction is the result of either missing or unreadable Census pages, or missing values for specific crops' acreage in counties where fewer than three farms reported in 1940 (primarily barley and rye).
} 
grain-producing counties in quantity and value, making it of inherent interest.

The analysis integrates data from several sources. I use county-level data in Midwest states from the 1910 to 1950 U.S. Census of Agriculture to measure tractor diffusion, investment in agricultural implements, farmland, crop mix, and other characteristics of farms and farmers. ${ }^{5}$ I draw on the U.S. Census of Population in the same years for supplementary county-level data. The dataset also includes records of bank failures from the FDIC; county-level New Deal expenditures from Fishback, Kantor, and Wallis (2003); Dust Bowl soil erosion from Hornbeck (2012); average levels and variation in elevation and rainfall at the county-level, from the USGS and PRISM Climate Group at Oregon State University, respectively; and state-level hybrid corn diffusion from the USDA Agricultural Statistics (Sutch 2011, 2014). I use these data to understand and control for other features of Midwest agriculture that may influence tractor adoption.

I use the NHGIS county boundary shapefiles (Minnesota Population Center 2011) for the 19101950 Census years to aggregate continuous geospatial data (elevation, rainfall) at the county level and drop all counties that merged or divided over the sample period as well as counties whose geographic centroids shifted more than 0.01 degrees in latitude or longitude between decades. The main analysis treats remaining counties' borders as static, reflecting the stability over these years of the centroids calculated by mapping software.

\section{Empirical Methods and Identification}

In the following sections, I compare tractor diffusion in counties with historically different concentrations of wheat and corn, the principal crops grown for harvest and sale in the Midwest and U.S. as a whole. If the historical account is true, diffusion in the 1920s should have occurred more rapidly in counties growing wheat and more slowly in counties concentrated in corn. Following the development of the general-purpose tractor in the late 1920s, the difference should then mitigate or reverse, with corn-heavy counties experiencing catch-up growth in diffusion.

I do so in a difference-in-differences framework, removing county-level fixed effects and identifying off county-level changes in diffusion over time. The identification strategy hinges on the fact that

\footnotetext{
${ }^{5}$ In most tables and figures, I define diffusion as the fraction of farms with a tractor. The 1925 Census of Agriculture is the first year that data on tractor ownership were reported and provides the number of tractors in a county. The 1930, 1940, and 1950 Censuses report both the number of tractors and the number of farms with tractors. I approximate diffusion in 1925 as the number of tractors over the number of farms, under the assumption that each farm owns at most one tractor. This assumption approximates the reality on the ground, especially given patterns in later Censuses (e.g., in 1930, the mean number of tractors per farm with tractors is 1.04 (90th percentile 1.11).
} 
different areas are inherently better suited to growing wheat versus corn for exogenous reasons, such as soil type and climate, and that local crop choices reflect these advantages - a fact which is plainly visible in maps of spatial crop distributions and is hardly disputed. Formally, the assumption is that county-level wheat and corn concentrations are independent of unobserved factors that may influence changes in diffusion. To eliminate any possibility of simultaneity in crop choices and tractor adoption, I use pre-period (1925) crop intensities in regressions, though results are similar using other years (1910/1920). Appendix B.2 provides evidence that crop shares are persistent over the sample period, both in cross-section and in the aggregate.

\section{Characteristics of Sample}

Table 2 shows descriptive statistics by year for the sampled counties, including: tractor diffusion, the fraction of farmland in each of the six most-common crops, the fraction of farms in six size categories, average farm size, and financial conditions. It is important to note that this period was a dynamic time in U.S. agriculture - by no means was the tractor the only change taking place and it will therefore be important to control for concurrent trends. ${ }^{6}$

[Table 2 about here]

\section{Descriptive Evidence}

The main empirical fact of this paper - that tractors diffused first to the Wheat Belt, and only later to the Corn Belt - is summarized by Figure 1. The top row of the figure maps the fraction of farmland in wheat and corn (left and right, respectively) across Midwest counties in 1925, with darker blues representing higher concentrations. The second row maps increases in tractor diffusion from 1925-30 (left) and 1930-40 (right). The third row maps the fraction of mechanized farms in 1940 whose latest vintage tractor was manufactured pre-1930 (left) versus between 1935-40 (right), using data on tractor vintages from the 1940 Agricultural Census.

[Figure 1 about here]

\footnotetext{
${ }^{6}$ Concurrent changes include growing farm sizes; changing financial conditions, particularly due to the Depression, New Deal, and Dust Bowl; and the diffusion of hybrid corn. These are discussed in depth in Section 4.
} 
Tractor diffusion through 1930 was visibly concentrated in wheat-growing states, while over the following decade it was almost fully coincident with the Corn Belt. As Section 4 will show, traditional explanations for technology diffusion cannot fully account for these patterns.

Figure 3 provides a more quantitative presentation of this pattern. The figure plots tractor diffusion between 1920 and 1940 for three state pairs: (i) North Dakota and Kansas, which are outliers in wheat intensity; (ii) Iowa and Illinois, which are outliers in corn intensity; and (iii) Michigan and Wisconsin, which grow little of either crop and thus serve as a control group. ${ }^{7}$

[Figure 3 about here]

The figure paints a clear quantitative picture of the story. Between 1920 and 1925, all three state pairs follow a similar trend, with the wheat and corn states tracking each other in both levels and changes. Over the next five years (to 1930), diffusion in the wheat states leaps past the corn states, which follow the control trend. The subsequent decade (to 1940), this pattern is precisely reversed: diffusion in the wheat states follows the control trend, and diffusion in the corn states catches up, to within two percentage points. Over the next decade (to 1950), the control states catch up to the wheat and corn states, which themselves follow a common trend. This is the pattern that I will argue is explained by changes in the capabilities and limitations of tractor technology, particularly in the earlier periods (through 1940), which are the focus of the paper. The natural question for a counterfactual is then what would have been the effects of accelerating the development of generalpurpose tractors such that the corn-growing states mechanized as quickly as the wheat-growing states - a question which is considered in Section 7.

\section{Regression Evidence}

To formalize this evidence and control for contemporaneous conditions of Midwest agriculture, I turn to regressions. The main estimating equation throughout this section has the form:

$$
\begin{aligned}
\text { Diffusion }_{i t}= & \beta_{0}+\beta_{1} \cdot \text { PctWheat }_{i, 1925}+\beta_{2} \cdot \operatorname{PctCorn}_{i, 1925}+\beta_{3} \cdot \text { Post }_{t} \\
& +\beta_{4} \cdot \text { PctWheat }_{i, 1925} \cdot \text { Post }_{t}+\beta_{5} \cdot \operatorname{PctCorn}_{i, 1925} \cdot \text { Post }_{t}+\mathbf{X}_{i t} \theta+\varepsilon_{i t}
\end{aligned}
$$

\footnotetext{
${ }^{7}$ See Appendix Figures B.5 and B.6 for a cross-sectional view of state-level crop intensities.
} 
where $i$ and $t$ index counties and years. I estimate this difference-in-differences separately on the 1925-30 and 1930-40 samples (and in one case, over a pooled 1925-40 sample). Diffusion is measured as the fraction of farms in county $c$ and year $t$ with a tractor, and crop percentages are calculated as harvested acreage as a fraction of farmland. The $\mathbf{X}_{i t}$ term represents a set of county-level controls, which are sequentially expanded over a set of several robustness checks.

Table 3 provides results from baseline specifications without controls. Column (1) shows differencein-difference estimates for 1925-30, Column (2) for 1930-40, and Column (3) for the pooled sample. The important quantity in these models is not the point estimates per se, but rather the difference between them, and for each regression I calculate the difference in coefficients for corn and wheat, which is provided as a summary statistic at the bottom of the table.

[Table 3 about here]

In these baseline models, we see that diffusion increased 0.4 percentage points (p.p.) from 1925 to 1930 per p.p. in wheat intensity but did not vary with corn intensity. The following decade, this pattern reverses. The net effect is that cumulative diffusion from 1925 to 1940 co-varied with corn and wheat intensity at similar rates. Standard errors are sufficiently precise that we can assert the presence of a large divergence from 1925 to 1930 and re-convergence by $1940 .{ }^{8}$

However, this period was a dynamic era in U.S. agriculture, featuring expansion and consolidation, technical advances in plant breeding, and two economic shocks: the Depression and the Dust Bowl. To evaluate the robustness of these patterns to concurrent trends in agriculture, Table 4 presents a battery of additional checks. Each of these checks either adds controls - described in detail below - or restricts the sample to a focused subset of counties. The table is split into two Panels: Panel A estimates models for the 1925-30 period, and Panel B for the 1930-40 period. As before, the difference in coefficients for corn and wheat is provided as a summary statistic.

The first column of each panel presents the baseline result from Table 3. Each column thereafter cumulatively adds controls. Column (2) controls for county-level changes in the stock of agricultural implements and machinery as a fraction of land values from 1910 to 1925, as a proxy for pre-trends in mechanization. Column (3) controls for the intensity of other crops (oats, barley, rye, and hay). Column (4) controls for farm size (fraction of farms <20 acres, 20-49 acres, 50-99 acres, 100-259

\footnotetext{
${ }^{8}$ Figure 4 makes this point clear, plotting the estimated increase diffusion from 1925 to 1940 (with $95 \%$ confidence intervals) in a hypothetical county that is all-wheat versus all-corn.
} 
acres, and >260 acres, and log mean farm size). Column (5) controls for substitute inputs (horses, mules, and labor expenditure per acre). Column (6) controls for local financial conditions (farm mortgage interest rates and debt ratios). Column (7) controls for geographic and climatic variables (geographic coordinates; distance from Detroit and Chicago, which were the basis for calculating shipping charges; distance from the nearest Ford and IHC branch houses; quadratics in county mean temperature and annual rainfall; and intra-county variation in elevation). Column (8) controls for local New Deal Relief in post-1930 samples (measured as AAA spending and FCA lending from 1933-1939, per harvested acre, from Fishback et al. 2003). The latter two columns in Panel B retain the controls but restrict to counties in the Hornbeck (2012) Dust Bowl sample or to states that were leading adopters of hybrid seed corn to evaluate whether the effects might be explained by contemporaneous shocks to Midwest agriculture in the 1930s.

[Table 4 about here]

This battery of checks serves to rule out several competing explanations for the sequential diffusion of tractors to wheat- and corn-growing counties, including differential pre-trends in mechanization and changes in farm sizes, substitute inputs, credit constraints, proximity to manufacturers' branch houses, and more. In Panel A (1925-30), we see that the difference in coefficients on wheat and corn intensity are relatively stable across specifications - matching the baseline result - and precisely estimated. The differece in Panel B (1930-40) is approximately the inverse of that in Panel A and similarly precise, although it varies modestly more with controls.

Another potential explanation is that the advent of the mechanical corn harvester, which required a tractor to operate, triggered the wave of tractor diffusion in the Corn Belt. This interpretation would in a literal sense put the cart before the horse, as the general-purpose tractor was necessary for a mechanical corn harvester to be of value - if anything, advances in tractor technology likely stimulated R\&D in corn harvesters, due to their complementarities, and they diffused together (see the model in Section 6). Though this potential confound is difficult to evaluate in regressions due to a lack of county-level data on harvester diffusion, Colbert (2000) provides enough information to do so for one state in the heart of the Corn Belt: Iowa.

According to Colbert (2000), there were 6,000 mechanical corn harvesters in use on Iowa farms in 1937, and by 1940 this count had reached only 21,934 - as compared to 128,516 tractors. Assuming each farm owned at most one corn harvester, a mere $10.3 \%$ of Iowa farms owned mechanical corn 
harvesters in 1940, up from $0 \%$ in 1930. In contrast, $55.3 \%$ of farms owned a tractor in 1940, up from $29.4 \%$ in 1930 . The introduction of mechanical corn harvesting thus seems unable to fully explain either the level of or increase in tractor diffusion over the decade.

Data on tractor vintage from the 1940 Agricultural Census provide a distinct opportunity to connect advances in tractor technology to sequential diffusion across the Midwest, and perhaps the most direct test of the claims in this paper. This Census (and only this Census) reports the number of farms whose latest model-year tractor is pre-1930, 1931-1935, and 1936-1940. In Table 5, I replicate the previous table, replacing the dependent variable with the fraction of mechanized farms in 1940 whose latest-vintage tractor is pre-1930 (Panel A) or post-1935 (Panel B).

[Table 5 about here]

From Column (3) onwards, the results are statistically similar across specifications. Mechanized farms in wheat-growing counties were much more likely to own a pre-1930 vintage: these farms tended to adopt early and were unlikely to upgrade. Mechanized farms in corn-growing counties were much more likely to own a post-1935 vintage, which was presumably their first tractor. The magnitudes of these differences are large. In essence, as of 1940, wheat-growing counties were using Fordsons, and corn-growing counties were using Farmalls.

\section{Additional Robustness Checks}

The regressions in Tables 3 and 4 define diffusion as the fraction of farms in a county reporting a tractor, and model it as a linear function of observables. This definition imposes an assumption of perfect indivisibility, despite historical evidence of cooperative ownership (Myers 1921) and custom work (Gilbert 1930). Moreover, although the linear specification is easy to interpret, and can be a natural modeling choice over short time horizons, if diffusion is logistic in observables then it is the log-odds (rather than the adoption probability) that follows a linear model.

To evaluate whether the results are sensitive to these assumptions, Appendix $\mathrm{C}$ re-estimates the regressions in Table 4 using alternative definitions. Table C.1 replaces diffusion with the log-odds ratio. Table C.2 re-defines diffusion as the number of tractors per 100 acres of county farmland. This table excludes the Plains states from Panel A (1925-30), where farmland was rapidly expanding 
in the late $1920 \mathrm{~s}$, confounding the diffusion measure. ${ }^{9}$ Both variants yield results similar to those in the tables above and are robust to controls and within subsamples.

I also test the sensitivity of the results to assumptions on the error structure. In Tables C.3 to C.5, I re-estimate Table 4 allowing for spatial correlation in the error term that declines linearly in the distance between county centroids up to 20-, 50-, and 100-mile cutoffs (Conley 1999), which may be desirable given the spatial nature of technology diffusion. Though standard errors increase with the cutoff distance, the results remain significant at the widest radius.

\section{Later Periods and Other Regions}

\subsection{Patterns in Diffusion from 1940-1950}

Tractor diffusion continued briskly in most parts of the Midwest through the 1940s. By this time, tractors were already in widespread use around the region, and the technology had matured, such that further increases in diffusion are unlikely to be the result of changes to tractors themselves. However, as an extension on the previous results, Table 6 estimates the same specifications for the 1940 to 1950 period. ${ }^{10}$ By 1950, diffusion reached 80\% in many states and was plateauing to its eventual ceiling of around $90 \%$ in all states (Appendix Table B.1).

Figure 3 already indicates that Midwest states previously lagging in diffusion, such as Michigan and Wisconsin - which produced little wheat or corn and primarily grew hay as fodder for livestock - experienced the largest increases over this period. The results across all specifications in Table 6 are consistent with this evidence, showing that diffusion increased the most in counties with little of either staple crop. In unreported regressions, I include counties' 1925 hay intensity as an explanatory variable, and find that diffusion in this period was particularly concentrated in counties with a relatively high percentage of farmland harvested as hay.

\section{[Table 6 about here]}

Although mechanical hay balers were invented in 1940 and were adopted over the decade, by 1950 only $5.3 \%$ of Midwest farms owned a hay baler, while tractor diffusion increased from $44.3 \%$ to

\footnotetext{
${ }^{9}$ Counties in North Dakota, South Dakota, Nebraska, and Kansas on average increased their farmland by $12 \%$, $8 \%$, $7 \%$, and $10 \%$ (respectively) from 1925 to 1930, whereas counties in other states were stable. Agriculture expansion was significantly more subdued from 1930 to 1940 .

${ }^{10}$ Table 6 repeats the specifications in previous tables, but omits controls for farm mortgage interest rates and debt loads (Tables 4 and 5, Column 6), which are not reported in the 1950 Census of Agriculture.
} 
$70.7 \%$ over this period - and the difference is even larger in hay-intensive states such as Michigan and Wisconsin. The relatively high increase in diffusion from 1940 to 1950 in counties with little acreage in cash crops is more likely to be catch-up growth, fueled by labor shortages during World War II and a sharp decline in farm populations, which fell roughly $20 \%$ during the war both in the Midwest and across the country and did not recover (Appendix Table B.3). County-level farm population is not available from the 1950 Census to formally test this hypothesis, but the negative aggregate shock to labor supply, interacted with the distribution of mechanization in 1940, lends itself to laggard counties experiencing catch-up growth over the decade.

Such evidence is consistent with the central argument of this paper: changes in a technology are first-order to explaining when its adoption for different applications or in different regions takes off, but it is only one of several possible explanations for the pace at which diffusion continues - what this paper refers to as the scope and scale of diffusion, respectively.

\subsection{Diffusion in Other Regions}

As the locus of U.S. agriculture, and the region where tractors were adopted most rapidly, the Midwest is a natural target for study - but evidence of expanding scope can also be seen in other regions. For example, tractors with continuous track were developed for regions with soft soils, and models with protective outer shells for navigating through delicate orchards and vineyards. Table 7 shows the fraction of farms in each Census Region with tractors from 1920 to 2002. Between 1920 and 1940, the Midwest led the country in tractor adoption, with 42.4 percent of farms adopting by 1940. Northeastern and Western states were also mechanizing at this time, albeit at a slower pace (29.2 and 27.9 percent of farms adopting by 1940, respectively), reflecting the increasing utility of tractors across regions. The exception to this trend was the South: in states where agriculture was sharecropped, less than five percent of farms owned a tractor in 1940.

[Table 7 about here]

The slow mechanization of Southern agriculture prior to World War II is the subject of a large existing literature. ${ }^{11}$ Researchers have largely converged on two explanations: labor market institutions that discouraged the adoption of labor-saving machinery, and the difficulty of designing an

\footnotetext{
${ }^{11}$ E.g., see Fite (1980), Musoke (1981), Whatley (1985), Whatley (1987), and Hornbeck and Naidu (2013) for evidence and discussion of barriers to tractor diffusion in the South. Several of these papers, and others cited therein, also address the mechanization of the cotton harvest specifically.
} 
affordable, functional mechanical cotton picker. The engineering problem is summarized by Fite (1980), who catalogs the many reasons why "the nature of the cotton plant made the invention of a successful harvesting machine especially difficult." Whatley $(1985,1987)$ explains how this obstacle, in conjunction with Southern labor institutions, inhibited even partial mechanization of cotton production: without a mechanical harvester, Southern farms required a large population of laborers to collect the harvest. In states where this labor was supplied by a migrant workforce, such as those on the Mexican border, cotton farms could mechanize pre-harvest operations without cutting into the harvest labor supply - but in most Southern states, labor was supplied by annual contract in the form of tenancy and sharecropping, which locked in labor supply for when it was needed most. Under these circumstances, mechanization was an all-or-nothing proposition: as long as the harvest technology was labor-intensive, and labor could only be secured with annual contracts, year-round operations tended to remain labor-intensive as well.

Whatley's argument is supported by the evidence in Table 7. In the cotton-heavy states of Texas and Oklahoma, where migrant labor was abundant, tractor diffusion increased between 1930 and 1940 to a level comparable to much of the rest of the country. According to Fite (1950), cotton mechanization in these states indeed began in the late-1920s with the general-purpose tractor, and with the subsequent development of implements for pre-harvest operations, "remarkable progress occurred in the mechanization of cotton" even prior to the invention of a functional cotton picker. ${ }^{12}$ Given that cotton farms in these states were using tractors, the lagging diffusion in the rest of the South cannot be explained by the technology alone, which was common to both regions. Whatley (1985) further argues that the delayed invention of the mechanical cotton picker was itself more the consequence of institutions than the engineering challenge: "the structure of the plantation economy reduced the Southern demand for new inventions," and it therefore "may have been no accident that the technical 'difficulties' of mechanizing the cotton harvest were solved soon after the tractor became available, sharetenancy began to disappear, and the locus of cotton production began moving westward, away from the traditional Cotton South."

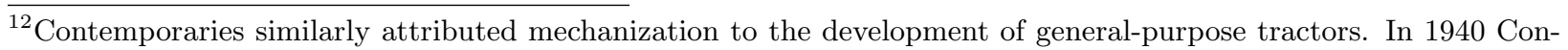
gressional testimony on mechanization and the displacement of agricultural labor, a UC Berkeley economist stated that in the western Cotton Belt, "displacement is occurring now over large areas because of introduction [sic] of all-purpose tractors and auxiliary equipment," even though the industry had believed that this "would not appear until the manufacture of mechanical cotton pickers" (Paul Taylor, in TNEC 1940).
} 


\section{Theoretical Framework}

To put more structure around these results, consider the following model. Suppose a given technology has the potential to serve two categories of users $a \in\{1,2\}$. This technology is characterized by its quality for each application, $z_{1}$ and $z_{2}$, and its general-purpose quality $z_{g}$ in all applications. General-purpose quality is embodied in features that are broadly useful, such as the rotary motion produced by a motor. Application-specific quality is embodied in features with more limited use. The technology is designed to be used with two application-specific complements, which themselves have qualities $T_{1}$ and $T_{2}$. We can think of the focal technology as the tractor, the complements as argicultural implements, and the sectors of users as wheat and corn farms.

Each sector has a total market size of $M$. Let the fraction of potential users in sector $a$ adopting the technology be an increasing, convex function of the interaction of its total quality in application $a\left(z_{g}+z_{a}\right)$, and the quality of the sector-specific complement $\left(T_{a}\right)$ :

$$
D_{a}=F\left(\left(z_{g}+z_{a}\right) T_{a}\right), \text { with } F^{\prime}(x)>0, F^{\prime \prime}(x)<0, F(0)=0 \text { and } \lim _{x \rightarrow \infty} F(x)=1
$$

Total demand is $Q=\sum_{a} Q_{a}=M \sum_{a} F\left(\left(z_{g}+z_{a}\right) T_{a}\right)$. Further suppose that the complements are perfect, and individually have identical demand $Q_{1}$ and $Q_{2}$.

To simplify the exposition, suppose there is one firm developing the focal technology, and one (distinct) firm developing the complementary technologies, and further suppose that R\&D in the focal and complementary technologies occurs in alternating periods - such that developments in one may respond to developments in the other. The firm developing the focal technology can only develop one of $z \in\left\{z_{1}, z_{2}, z_{g}\right\}$ at a time. Firms which undertake $\mathrm{R} \& \mathrm{D}$ realize monopoly rents on the incremental sales (e.g., due to exclusivity), but these rents dissipate after one period (e.g., when competitors in the product market imitate or design around). Developing firms thus engage in $R \& D$ to maximize incremental demand, net of incremental R\&D costs. ${ }^{13,14}$ Henceforth, we will

\footnotetext{
${ }^{13}$ The assumption that only one firm engages in $\mathrm{R} \& \mathrm{D}$ on each side of the technology is made to simplify the exposition, but is not strictly necessary. To generalize, we could introduce i.i.d. noise into the R\&D production function, and assume that each period, one firm notches the furthest up a quality ladder and temporarily earns rents, and other firms automatically catch up the next period. Even in this more general framework, the results of this section will hold, as firms will pursue the same sequence of $R \& D$, driven by complementarities rather than competition.

${ }^{14}$ Also note that prices are omitted, as they are nonessential to the intuition or the results. Prices can be written into the model as being set downstream in the product market to maximize production profits, and taken as given or backwards-inducted at the time R\&D is allocated. Doing so would not affect the core results, which are driven by complementarities rather than the downstream market structure: provided there are production profits available to the innovating firm downstream, the same results will obtain under any prices.
} 
include a subscript $t$ on each parameter to denote time-varying values.

The final input to the model is then the cost of $R \& D$. Suppose the total $R \& D$ cost for the focal technology through time $t$ is the sum of the costs for developing each quality:

$$
C_{1}\left(z_{1, t}\right)+C_{2}\left(z_{2, t}\right)+C_{g}\left(z_{g, t}\right)
$$

where $C_{1}=C_{2}=C_{z}, C_{g}=\lambda C_{z}$ with $\lambda>1, C_{z}^{\prime} \geq 0$ and $C_{z}^{\prime \prime}>0$, and $C_{z}(0)=C_{z}^{\prime}(0)=0$. In words, R\&D costs are increasing and convex, and general-purpose improvements are more difficult or expensive than application-specific improvements. The complements have similar cost functions, $\Gamma_{1}\left(T_{1, t}\right)$ and $\Gamma_{2}\left(T_{2, t}\right)$, where $\Gamma_{1}=\Gamma_{2}=\Gamma_{T}$, and $\Gamma_{T}$ is increasing and convex.

As a final assumption, suppose that sector 1 initially has a complement available for use with the focal technology, with quality $T>0$, whereas sector 2 does not (without loss of generality). For example, when tractors developed, there existed horse-drawn plows and grain harvesting equipment that could be used or easily adapted to the new technology - and in particular, when the Fordson developed, there was already a full line of implements in the small grains sector with which it could be used. Initial values of the quality parameters are thus as follows:

$$
z_{1,0}=z_{2,0}=z_{g, 0}=0, \quad T_{1,0}=T>0, \quad T_{2,0}=0
$$

\subsection{The Path of Product Development}

The firm performing $R \& D$ on the focal technology must decide which features to develop each period: $z_{1}, z_{2}$, or $z_{g}$. Treating the quality parameters as state variables, in any given period, the returns to incrementing each one by $\delta_{z}$ are as follows:

$$
\begin{aligned}
z_{1}, z_{2}: \Pi_{z_{a}}\left(\delta_{z} \mid \mathbf{z}, \mathbf{T}\right) & =\underbrace{M \cdot\left[F\left(\left(z_{g}+z_{a}+\delta_{z}\right) T_{a}\right)-F\left(\left(z_{g}+z_{a}\right) T_{a}\right)\right]}_{\text {Incremental benefit }}-\underbrace{\left[C_{a}\left(z_{a}+\delta_{z}\right)-C_{a}\left(z_{a}\right)\right]}_{\text {Incremental cost }} \\
z_{g}: \Pi_{z_{g}}\left(\delta_{z} \mid \mathbf{z}, \mathbf{T}\right) & =M \sum_{a=1,2}\left[F\left(\left(z_{g}+z_{a}+\delta_{z}\right) T_{a}\right)-F\left(\left(z_{g}+z_{a}\right) T_{a}\right)\right]-\left[C_{g}\left(z_{g}+\delta_{z}\right)-C_{g}\left(z_{g}\right)\right]
\end{aligned}
$$

In words, the expressions measure the incremental number of units sold, less the incremental cost of the $\mathrm{R} \& \mathrm{D}$ incurred to advance quality. Note that increasing $z_{a}$ only yields benefits vis-à-vis sector $a$, whereas increasing $z_{g}$ yields benefits across both sectors $a \in\{1,2\}$.

Analogously, complementors must decide how much of $T_{1}$ and $T_{2}$ to develop each period, and the 
returns to incrementing each by $\delta_{T}$ are:

$$
T_{1}, T_{2}: \quad \Pi_{T_{a}}\left(\delta_{T} \mid \mathbf{z}, \mathbf{T}\right)=M \cdot\left[F\left(\left(z_{g}+z_{a}\right)\left(T_{a}+\delta_{T}\right)\right)-F\left(\left(z_{g}+z_{a}\right) T_{a}\right)\right]-\left[\Gamma_{a}\left(T_{a}+\delta_{T}\right)-\Gamma_{a}\left(T_{a}\right)\right]
$$

These ingredients lead directly to the first proposition:

Proposition 1. The Path of Product Development.

The focal technology will develop in the order of (i) $z_{1}$, (ii) $z_{g}$, and (iii) $z_{2}$. As such, it will develop as an application-specific technology before it becomes a general-purpose technology.

Proofs to propositions are provided in Appendix D. The intuition behind this result is simple: $\mathrm{R} \& \mathrm{D}$ in the focal technology follows the development of its complements. In period $t=1$, because complements are available for sector 1 but not sector 2 , and because application-specific R\&D is ceteris paribus less expensive than general-purpose $R \& D, z_{1}$ will be developed first. Once these returns are exhausted, $z_{g}$ will develop next, taking advantage of its complementarity with $T_{1}$ as well. This development will spark investment in $T_{2}$, which in turn triggers investment in $z_{2}$. The three assumptions responsible for this result are that (i) general-purpose R\&D is more costly than application-specific $R \& D$, (ii) complements are initially available in one sector but not the other, and (iii) the rents from R\&D are temporary (for example, technical advances are quickly imitated) - all of which are qualitatively consistent with the tractor's history.

A more relaxed set of assumptions can also generate this proposition under the right parametrizations. For example, if both sectors have pre-existing complements, but one sector is larger than the other, has lower R\&D costs than the other, or has higher-quality complements than the other, then the same pattern may obtain: functionality for the advantaged sector will develop before that for the other sector and before general-purpose functionality, as long as general-purpose R\&D is sufficiently expensive. In this case, $\mathrm{R} \& \mathrm{D}$ in $z_{1}$ will initially strictly dominate that in $z_{2}$, as well as that in $z_{g}$. These alternatives are discussed further in Appendix D.

\subsection{Implications for the Scope of Diffusion}

The most important result of the model, as it relates to the evidence above, is its implication for diffusion - and in particular for explaining its scope and cross-sectoral lags in diffusion, which are shaped by the set of applications for which a given technology can be used. It follows mechanically 
from Proposition 1 that the focal technology will initially be adopted by users in sector 1 and only later by those in sector 2, following that technology's generalization.

In his canonical study of hybrid corn, Griliches (1957) recognized this phenomenon, calling it the "availability" problem: the diffusion of hybrid corn at the level of crop reporting districts required seed varieties adapted to local growing conditions. The key insight is that cross-sectional variation in diffusion is driven not only by the rate at which it proceeds, but also by when it begins. Because product development often proceeds from specific- to general-purpose variants, diffusion may even follow the characteristic S-curve not only within applications, but also across them. This appears to have been the case for hybrid corn: for any fixed level of diffusion, and in particular for lower levels indicating availability of locally-suitable varieties, the number of states that had surpassed that level of diffusion forms an S-shape over time (see Appendix E).

An additional implication of the model that emerges in the proof to Proposition 1 is that when the general-purpose quality of tractors increases, complements should soon develop to exploit these new features. Historical experience broadly concords: for example, R\&D efforts at mechanical corn and cotton harvesting equipment immediately followed the Farmall. Williams (1987) recounts that the introduction of the three-point hitch prompted a "frantic race" to develop additional implements to exploit the tractor's increased utility, including some implements never seen before, such as tanks, pumps, and spray booms for fertilizers and pesticides.

\subsection{Extensions and policy implications: R\&D spillovers}

Suppose now that firms can also earn positive returns on the incremental diffusion of their technology in periods when they are not actively performing R\&D. An extension on these results brings into focus $\mathrm{R} \& \mathrm{D}$ spillovers between complementors, which drive a wedge between private and social returns to $R \& D$ and can result in suboptimal $R \& D$ investment.

Proposition 2. R\&D spillovers (complementors' rents from own R\&D).

If developers can earn rents on the contemporaneous, incremental sales of complements generated by their own RED, then firms would invest more heavily in R\&D in each period.

Recall that the focal and secondary technologies are perfect complements, such that improvements in one generate additional sales of both, as they are used jointly. Because the inventing firm can neither realize nor appropriate returns to its $\mathrm{R} \& \mathrm{D}$ from diffusion of complements, it will tend to 
undersupply quality, by not factoring in the effects of its own R\&D on complements when making R\&D investments (similar to Bresnahan and Trajtenberg 1995). This will especially lead to the firms undersupplying general-purpose quality, which generates the most spillovers - suggesting that generality may be a potential target for R\&D policy intervention.

In the tractor industry, this inefficiency was in part relieved by the presence of long-line firms which manufactured both tractors and implements. Ford notoriously left the production of implements for its tractors to others, but IHC, Deere, Allis-Chalmers, and others began as or evolved into long-line implement manufacturers. This organizational form might thus serve as a model for similar cases. Even so, vertical integration is only a partial solution and not a panacea, as it does not internalize the returns to other firms - or in many cases, farmers themselves - inventing implements which these farmers might use with the given firm's tractors.

\section{Counterfactual Diffusion}

What if general-purpose tractors had developed earlier? In particular, what would be the welfare impact had diffusion in the Corn Belt kept pace with the Wheat Belt? This question is first-order to understanding the consequences of impediments to technology diffusion. In the case of tractors, it amounts to evaluating the effect of eliminating a transitory deficit in the late 1920s and 1930s, since corn-growing counties caught up to their wheat-growing counterparts by 1940 .

To get a better handle on this question, I use the estimates from Table 3 to project diffusion in the counterfactual. Although these estimates are linear approximations, they can provide a sense of the magnitude of the effect. Figure 5 plots the cumulative increase in aggregate diffusion throughout the Midwest as (i) observed, (ii) as estimated, and (iii) in a counterfactual in which tractors diffuse at the same rate with respect to corn intensity as wheat intensity.

[Figure 5 about here]

The estimated increase in diffusion closely tracks observed values, validating the model's predictive power. In the counterfactual, aggregate diffusion would have been roughly 6.6 p.p. (i.e., $25 \%$ on a base of 25.6 p.p.) higher than observed in 1930, but little different in 1940 .

Given the tractor's impact on U.S. agriculture, a temporal shift of this magnitude would have had large (if transitory) effects on agricultural productivity. The tractor upended the organization of the 
sector, dramatically reducing labor inputs and increasing cropland available for human consumption (Olmstead and Rhode 2001). As Olmstead and Rhode (1994) describe, "the conversion from draft power to the internal combustion engine was one of the most far-reaching technological changes ever to occur in the United States." Steckel and White's (2012) estimates suggest that by 1954 the tractor was generating social savings of as much as 8.6 percent of GNP.

Using historical wages and estimates of the labor savings from mechanization, we can calculate a back-of-the-envelope estimate of the savings from the reduction in labor inputs alone. Appendix F provides details of the calculations, and Table 8 the results.

[Table 8 about here]

The calculation begins with an estimate from Cooper et al. (1947) that tractors had reduced labor requirements in U.S. agriculture by 1.7 billion man-hours per year by 1944, roughly half of which is attributable to time-savings in field operations, and half to reduced time spent caring for horses and mules. I then allocate a fraction of these savings to the Midwest based on the region's share of mechanized farms in 1945. To obtain an estimate of the labor savings from tractors in 1930, I scale down this quantity by the proportionality factor Diffusion $1930 / \operatorname{Diffusion}_{1945}$.

The calculations suggest that accelerated diffusion to the Corn Belt would have reduced agricultural labor inputs by 111 million man-hours in 1930, or $10.2 \%$ of hired labor in Midwest agriculture at that time. This labor would likely have reallocated to other sectors. At prevailing manufacturing and wholesale wages (and setting aside any potential general equilibrium effect), the value of these labor savings is approximately $\$ 83.3$ million in 1930 dollars, equivalent to nearly $\$ 1$ billion today - or $1.2 \%$ of current Midwest agricultural GDP. Note that this figure does not reflect a pure productivity increase, as they do not account for the purchase and operating costs of the additional tractors - though these costs would be offset by analogous savings from the reduced use of draft animals and other non-labor inputs, which could yield even further savings (see Johnson 1922, Ankli and Olmstead 1981, Clarke 1991, or White 2000 for examples).

\section{Conclusion}

In his seminal work, Griliches (1957) showed that differences in the adoption of hybrid seed corn across U.S. states and crop reporting districts were a function of both (i) when it begins in each 
state or district, and (ii) the rate at which it proceeds. This paper brings into focus the distinction between these two margins, which this paper refers to as scope and scale, respectively: the former defines the set of potential adopters, and the latter describes what fraction of them are adopting. Since Griliches (1957), researchers have largely sought to explain differences in scale, leaving the determinants of the scope of diffusion less well-understood.

The farm tractor is a case in point: although tractors are now pervasive in agriculture, they were not born to be. The earliest models were suitable only for tillage and harvesting small grains, and only in the late 1920s did the technology begin to generalize for use with row crops such as corn, cotton, and vegetables. Using county-level data on tractor ownership from the 1910 to 1950 Census of Agriculture, I show that tractors were accordingly quick to diffuse to areas of the U.S. Midwest growing wheat and other small grains and slower to penetrate the Corn Belt. Had the tractor diffused at the same rate for corn-intensive counties as for wheat-intensive counties, total diffusion in the Midwest would have been roughly $25 \%$ higher by 1930, generating annual labor savings of $10 \%$ of hired agricultural labor alone. Conversely, had the tractor not generalized, its impact would be so limited that it would most likely be an afterthought today.

To explain these patterns, the paper proposes a model of R\&D in which firms develop technologies with general-purpose and application-specific features. The model suggests that technologies will first develop for applications with existing complements, high demand, and low R\&D costs, and only when the gains to specialization are exhausted will $R \& D$ proceed to a general-purpose variant. Diffusion is in turn constrained to applications for which the technology can be used. The presence of positive spillovers to the developers of complementary technologies implies that inventors are under-incentivized to generalize their technology for broader use.

The evidence supports a substantially different interpretation of lagging technology diffusion than what is typically found in the literature, which tends to focus on fixed costs, factor prices, credit constraints, information, and human capital. In the case of tractors, lags resulted from a fundamental mismatch between the technology's capabilities and the technical requirements of users in different settings, and were resolved only when the technology advanced to fulfill these demands. Indeed, the late-adopting U.S. Corn Belt had to wait for the row-crop tractor to be invented before farms growing corn for harvest could be fully mechanized. The results of this paper thus highlight the importance of product designs that meet the heterogeneous requirements of users in different settings, and they suggest that the most effective way to get technology into the hands of new users may simply be to develop a variant adapted to their needs. 


\section{References}

Acemoglu, Daron and Fabrizio Zilibotti, "Productivity Differences," The Quarterly Journal of Economics, 2001, 116 (2), 563-606.

Alston, Lee J., "Farm Foreclosures in the United States during the Interwar Period," The Journal of Economic History, 1983, 43 (4), 885-903.

Ankli, Robert and Alan Olmstead, "The Adoption of the Gasoline Tractor in California," Agricultural History, 1981, 55 (3), 213-230.

Basu, Susanto and David N. Weil, "Appropriate Technology and Growth," The Quarterly Journal of Economics, 1998, 113 (4), 1025-1054.

Bresnahan, Timothy F. and Manuel Trajtenberg, "General purpose technologies: 'Engines of growth'?," Journal of Econometrics, 1995, 65 (1), 83-108.

Carter, Susan B., Scott Sigmund Gartner, Michael R. Haines, Alan L. Olmstead, Richard Sutch, and Gavin Wright, eds, Historical Statistics of the United States, Earliest Times to the Present: Millenial Edition, New York: Cambridge University Press, 2006.

Caselli and Coleman, "The World Technology Frontier," The Quarterly Journal of Economics, 2006, 96 (3), 499-522.

Clarke, Sally, "New Deal Regulation and the Revolution in American Farm Productivity: A Case Study of the Diffusion of the Tractor in the Corn Belt, 1920-1940," The Journal of Economic History, 1991, 51 (1), 101-123.

Colbert, Thomas Burnell, "Iowa Farmers and Mechanical Corn Pickers, 1900-1952," Agricultural History, 2000, 74 (2), 530-544.

Comin, Diego and Bart Hobijn, "Cross-country technology adoption: making the theories face the facts," Journal of Monetary Economics, 2004, 51 (1), 39-83.

Conley, Timothy G., "GMM Estimation with Cross-Sectional Dependence," Journal of Econometrics, 1999, 92 (1), 1-45.

- and Christopher R. Udry, "Learning about a New Technology: Pineapple in Ghana," American Economic Review, 2010, 100 (1), 35-69.

Cooper, Martin R., Glen T. Barton, and Albert P. Brodell, Progress of Farm Mechanization U.S. Department of Agriculture 1947.

David, Paul A., "The Mechanization of Reaping in the Ante-bellum Midwest," in Henry Rosovsky, ed., Industrialization in Two Systems: Essays in Honor of Alexander Gerschenkron, John Wiley \& Sons, 1966, pp. 3-39.

Duflo, Esther, Michael Kremer, and Jonathan Robinson, "How High are Rates of Return to Fertilizer? Evidence from Field Experiments in Kenya," American Economic Review: Papers 83 Proceedings, 2008, 98 (2), 482-488.

_ , _ , and _, "Nudging Farmers to Use Fertilizer: Theory and Experimental Evidence from Kenya.," American Economic Review, 2011, 101 (6), 2350-90.

Dupas, Pascaline, "Short-Run Subsidies and Long-Run Adoption of New Health Products: Evidence From a Field Experiment," Econometrica, 2014, 82 (1), 197-228.

Fishback, Price V., Shawn Kantor, and John Wallis, "Can the New Deal's Three R's Be Rehabilitated? A Program-by-Program, County-by-County Analysis," Explorations in Economic History, 2003, 40 (3), 278-307. 
Fite, Gilbert C., "Recent Progress in the Mechanization of Cotton Production in the United States," Agricultural History, 1950, 24 (1), 19-28.

_ , "Mechanization of Cotton Production Since World War II," Agricultural History, 1980, 54 (1), 190-207.

Fordson House, Serial numbers for assorted tractor models 2015. Available at: http://www. thefordsonhouse.com/.

Gilbert, C., An Economic Study of Farm Tractors in New York, Ithaca: Cornell University, 1930.

Griliches, Zvi, "Hybrid Corn: An Exploration in the Economics of Technological Change," Econometrica, 1957, 25 (4), 501-522.

Gunlogson, G. B., "General Purpose Tractor Needed for American Farm Market," Automotive Industries, 1922, $4 \%$.

Hornbeck, Richard, "Barbed Wire: Property Rights and Agricultural Development," The Quarterly Journal of Economics, 2010, 125 (2).

_ , "The Enduring Impact of the American Dust Bowl: Short- and Long-Run Adjustments to Environmental Catastrophe," American Economic Review, 2012, 102 (4), 1477-1507.

- and Suresh Naidu, "When the Levee Breaks: Black Migration and Economic Development in the American South." Forthcoming in American Economic Review.

International Harvester Company, Serial Number List, Farmall Works, 1926-1971 2015. Available from the Wisconsin Historical Society: http://www.wisconsinhistory.org/libraryarchives/ihc/.

Iverson, George W., "Possibilities of the All-Purpose Tractor," Transactions of the American Society of Agricultural Engineers, 1922, 16.

Johnson, Bernard L., "Henry Ford and His Power Farm," Farm Mechanics, 1922, February.

Keller, Wolfgang, "Geographic Localization of International Technology Diffusion," American Economic Review, 2002, 92 (1), 120-142.

Klancher, Lee, The Farmall Dynasty, St. Paul: 671 Press, 2008.

Leffingwell, Randy, Ford Farm Tractors, Minneapolis: Voyageur Press, 1998.

_, The American Farm Tractor, Minneapolis: Voyageur Press, 2002.

Manuelli, Rodolfo E. and Ananth Seshadri, "Frictionless Technology Diffusion: The Case of Tractors," American Economic Review, 2014, 104 (4), 1368-1391.

Minnesota Population Center, National Historical Geographic Information System: Version 2.0, Minneapolis: University of Minnesota, 2011.

Munshi, Kaivan, "Social learning in a heterogeneous population: technology diffusion in the Indian Green Revolution," Journal of Development Economics, 2004, 73 (1), 185-213.

Musoke, Moses S., "Mechanizing Cotton Production in the American South: The Tractor, 19151960," Explorations in Economic History, 1981, 18 (4), 347-375.

Myers, W., An Economic Study of Farm Tractors in New York, Ithaca: Cornell University, 1921.

Olmstead, Alan L., "The Mechanization of Reaping and Mowing in American Agriculture, 18331870," The Journal of Economic History, 1975, 35 (2), 327-352. 
- and Paul W. Rhode, "The Agricultural Mechanization Controversy of the Interwar Years," Agricultural History, 1994, 68 (3), 35-53.

_ and _, "Reshaping the Landscape: The Impact and Diffusion of the Tractor in American Agriculture, 1910-1960," The Journal of Economic History, 2001, 61 (3), 663-698.

PRISM Climate Group at Oregon State University, United States Average Monthly or Annual Precipitation, 1971-2000 and 1981-2010 2012. Available at: http://prism.oregonstate.edu/ products $/$ matrix.phtml? vartype $=$ ppt\&view $=$ data.

Sanders, Ralph W., The Farm Tractor: 100 Years of North American Tractors, Minneapolis: Voyageur Press, 2009.

Steckel, Richard H. and William J. White, "Engines of Growth: Farm Tractors and TwentiethCentury US Economic Welfare," 2012. NBER Working Paper 17879.

Suri, Tavneet, "Selection and Comparative Advantage in Technology Adoption," Econometrica, 2011, 79 (1), 159-209.

Temporary National Economic Committee (TNEC) of the 76th U.S. Congress, Investigation of Concentration of Economic Power, Part 30: Technology and Concentration of Economic Power, Washington: GPO, 1940.

Tractor and Construction Plant Wiki, Serial numbers for assorted tractor models 2015. Available at: http://tractors.wikia.com/.

TractorData, Serial numbers for assorted tractor models 2015. Available at: http://www. tractordata.com/.

U.S. Census Bureau, Census of Agriculture, Washington: GPO, 1910-1954.

_, Census of Agriculture, Washington: GPO, 2002.

_, Census of Agriculture, Washington: GPO, 2007.

U.S. Geological Survey, National Elevation Dataset 2009. Available at: http://ned.usgs.gov/.

Whatley, Warren C., "A History of Mechanization in the Cotton South: The Institutional Hypothesis," Quarterly Journal of Economics, 1985, 100 (4), 1191-1215.

_ , "Southern Agrarian Labor Contracts as Impediments to Cotton Mechanization," Journal of Economic History, 1987, 47 (1), 45-70.

White, William J., "An Unsung Hero: The Tractor's Contribution to Twentieth-Century United States Economic Growth," 2000. Unpublished dissertation.

_ , "Economic History of Tractors in the United States," 2010. EH.Net Encyclopedia. Available at: http://eh.net/encyclopedia/article/white.tractors.history.us.

Williams, Robert C., Fordson, Farmall, and Poppin' Johnny: A History of the Farm Tractor and Its Impact on America, Urbana: University of Illinois Press, 1987. 
Figure 1: Crop Mix and Tractor diffusion in U.S. Midwest, 1925-1930 and 1930-1940

Wheat concentration, 1925

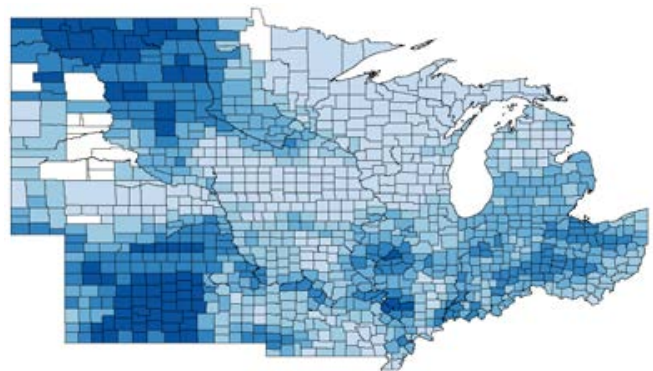

Tractor diffusion, 1925-30

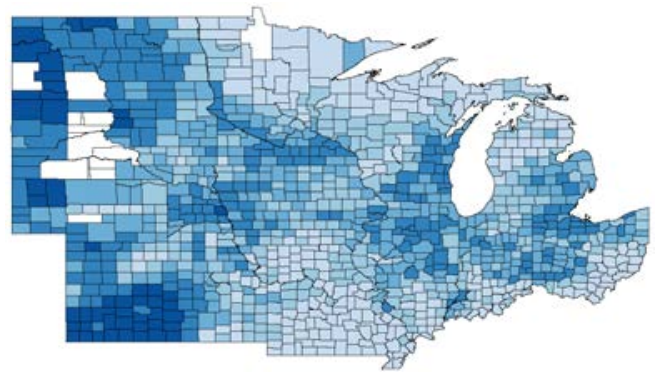

Early Vintage in 1940

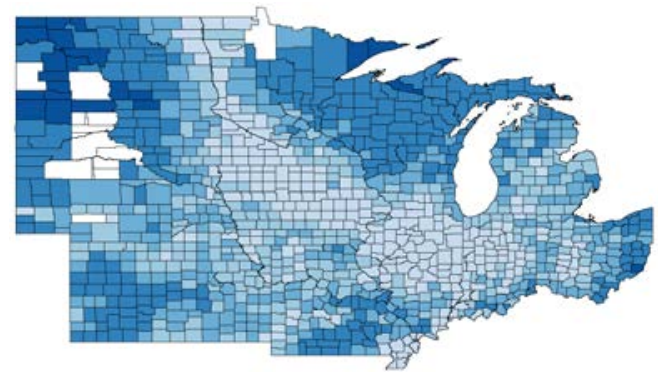

Corn concentration, 1925

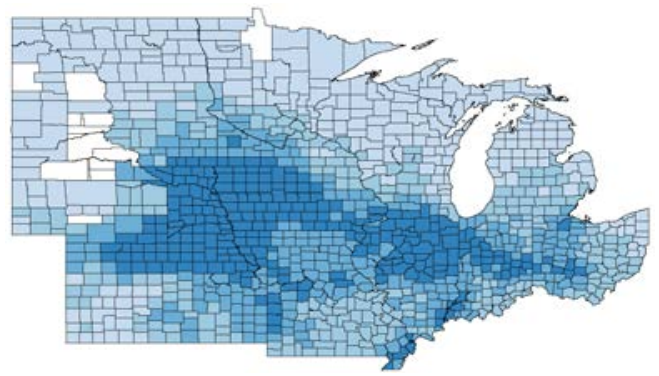

Tractor diffusion, 1930-40

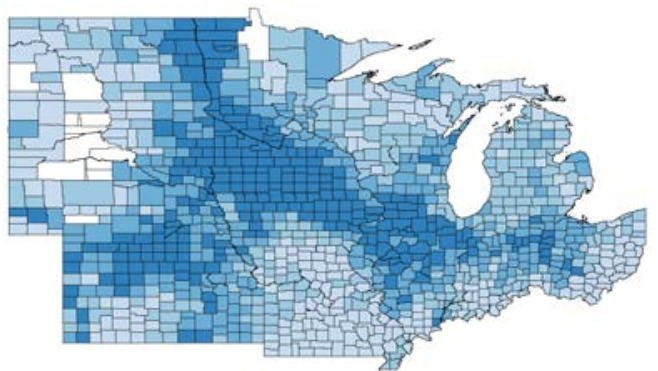

Late Vintage in 1940

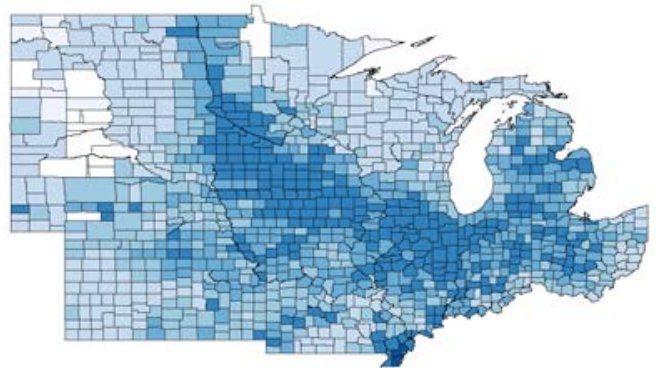

Notes: Figure shows the distribution of 1925 wheat and corn intensity across the U.S. Midwest (top row), changes in tractor diffusion from 1925-30 and 1930-40 (middle row), and the fraction of mechanized farms in 1940 with pre-1930 versus post-1935 vintage tractors (bottom row). Crop concentrations calculated as the fraction of farmland in the given crop, and tractor diffusion as the fraction of farms owning a tractor. Darker blues represent higher values. Counties in white omitted due to missing data or because their borders changed over the sample period. Data from 1925 to 1940 Census of Agriculture. 
Figure 2: Draft animals, tractors, and implements in the U.S.

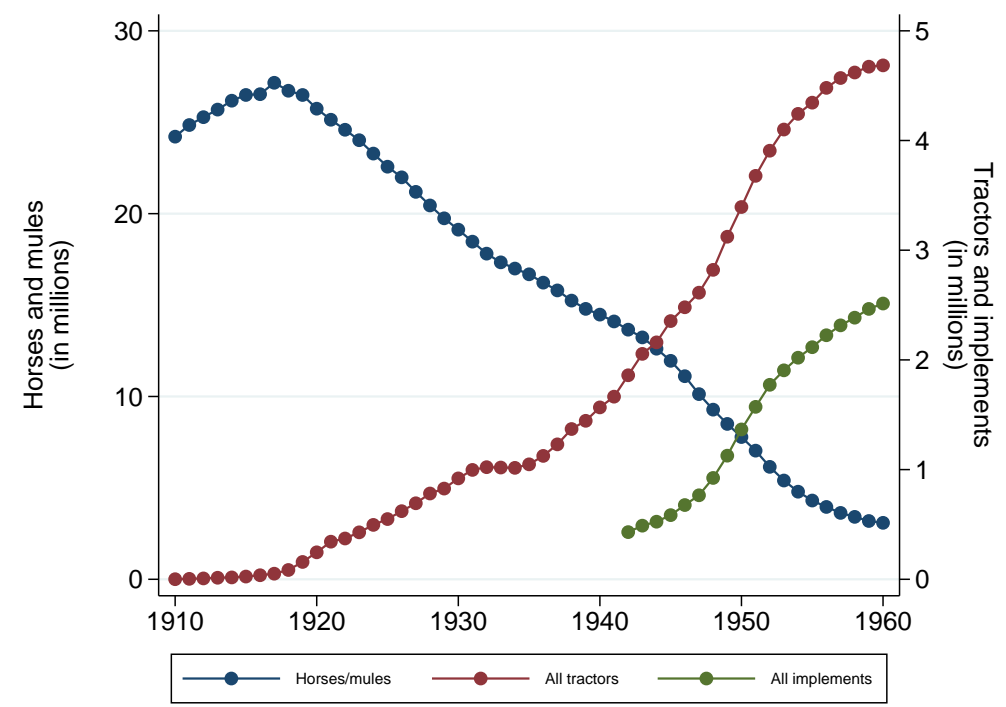

Notes: All implements refers to the sum of grain combines, corn harvesters, and pick-up hay balers owned by U.S. farms; this total does not include other implements not provided in the Historical Statistics or recorded in historical Censuses. Correlation of tractors and implements on U.S. farms is 0.996 over the 19 years for which data on all three implements are available. Data from Historical Statistics of the U.S., Series Da623, Da629-631, Da983, Da985, Da987.

Figure 3: Tractor diffusion in Midwest states, 1920-1950

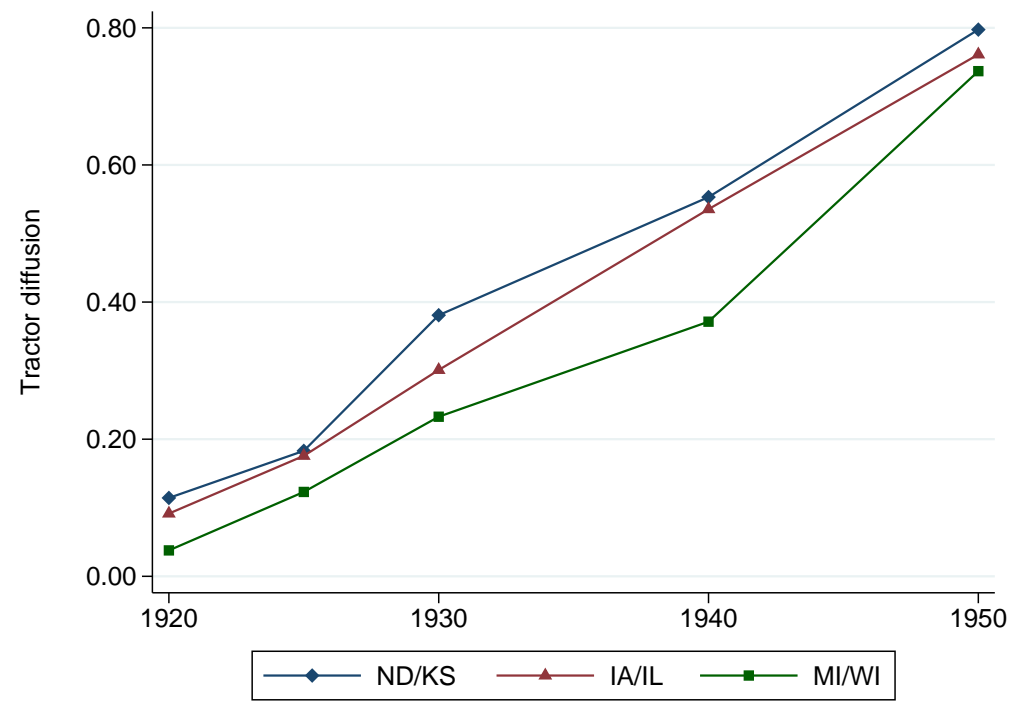

Notes: Figure shows the path of tractor diffusion from 1920 to 1950 in the states that form the core of the U.S. Corn Belt (IA/IL) and Wheat Belt (ND/KS), as well as in two states with low crop concentrations and little of either staple crop (MI/WI). Data from 1920 to 1950 Census of Agriculture. 
Figure 4: Estimated cumulative change in tractor diffusion, 1925-1940, all-wheat vs. all-corn

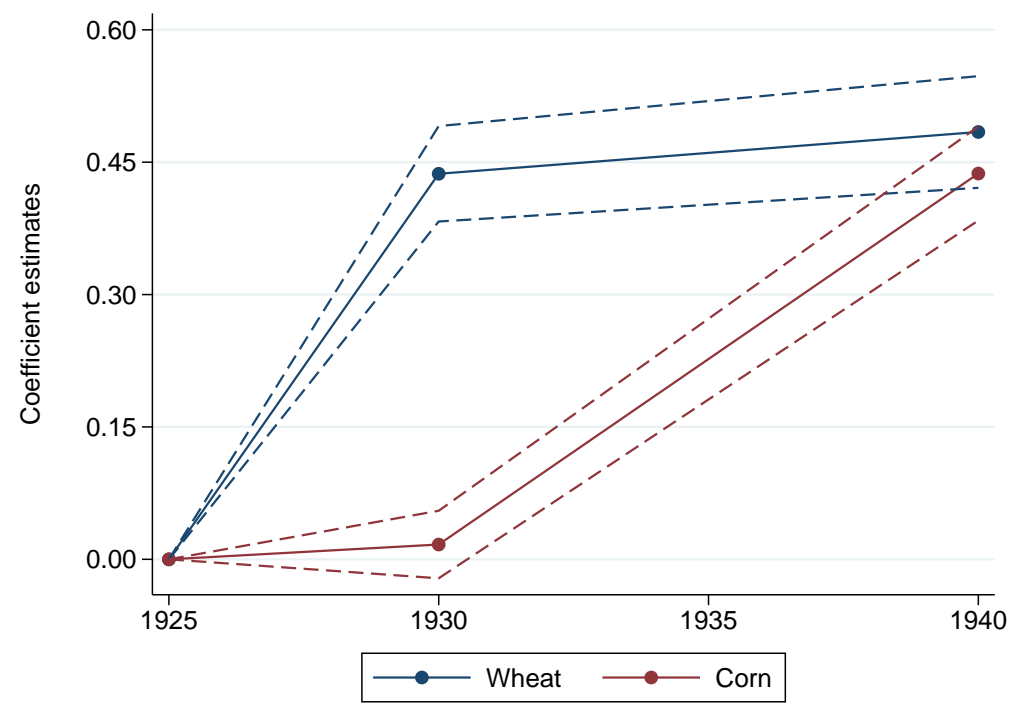

Notes: Figure plots the point estimates from the 1925-1940 specification in Table 5 , Column 3, showing the cumulative change in diffusion for a county with all farmland planted to wheat versus all farmland planted to corn. The dashed lines bound the $95 \%$ confidence interval for each estimate.

Figure 5: Est. differential increase in tractor diffusion in counterfactual, 1925-1940

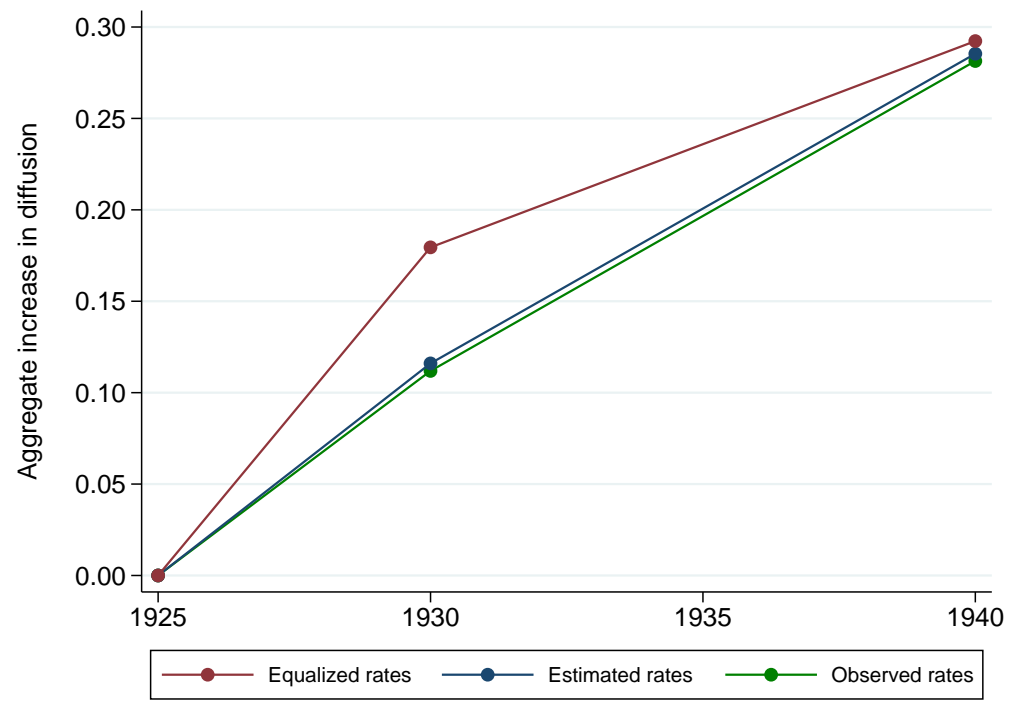

Notes: Figure plots the aggregate difference in tractor diffusion implied by the estimates in Table 3, Column 3, had tractors diffused as rapidly in corn-growing regions as they did in wheat-growing regions. Calculated as described in text. 
Table 1: Tractor Production from Select Manufacturers, Fixed Tread vs. General-Purpose

\begin{tabular}{|c|c|c|c|c|c|c|}
\hline \multirow[b]{2}{*}{ Туре } & \multicolumn{2}{|c|}{ Pre-study period } & \multicolumn{4}{|c|}{ Study Period } \\
\hline & $1917-1920$ & 1921-1924 & 1925-1928 & 1929-1932 & 1933-1936 & 1937-1940 \\
\hline Fixed Tread & 226,728 & 375,217 & 532,392 & 259,539 & 58,148 & 75,381 \\
\hline General-Purpose & 0 & 214 & 50,884 & 125,577 & 260,626 & 524,666 \\
\hline
\end{tabular}

Notes: Table shows total production of regular and general-purpose tractors by select manufacturers between 1917 and 1940. Sample covers production by Ford, IHC, Deere, and Allis-Chalmers, which account for $80 \%$ of tractors manufactured in each of the 1920s and 1930s (White 2010). Production totals calculated from manufacturer serial numbers, which were acquired from the McCormick collection at the Wisconsin Historical Society (IHC), thefordsonhouse.com (Ford), tractordata.com (Deere, Allis-Chalmers), and tractors.wikia.com (all).

Table 2: Descriptive Statistics: Average Farm Characteristics, by Year

\begin{tabular}{|c|c|c|c|c|c|}
\hline & \multicolumn{2}{|c|}{ Pre-study period } & \multicolumn{3}{|c|}{ Study period } \\
\hline & $\begin{array}{c}1910 \\
(\mathrm{~N}=1033)\end{array}$ & $\begin{array}{c}1920 \\
(\mathrm{~N}=1033)\end{array}$ & $\begin{array}{c}1925 \\
(\mathrm{~N}=1033)\end{array}$ & $\begin{array}{c}1930 \\
(\mathrm{~N}=1033)\end{array}$ & $\begin{array}{c}1940 \\
(\mathrm{~N}=1033)\end{array}$ \\
\hline Fraction with tractors & $\begin{array}{l}- \\
-\end{array}$ & $\begin{array}{l}- \\
-\end{array}$ & $\begin{array}{l}0.149 \\
(0.10)\end{array}$ & $\begin{array}{l}0.267 \\
(0.16)\end{array}$ & $\begin{array}{l}0.437 \\
(0.21)\end{array}$ \\
\hline \multicolumn{6}{|l|}{ Crop percentages: } \\
\hline Corn & $\begin{array}{l}0.168 \\
(0.12)\end{array}$ & $\begin{array}{l}0.143 \\
(0.11)\end{array}$ & $\begin{array}{l}0.145 \\
(0.11)\end{array}$ & $\begin{array}{l}0.145 \\
(0.12)\end{array}$ & $\begin{array}{l}0.128 \\
(0.10)\end{array}$ \\
\hline Wheat & $\begin{array}{l}0.080 \\
(0.09)\end{array}$ & $\begin{array}{l}0.122 \\
(0.10)\end{array}$ & $\begin{array}{l}0.078 \\
(0.09)\end{array}$ & $\begin{array}{l}0.082 \\
(0.11)\end{array}$ & $\begin{array}{l}0.070 \\
(0.08)\end{array}$ \\
\hline Oats & $\begin{array}{l}0.075 \\
(0.06)\end{array}$ & $\begin{array}{l}0.081 \\
(0.06)\end{array}$ & $\begin{array}{l}0.087 \\
(0.07)\end{array}$ & $\begin{array}{l}0.078 \\
(0.07)\end{array}$ & $\begin{array}{l}0.064 \\
(0.06)\end{array}$ \\
\hline Barley & $\begin{array}{l}0.014 \\
(0.03)\end{array}$ & $\begin{array}{l}0.011 \\
(0.02)\end{array}$ & $\begin{array}{l}0.010 \\
(0.02)\end{array}$ & $\begin{array}{l}0.021 \\
(0.03)\end{array}$ & $\begin{array}{l}0.019 \\
(0.03)\end{array}$ \\
\hline Rye & $\begin{array}{l}0.005 \\
(0.01)\end{array}$ & $\begin{array}{l}0.015 \\
(0.02)\end{array}$ & $\begin{array}{l}0.007 \\
(0.01)\end{array}$ & $\begin{array}{l}0.005 \\
(0.01)\end{array}$ & $\begin{array}{l}0.007 \\
(0.01)\end{array}$ \\
\hline Hay & $\begin{array}{l}0.120 \\
(0.04)\end{array}$ & $\begin{array}{l}0.149 \\
(0.06)\end{array}$ & $\begin{array}{l}0.123 \\
(0.05)\end{array}$ & $\begin{array}{l}0.110 \\
(0.05)\end{array}$ & $\begin{array}{l}0.097 \\
(0.05)\end{array}$ \\
\hline \multicolumn{6}{|l|}{ Farm size distribution: } \\
\hline Frac. $<20$ acres & $\begin{array}{l}0.061 \\
(0.06)\end{array}$ & $\begin{array}{l}0.054 \\
(0.05)\end{array}$ & $\begin{array}{l}0.064 \\
(0.06)\end{array}$ & $\begin{array}{l}0.064 \\
(0.06)\end{array}$ & $\begin{array}{l}0.085 \\
(0.08)\end{array}$ \\
\hline Frac. $20-49$ acres & $\begin{array}{l}0.116 \\
(0.09)\end{array}$ & $\begin{array}{l}0.105 \\
(0.09)\end{array}$ & $\begin{array}{l}0.107 \\
(0.09)\end{array}$ & $\begin{array}{l}0.097 \\
(0.08)\end{array}$ & $\begin{array}{l}0.100 \\
(0.08)\end{array}$ \\
\hline Frac. 50-99 acres & $\begin{array}{l}0.206 \\
(0.12)\end{array}$ & $\begin{array}{l}0.204 \\
(0.13)\end{array}$ & $\begin{array}{l}0.201 \\
(0.12)\end{array}$ & $\begin{array}{l}0.191 \\
(0.12)\end{array}$ & $\begin{array}{l}0.180 \\
(0.11)\end{array}$ \\
\hline Frac. $100-174$ acres & $\begin{array}{l}0.304 \\
(0.11)\end{array}$ & $\begin{array}{l}0.298 \\
(0.10)\end{array}$ & $\begin{array}{l}0.295 \\
(0.10)\end{array}$ & $\begin{array}{l}0.293 \\
(0.10)\end{array}$ & $\begin{array}{l}0.282 \\
(0.10)\end{array}$ \\
\hline Frac. $175-259$ acres & $\begin{array}{l}0.121 \\
(0.06)\end{array}$ & $\begin{array}{l}0.128 \\
(0.07)\end{array}$ & $\begin{array}{l}0.128 \\
(0.07)\end{array}$ & $\begin{array}{l}0.135 \\
(0.07)\end{array}$ & $\begin{array}{l}0.124 \\
(0.06)\end{array}$ \\
\hline Frac. $>260$ acres & $\begin{array}{l}0.192 \\
(0.23)\end{array}$ & $\begin{array}{l}0.211 \\
(0.25)\end{array}$ & $\begin{array}{l}0.204 \\
(0.25)\end{array}$ & $\begin{array}{l}0.219 \\
(0.25)\end{array}$ & $\begin{array}{l}0.229 \\
(0.25)\end{array}$ \\
\hline Average farm acres & $\begin{array}{c}194.333 \\
(160.49)\end{array}$ & $\begin{array}{l}220.469 \\
(237.27)\end{array}$ & $\begin{array}{l}212.241 \\
(243.28)\end{array}$ & $\begin{array}{l}224.472 \\
(271.78)\end{array}$ & $\begin{array}{l}248.032 \\
(366.89)\end{array}$ \\
\hline \multicolumn{6}{|l|}{ Farm mortgages: } \\
\hline Debt ratio & $\begin{array}{l}0.255 \\
(0.05)\end{array}$ & $\begin{array}{l}0.278 \\
(0.05)\end{array}$ & $\begin{array}{l}0.424 \\
(0.06)\end{array}$ & $\begin{array}{l}0.418 \\
(0.08)\end{array}$ & $\begin{array}{l}0.480 \\
(0.11)\end{array}$ \\
\hline Interest rate (p.p.) & $\begin{array}{l}- \\
-\end{array}$ & $\begin{array}{l}5.941 \\
(0.50)\end{array}$ & $\begin{array}{l}- \\
-\end{array}$ & $\begin{array}{l}6.022 \\
(0.44)\end{array}$ & $\begin{array}{l}5.023 \\
(0.44)\end{array}$ \\
\hline
\end{tabular}

Notes: Table reports mean county characteristics in the sample from 1910 to 1940. Standard deviations shown in parentheses. Tractor diffusion is the fraction of farms reporting tractors, available for 1925, 1930, and 1940. Crop percentages calculated as the acreage planted, harvested, and in each of six principal crops as a fraction of total farmland. Farm size distribution calculated as the fraction of all farms in each of six size categories. Data on farm finances is reported in the Census of Agriculture for mortgaged farms and reflects local debt loads and access to capital. Data from 1910 to 1940 U.S. Census of Agriculture. 
Table 3: Crop Intensity and Changes in Tractor Diffusion from 1925 to 1940

\begin{tabular}{|c|c|c|c|}
\hline & $\begin{array}{c}1925-1930 \\
(1)\end{array}$ & $\frac{1930-1940}{(2)}$ & $\frac{1925-1940}{(3)}$ \\
\hline $\begin{array}{l}\text { Pct. in Wheat } \\
\text { x Year }=1930\end{array}$ & $\begin{array}{c}0.437^{* * *} \\
(0.028)\end{array}$ & & $\begin{array}{c}0.383^{* * *} \\
(0.028)\end{array}$ \\
\hline $\begin{array}{l}\text { Pct. in Corn } \\
\text { x Year }=1930\end{array}$ & $\begin{array}{c}0.017 \\
(0.020)\end{array}$ & & $\begin{array}{c}0.024 \\
(0.020)\end{array}$ \\
\hline $\begin{array}{l}\text { Pct. in Wheat } \\
\text { x Year }=1940\end{array}$ & & $\begin{array}{c}0.037 \\
(0.030)\end{array}$ & $\begin{array}{c}0.420^{* * *} \\
(0.033)\end{array}$ \\
\hline $\begin{array}{l}\text { Pct. in Corn } \\
\text { x Year }=1940\end{array}$ & & $\begin{array}{c}0.413^{* * *} \\
(0.021)\end{array}$ & $\begin{array}{c}0.437^{* * *} \\
(0.028)\end{array}$ \\
\hline $\begin{array}{l}\text { Difference } \\
\text { s.e. } \\
\text { Diff. by } 1930 \\
\text { s.e. } \\
\text { Diff. by } 1940 \\
\text { s.e. }\end{array}$ & $\begin{array}{c}-0.42^{* * *} \\
(0.04)\end{array}$ & $\begin{array}{c}0.38^{* * *} \\
(0.04)\end{array}$ & $\begin{array}{c}-0.36^{* * *} \\
(0.04) \\
0.02 \\
(0.04)\end{array}$ \\
\hline $\begin{array}{l}\mathrm{N} \\
R^{2}\end{array}$ & $\begin{array}{c}2064 \\
0.56\end{array}$ & $\begin{array}{l}1884 \\
0.61\end{array}$ & $\begin{array}{c}2826 \\
0.68\end{array}$ \\
\hline
\end{tabular}

Notes: Table shows the relationship between pre-period crop intensity and changes in county-level tractor diffusion from 1925-30 and 193040 (Columns 1 and 2) and for a pooled sample (Column 3). The sample is restricted to counties whose borders did not change over the sample period and for which data are available for all subsequent robustness checks (1,030 counties in 1925-30; 942 counties in 193040 and the pooled sample). The difference in the diffusion rates to wheat- vs. corn-intensive counties is provided below the regression estimates. *,**,*** represent significance at the $0.1,0.05$, and 0.01 levels, respectively. SEs clustered by county in parentheses. 


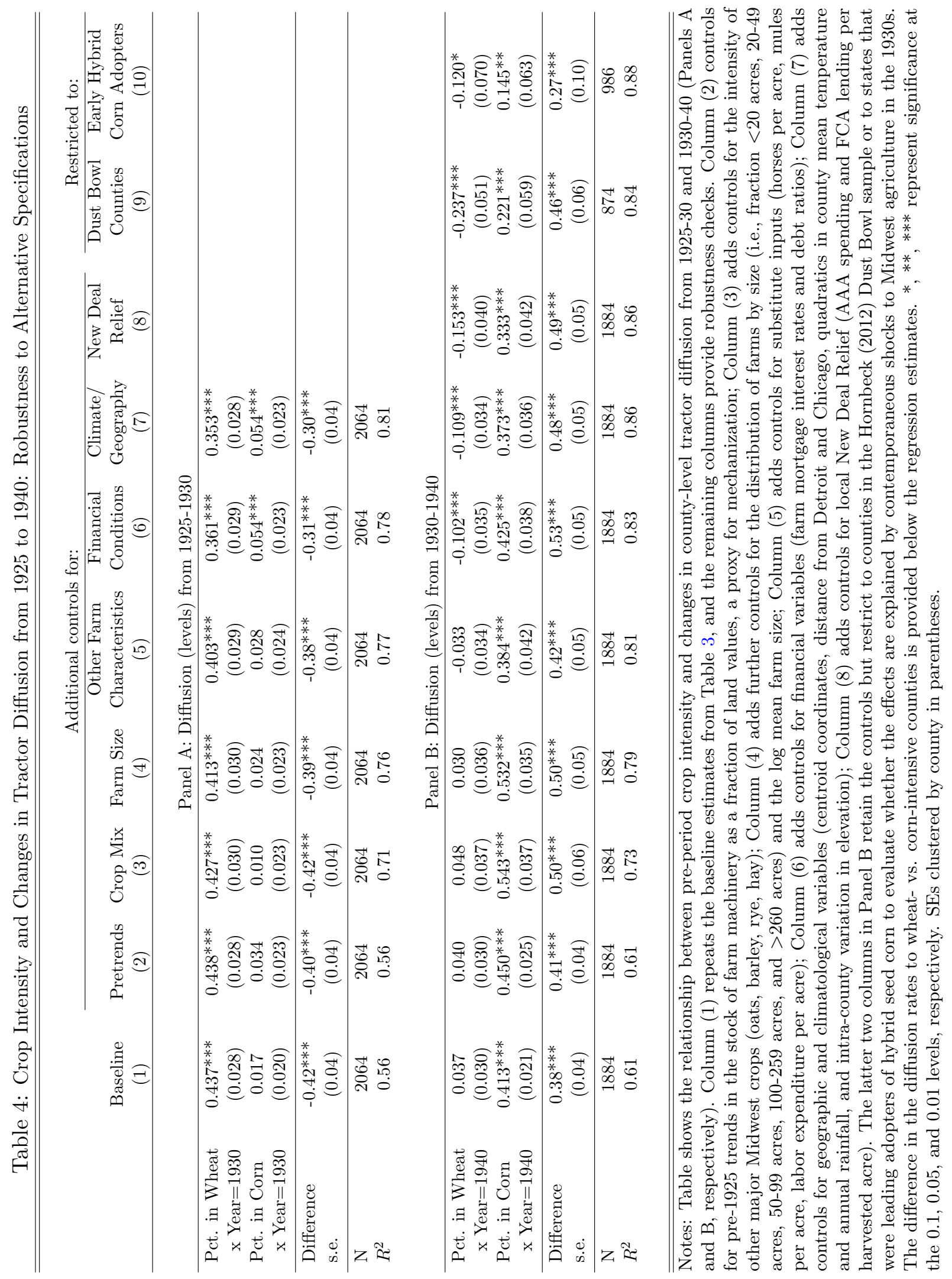




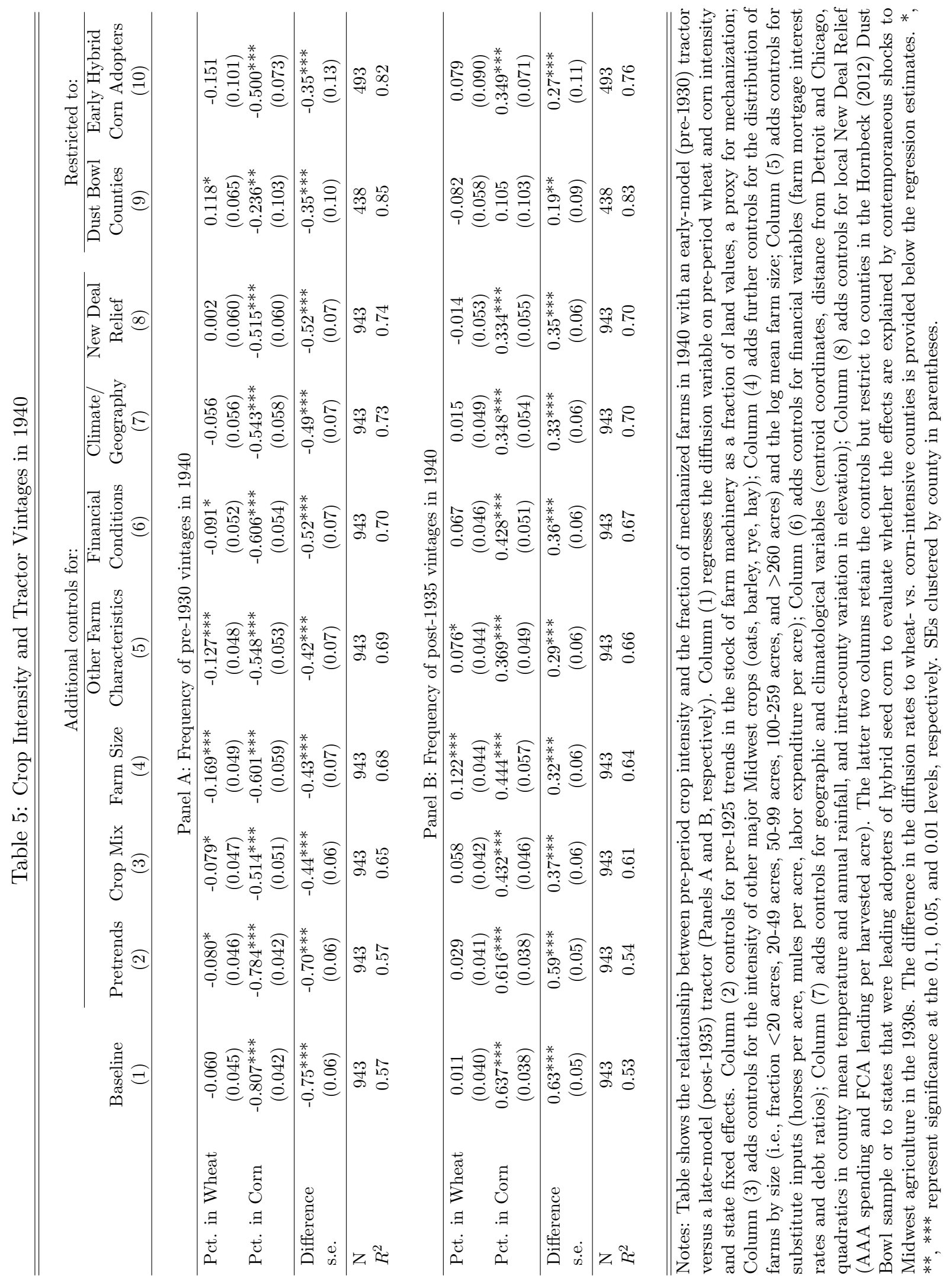




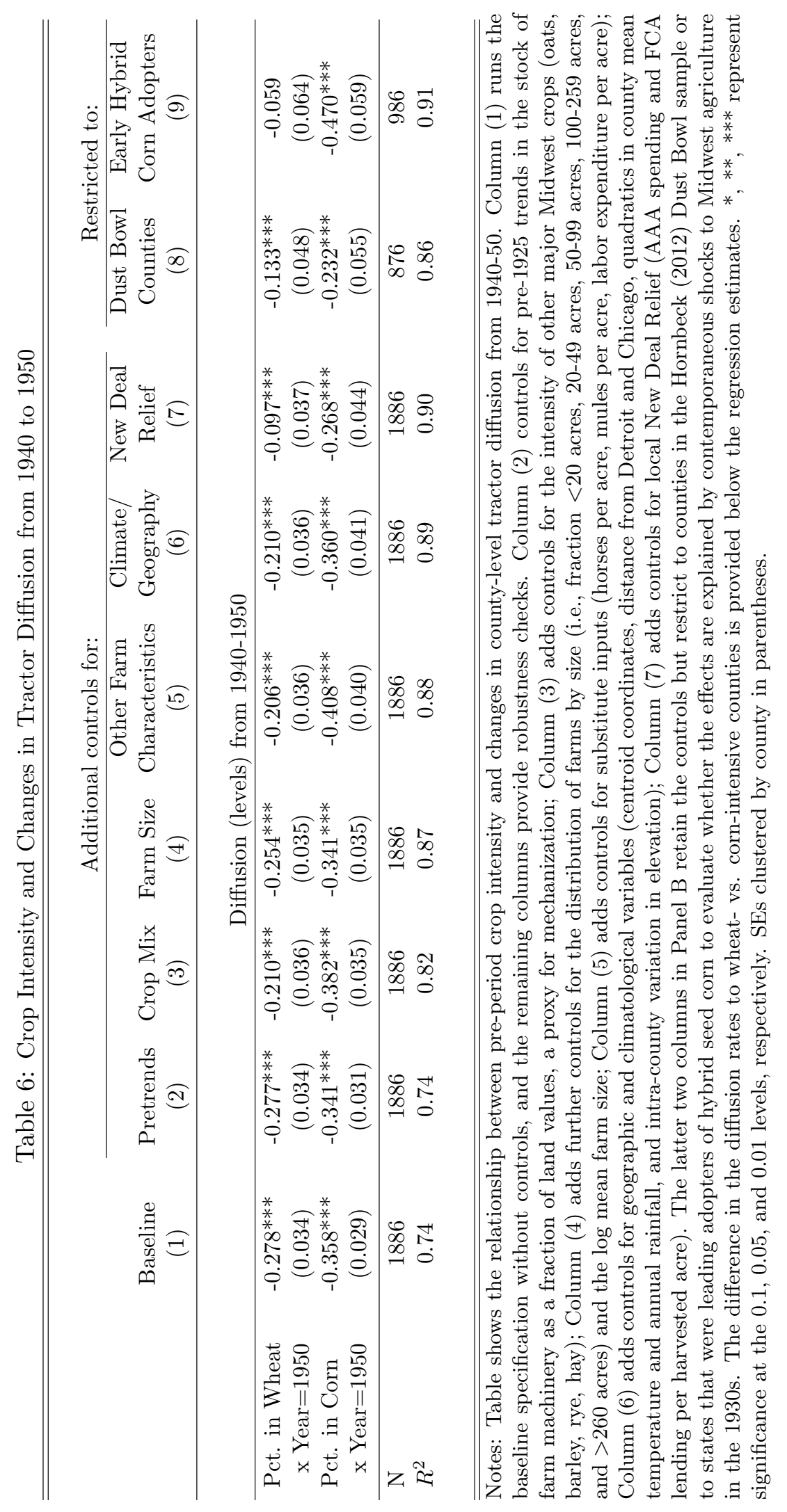


Table 7: Tractor Diffusion by Region, from 1920 to Present

\begin{tabular}{lcccc|c}
\hline \hline Census Region & $\mathbf{1 9 2 0}$ & $\mathbf{1 9 2 5}$ & $\mathbf{1 9 3 0}$ & $\mathbf{1 9 4 0}$ & $\mathbf{2 0 0 2}$ \\
\hline Northeast & 2.7 & 9.5 & 18.6 & 29.2 & 86.2 \\
Midwest & 6.8 & 13.6 & 25.7 & 42.4 & 89.6 \\
South & 1.0 & 2.3 & 4.0 & 7.9 & 91.8 \\
excl. DE, MD, OK, TX & 0.7 & 1.8 & 2.7 & 4.2 & 90.0 \\
DE, MD alone & 2.8 & 7.5 & 15.5 & 23.0 & 90.3 \\
OK, TX alone & 2.2 & 3.7 & 7.9 & 21.3 & 95.0 \\
West & 7.0 & 10.7 & 19.4 & 27.9 & 83.2 \\
\hline \hline
\end{tabular}

Notes: Table reports tractor diffusion by Census region in 1920, 1925, 1930, 1940, and 2002. The table highlights the lagging adoption of tractors in Southern states through 1940, especially those with historically poor labor institutions (slavery and sharecropping), and their eventual catch-up to the rest of the country.

Table 8: Regional Diffusion and Labor Savings in 1930 (counterfactual)

Panel A: Counterfactual increase in diffusion in 1930

\begin{tabular}{lrc}
\hline & Pct. of farms \\
Midwest diffusion, as observed, 1930 & 0.256 & $(1)$ \\
Estimated diffusion, 1930 & 0.259 & $(2)$ \\
Counterfactual diffusion, 1930 & 0.322 & $(3)$ \\
\hline level increase [(3)-(1)] & 0.066 & $(4)$ \\
pct. increase [(4)/(1)] & $25.7 \%$ &
\end{tabular}

Panel B: Added labor savings

\begin{tabular}{lrr}
\hline & \multicolumn{2}{c}{ Hours (mil.) } \\
Added labor savings under counterfactual & 110.99 & $(5)$ \\
Labor employed in Midwest agriculture & $1,088.35$ & $(6)$ \\
\hline as percent of labor employed $[(5) /(6)]$ & $10.2 \%$ & \\
& & \\
\multicolumn{1}{c}{ Panel C: Gross value of added labor savings } & \\
\hline Added labor savings, full-time equivalents & 55,496 & $(7)$ \\
Average non-farm annual wage (see appendix) & $\$ 1,501.45$ & $(8)$ \\
\hline Value of labor savings (mil. \$s, 1930) [(7)*(8)] & $\$ 83.32$ & \\
Value of labor savings (mil. \$s, 2014) & $\$ 952.97$ & $1.2 \%$ \\
as percent of Midwest Agricultural GDP & & \\
& & \\
\hline
\end{tabular}

Notes: Table reports counterfactual diffusion and potential reductions in agricultural labor inputs and increases in regional output had the tractor diffused at the same rate to corn-growing regions as to wheatgrowing areas of the Midwest 1930. Details of the calculations shown above are provided in the text and the appendix. 
Appendix 


\section{A Data Appendix}

The data used in this paper are primarily from the U.S. Census of Agriculture in 1910, 1920, 1925, 1930, 1940, and 1950. When possible, data were acquired from NHGIS; remaining variables were transcribed from PDFs obtained from the Census website. ${ }^{1}$ Stock variables (e.g., farms, farmland, number and value of farm machinery and draft animals, etc.) are reported for the Census year; flows (inputs, outputs) are always from the preceding year. Where corn acreage is separately reported for corn harvested for grain, cut for silage, cut for fodder, and hogged or grazed off (1925 and later), I use the acreage of corn harvested for grain, which is typically around 90 percent of total corn acreage and the subset most relevant to mechanization. Certain crops are not reported for certain states in certain years (barley and rye in Missouri, rye in Kansas - both in 1930) due to omission from the state-specific questionnaire, which likely reflects low acreage; production of these crops in the affected counties is coded as zero. Occasionally, a page went missing in the Census documents; in these cases, the affected observations were coded as missing. Modern Agricultural Census data were obtained from the U.S. Department of Agriculture Desktop Data Query Tool.

U.S. county shapefiles were obtained from NHGIS for each decade from 1910 to 1950. These maps were used to calculate counties' geographic centroids, as well as mean and standard deviation elevation (from the USGS National Elevation Dataset), mean and standard deviation annual rainfall (PRISM Climate Group 30-year normals), soil quality indices (National Commodity Crop Productivity Index), and other soil characteristics (USGS State Soil Geographic Database). I use county entry and exit into/out of the dataset and movement in geographic centroids to identify counties that formed, merged, split, or dissolved between Census years; any such counties are dropped from the analysis. As the text explains, I also apply Hornbeck's (2010) county border fix algorithm as a robustness check. I calculate distance to the f.o.b. shipping locations of Ford (Detroit) and International Harvester (Chicago) as a proxy for freight costs; comparison with point-to-point freight rates from Hartman (1916) suggests distance is a reasonable proxy, with correlations between route distance and point-to-point rates $>0.95$ for routes originating in Detroit or Chicago. Locations of Ford and IHC branch houses (showroom/dealer/service shops) and their years of operation were obtained from the website of The Henry Ford museum and from IHC annual reports, respectively. For each county in each Census year, I calculate the distance from the county centroid to the nearest Ford and IHC branch house, which enters into regressions as an additional control.

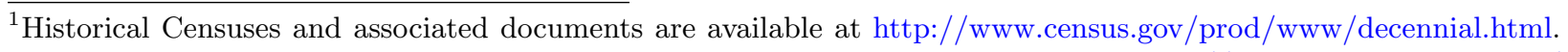
A complete collection of historical Agricultural Census publications can be found at http://www.agcensus.usda.gov/ Publications/Historical_Publications/index.php.
} 
The data used in the New Deal and Dust Bowl robustness checks were obtained from Fishback, Kantor, and Wallis (2003) and Hornbeck (2012), respectively. The New Deal robustness checks include the Fishback et al. measures of AAA relief spending and FCA lending by county from 1933-1939, normalized by harvested acreage; the Dust Bowl robustness checks restrict to counties in the Hornbeck dataset, which are located in the Plains states (Kansas, Nebraska, the Dakotas, Iowa, and Minnesota) and were those most affected by the Dust Bowl. Hybrid corn diffusion was provided by Richard Sutch (Sutch 2011, 2014) and originally obtained from the USDA Agricultural Statistics; the hybrid corn adopter robustness checks are restricted to the six states that were leading adopters of hybrids (by a wide margin, see Table A.1) in 1940.

Table A.1: Diffusion of Hybrid Corn through 1950, Midwest States

\begin{tabular}{lrrrrrrrr|r}
\hline \hline State & $\mathbf{1 9 3 3}$ & $\mathbf{1 9 3 4}$ & $\mathbf{1 9 3 5}$ & $\mathbf{1 9 3 6}$ & $\mathbf{1 9 3 7}$ & $\mathbf{1 9 3 8}$ & $\mathbf{1 9 3 9}$ & $\mathbf{1 9 4 0}$ & $\mathbf{1 9 5 0}$ \\
\hline IA & 0.7 & 2.1 & 6.0 & 14.4 & 30.7 & 51.9 & 73.4 & 90.3 & 100 \\
IL & 0.6 & 1.5 & 4.1 & 9.9 & 25.2 & 47.5 & 65.5 & 76.4 & 100 \\
IN & - & 0.3 & 1.0 & 3.5 & 11.1 & 28.5 & 50.8 & 63.1 & 99.0 \\
OH & - & - & 0.4 & 2.0 & 6.7 & 25.0 & 42.1 & 56.0 & 98.5 \\
MO & - & - & - & 0.3 & 0.6 & 1.8 & 12.1 & 26.9 & 97.0 \\
MN & 0.1 & 0.4 & 1.4 & 3.7 & 9.1 & 20.4 & 37.0 & 57.3 & 96.5 \\
WI & 0.1 & 0.6 & 1.8 & 5.0 & 11.1 & 24.0 & 39.7 & 56.6 & 95.5 \\
NE & 0.0 & 0.1 & 0.3 & 1.0 & 2.5 & 6.8 & 12.7 & 24.9 & 94.0 \\
MI & - & - & 0.1 & 0.5 & 1.1 & 3.2 & 8.1 & 20.9 & 89.5 \\
KS & - & - & - & - & 0.2 & 1.6 & 5.3 & 10.9 & 85.0 \\
SD & - & - & 0.1 & 0.4 & 1.2 & 3.1 & 7.0 & 12.6 & 74.5 \\
ND & - & - & - & - & - & 0.4 & 1.6 & 3.8 & 53.5 \\
\hline \hline
\end{tabular}

Notes: Table reports fraction of corn acreage planted to hybrids in each of the 12 Midwest states from 1933 - when records are first available - to 1940 and 1950. Data from Sutch (2011, 2014). 


\section{B Midwest Agriculture During the Sample Period}

\section{B.1 Cross-Sectional Distribution of Tractor Diffusion}

It is useful to include a high-level view of tractor diffusion in the Midwest over the period studied. Table B.1 shows the time series of tractor diffusion in each Midwest state, from 1920 to 1959 and in 2002, where it can be seen that North and South Dakota were historically the leaders in adoption, the Corn Belt (Iowa, Illinois, Nebraska) right behind, the Great Lakes region (Ohio, Indiana, Michigan, and Wisconsin) slower, and Missouri a clear laggard. All are discussed in the body of the paper. Figure B.1 shows the statistical distribution of tractor diffusion across the counties in the estimation sample for each of 1925, 1930, 1940, and 1950.

Table B.1: Tractor Diffusion by State, from 1920-Present

\begin{tabular}{crrrrrrrr|r}
\hline \hline State & $\mathbf{1 9 2 0}$ & $\mathbf{1 9 2 5}$ & $\mathbf{1 9 3 0}$ & $\mathbf{1 9 4 0}$ & $\mathbf{1 9 4 5}$ & $\mathbf{1 9 5 0}$ & $\mathbf{1 9 5 4}$ & $\mathbf{1 9 5 9}$ & $\mathbf{2 0 0 2}$ \\
\hline SD & 16.3 & 20.6 & 37.2 & 55.1 & 75.8 & 84.8 & 91.5 & 91.8 & 92.1 \\
ND & 15.2 & 20.9 & 43.8 & 59.2 & 81.4 & 89.3 & 93.9 & 95.0 & 81.7 \\
KS & 9.8 & 17.2 & 35.6 & 53.6 & 66.3 & 75.3 & 85.4 & 88.8 & 89.5 \\
IL & 9.2 & 18.4 & 30.8 & 51.8 & 64.6 & 72.7 & 84.2 & 89.5 & 93.1 \\
IA & 9.1 & 16.7 & 29.4 & 55.3 & 72.3 & 79.4 & 87.9 & 90.8 & 91.9 \\
MN & 8.3 & 13.6 & 24.9 & 48.6 & 68.1 & 79.8 & 89.3 & 92.1 & 84.6 \\
NE & 8.3 & 13.9 & 29.3 & 53.4 & 72.9 & 81.7 & 88.9 & 90.8 & 87.0 \\
WI & 4.8 & 15.0 & 26.8 & 41.2 & 61.5 & 75.6 & 88.5 & 92.8 & 89.8 \\
IN & 4.3 & 11.7 & 22.3 & 37.1 & 50.8 & 63.6 & 78.0 & 85.7 & 88.6 \\
OH & 3.9 & 12.2 & 23.1 & 35.6 & 50.2 & 63.9 & 77.7 & 85.5 & 91.0 \\
MI & 2.8 & 9.6 & 19.5 & 33.1 & 55.0 & 71.6 & 85.7 & 91.1 & 89.3 \\
MO & 2.8 & 4.6 & 9.2 & 16.4 & 27.8 & 43.6 & 63.9 & 76.1 & 91.0 \\
\hline \hline
\end{tabular}

Notes: Table reports tractor diffusion by Midwest state in from 1920 to 1959 and in 2002. Data from the 1959 and 2002 Census of Agriculture. 
Figure B.1: Tractor diffusion in U.S. Midwest, 1925-50: Histograms

Distribution of counties in 1925

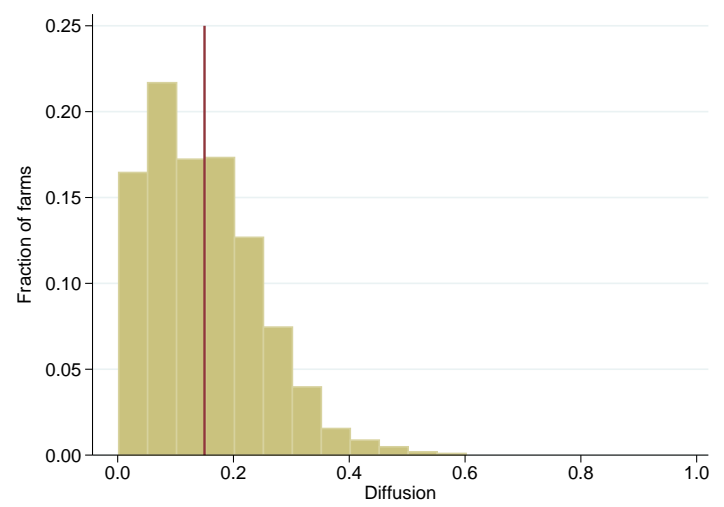

Distribution of counties in 1940

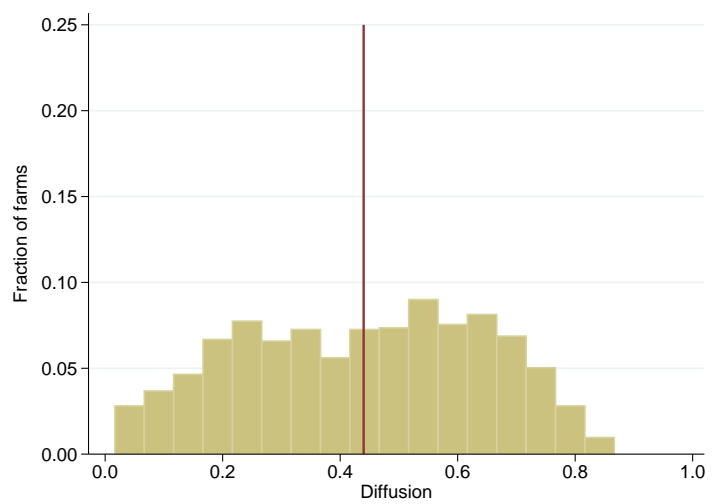

Distribution of counties in 1930

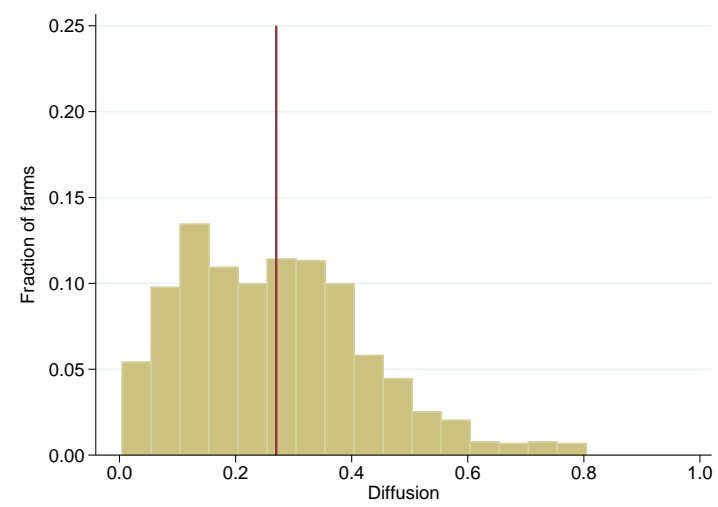

Distribution of counties in 1950

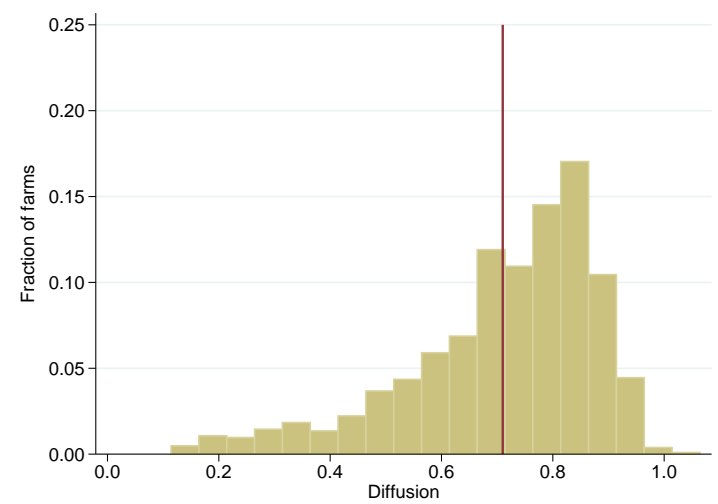

Notes: Figure shows the distribution of tractor diffusion across 1,033 counties in the U.S. Midwest in 1925, 1930, 1940, and 1950. Mean countylevel diffusion for each period is marked by the vertical line. Data from 1925 to 1950 Census of Agriculture. 


\section{B.2 Persistence of Crop Shares Over Time}

The following figures demonstrate the persistence of crop mix in the U.S. Midwest from 1910 to 1950. The six most common crops (by acreage) were corn, wheat, oats, barley, rye, and hay, which together comprised 85 percent of harvested acreage throughout the sample period. ${ }^{2}$ Figure B.2 shows the percent of Midwest farmland in each of these crops from 1925-40, while Figures B.3 and B.4 repeat for planted and harvested acreage, respectively - by all measures, persistence in the relative intensity of each crop over the sample period is observed in the aggregate.

Figures B.5 and B.6 present state-level wheat and corn intensity for Midwest states in 1925. From these figures it can be seen that North Dakota and Kansas are the heart of the Wheat Belt, and Iowa and Illinois the heart of the Corn Belt, motivating the comparisons in Figure 3 in the body of the paper. The maps in Figures B.7 to B.12 then show the disaggregated spatial distribution of each crop, by decade, where the Corn Belt and Wheat Belt are plainly visible, as are the growing regions for the other principal Midwestern crops. Correlations between counties' crop shares over the sampling period confirm the spatial persistence visible in these figures.

Figure B.2: Crop shares of midwest farmland, 1925-1950

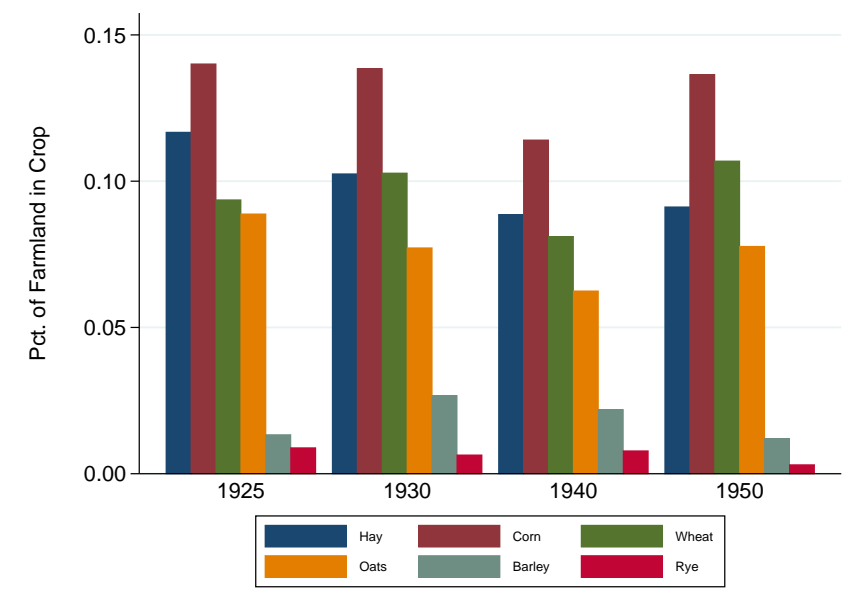

Notes: Percentages are measured as each crop's harvested acreage over total acres of farmland. Corn acreage is limited to corn harvested for grain only (versus silage). The six crops represented here constitute $46.1 \%$ of all acres of farmland in the Midwest in 1925, 45.4\% in 1930, 37.5\% in 1940, and $42.6 \%$ in 1950. Data from 1925 to 1950 Census of Agriculture.

\footnotetext{
${ }^{2}$ Soybeans were not grown in large quantity until the 1940s, when wartime foreign supply disruptions led to a dramatic expansion in domestic production, and are not included in these tables and figures.
} 
Figure B.3: Crop shares of midwest cropland, 1925-1950

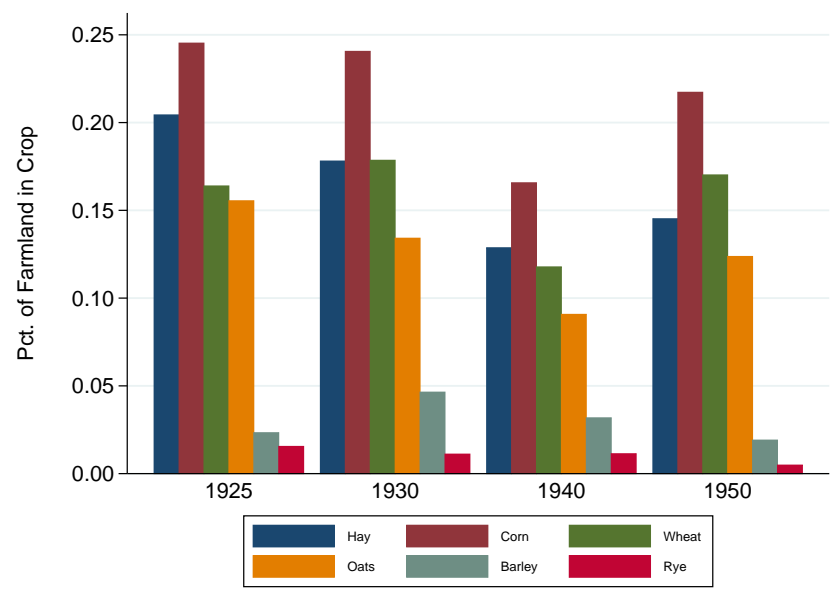

Notes: Percentages are measured as each crop's harvested acreage over total acres of cropland. Cropland includes harvested crops, crop failure, and land idle or fallow. Corn acreage is limited to corn harvested for grain only (versus fodder or grazed). The six crops represented here constitute $80.8 \%$ of all acres of cropland in the Midwest in 1925, 78.9\% in 1930, 54.6\% in 1940, and $68.0 \%$ in 1950 . The fraction of cropland in each crop is highly correlated with the fraction of farmland in each crop, with correlations of 0.94 for corn, 0.96 for wheat, 0.95 for oats, 0.96 for barley, 0.96 for rye, and 0.77 for hay. Data from 1925 to 1950 Census of Agriculture.

Figure B.4: Crop shares of midwest harvested acreage, 1925-1950

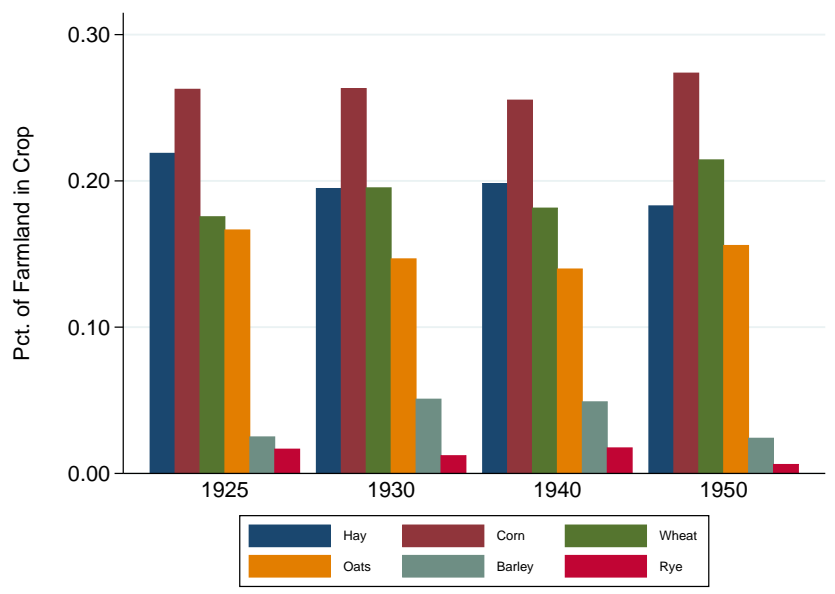

Notes: Percentages are measured as each crop's harvested acreage over total acres of cropland. Corn acreage is limited to corn harvested for grain only (versus fodder or grazed). The six crops represented here constitute $86.5 \%$ of all acres harvested in the Midwest in 1925, 86.3\% in 1930, 84.1\% in 1940, and $85.7 \%$ in 1950 . The fraction of harvested acreage in each crop is highly correlated with the fraction of farmland in each crop, with correlations of 0.91 for corn, 0.92 for wheat, 0.94 for oats, 0.95 for barley, 0.95 for rye, and 0.71 for hay. Data from 1925 to 1950 Census of Agriculture." 
Figure B.5: Percent of Farmland in Wheat, State Totals, 1925

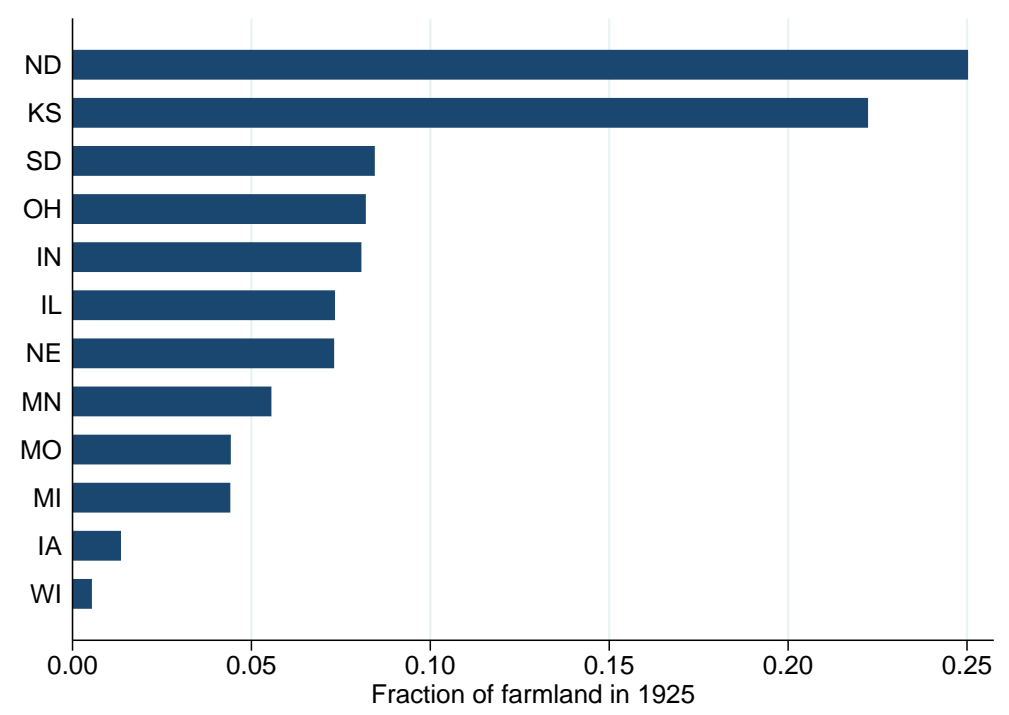

Notes: Table reports state-level wheat intensity as a fraction of farmland for the U.S. Midwest. Data from 1925 Census of Agriculture.

Figure B.6: Percent of Farmland in Corn, State Totals, 1925

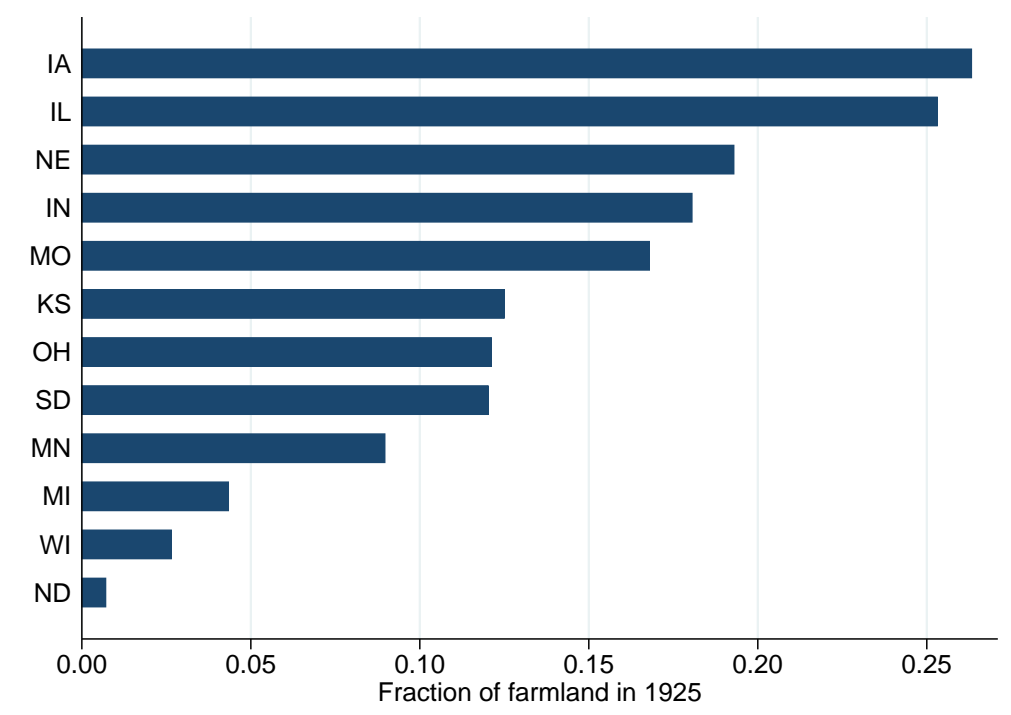

Notes: Table reports state-level corn intensity as a fraction of farmland for the U.S. Midwest. Data from 1925 Census of Agriculture. 
Figure B.7: Percent of farmland in corn, 1910-1950

Farmland in corn, 1910

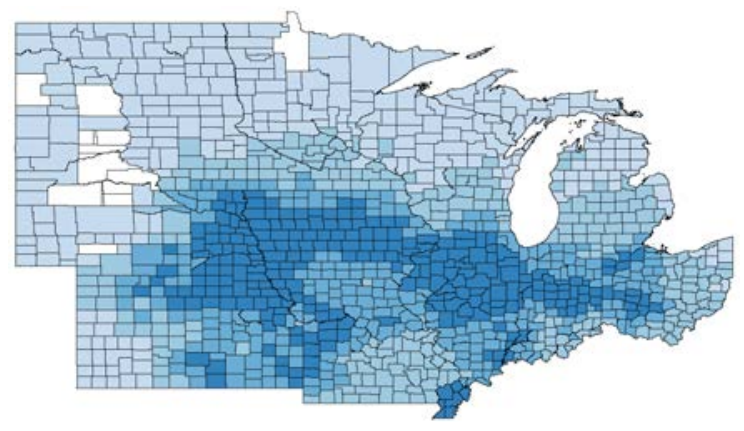

Farmland in corn, 1930

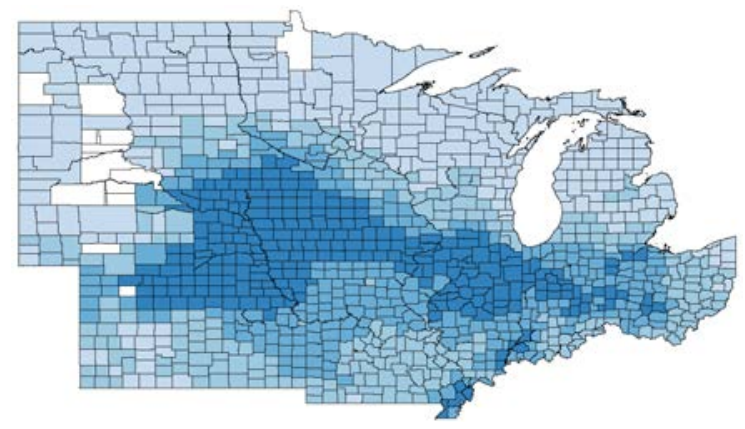

Farmland in corn, 1920

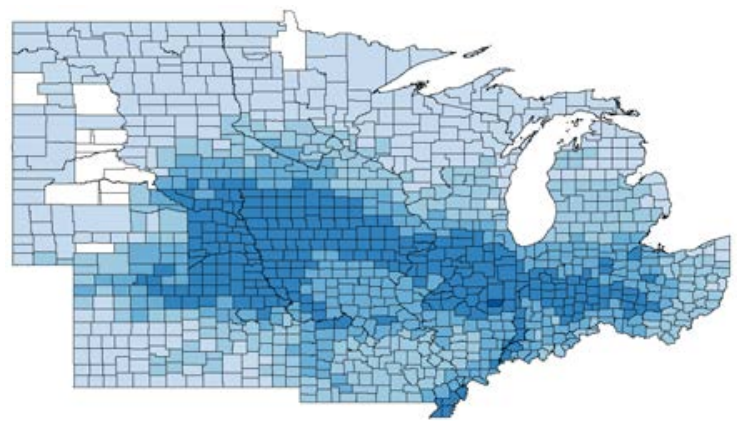

Farmland in corn, 1940

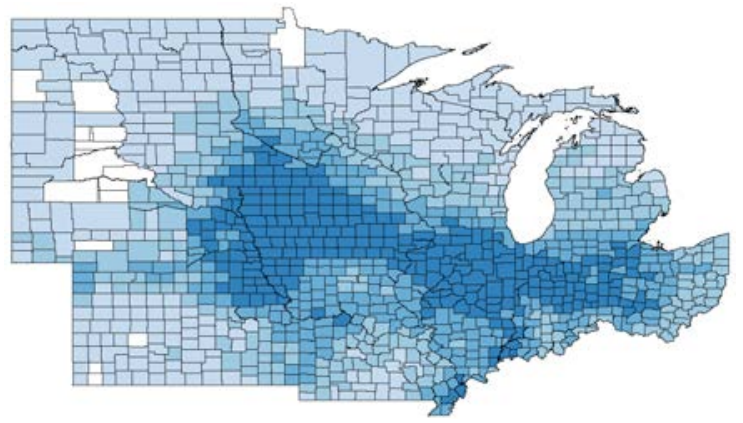

Farmland in corn, 1950

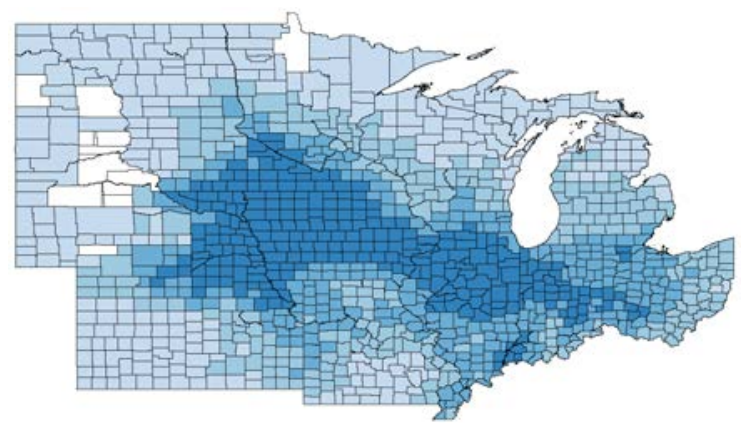

Notes: Map shows the percent of farmland planted in corn from 1910 to 1950, with darker colors indicating greater concentrations. Data from 1910 to 1950 Census of Agriculture. 
Figure B.8: Percent of farmland in wheat, 1910-1950

Farmland in wheat, 1910

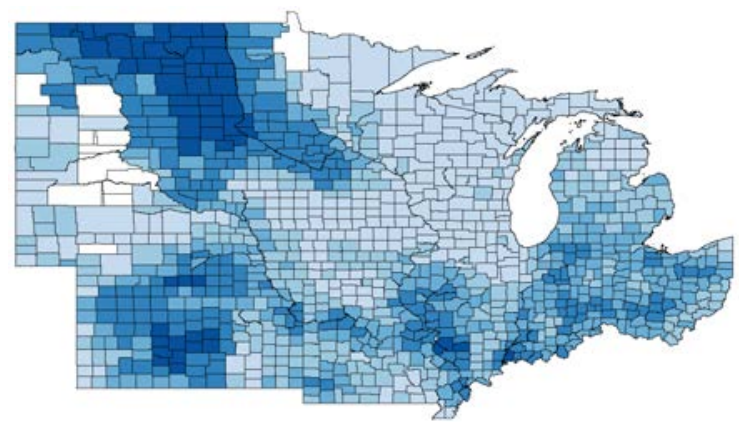

Farmland in wheat, 1930

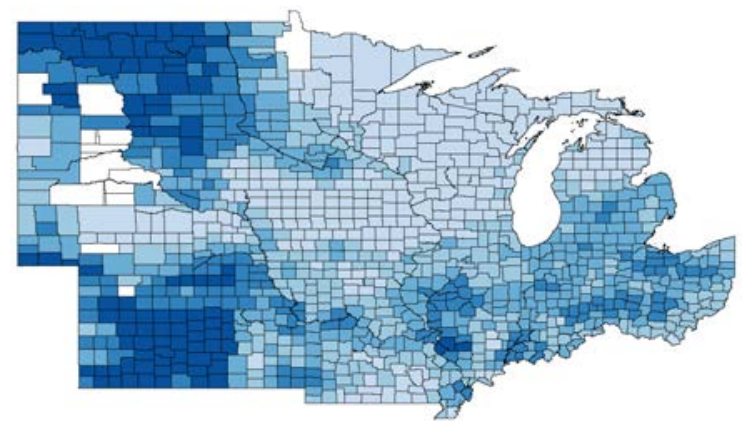

Farmland in wheat, 1920

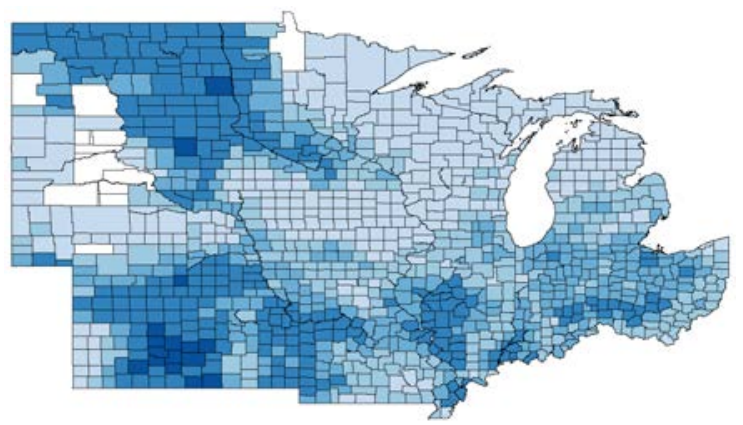

Farmland in wheat, 1940

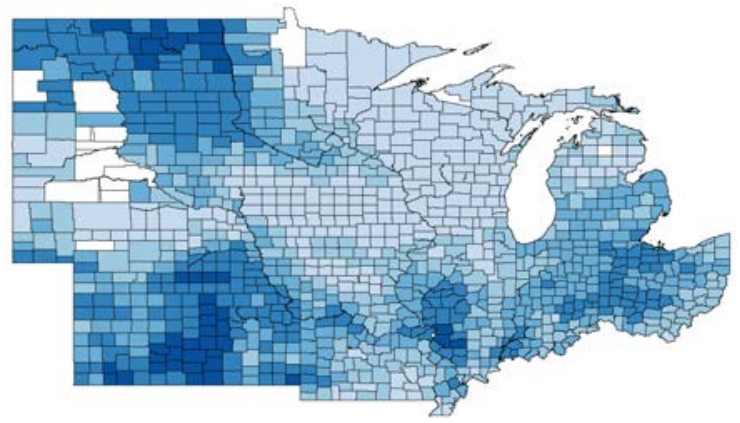

Farmland in wheat, 1950

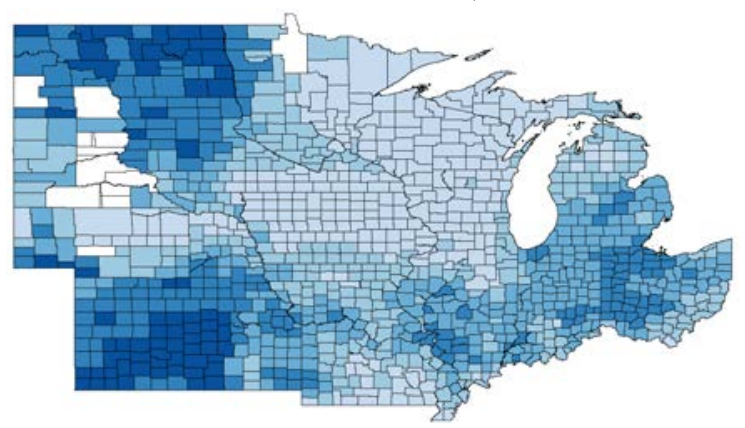

Notes: Map shows the percent of farmland planted in wheat from 1910 to 1950, with darker colors indicating greater concentrations. Data from 1910 to 1950 Census of Agriculture. 
Figure B.9: Percent of farmland in oats, 1910-1950

Farmland in oats, 1910

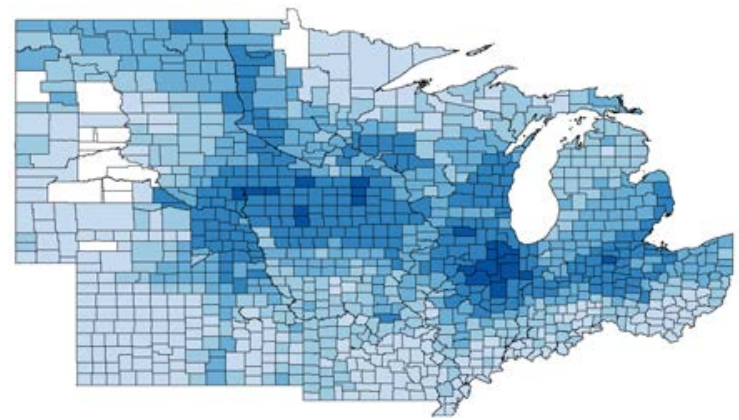

Farmland in oats, 1930

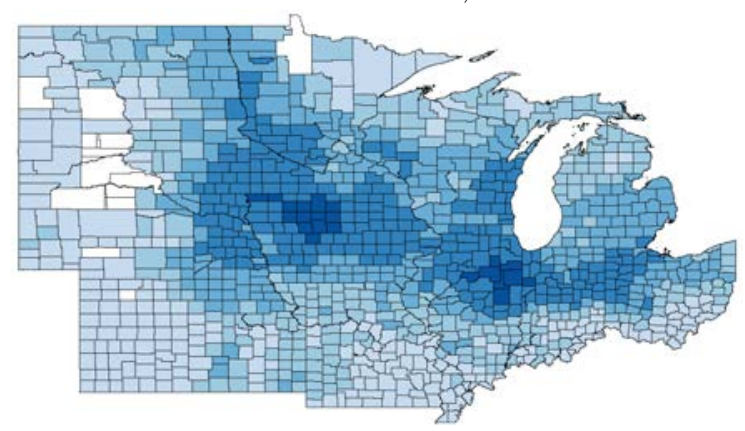

Farmland in oats, 1920

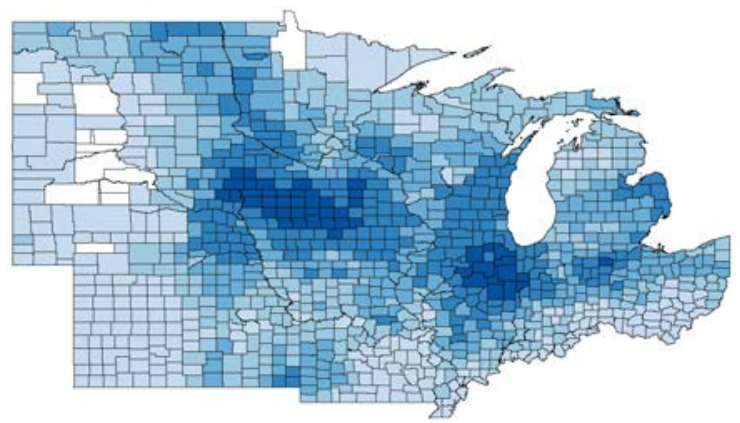

Farmland in oats, 1940

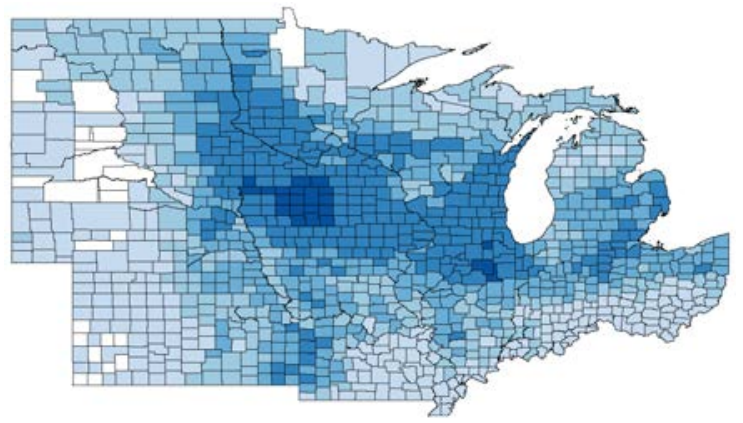

Farmland in oats, 1950

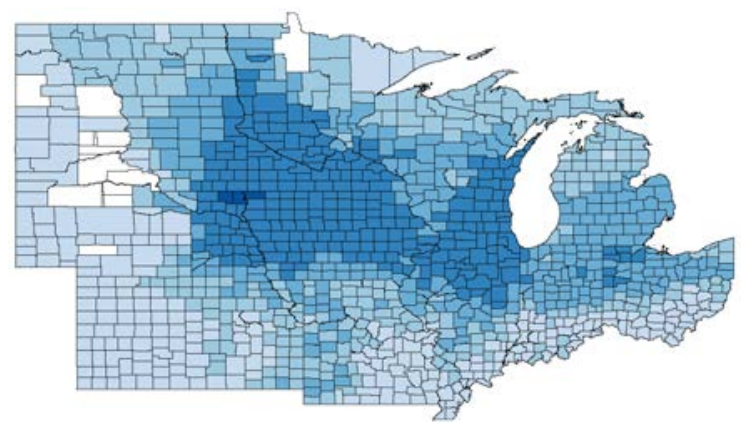

Notes: Map shows the percent of farmland planted in oats from 1910 to 1950, with darker colors indicating greater concentrations. Data from 1910 to 1950 Census of Agriculture. 
Figure B.10: Percent of farmland in barley, 1910-1950

Farmland in barley, 1910

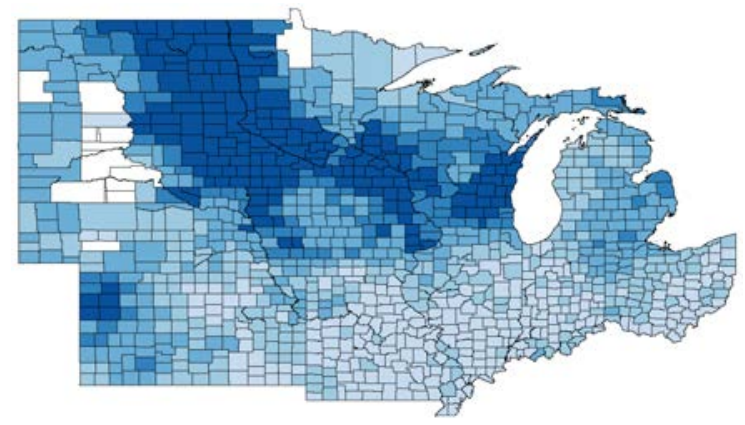

Farmland in barley, 1930

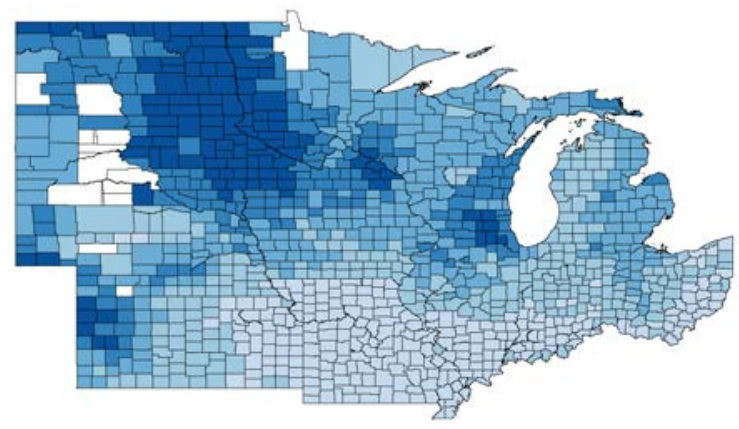

Farmland in barley, 1920

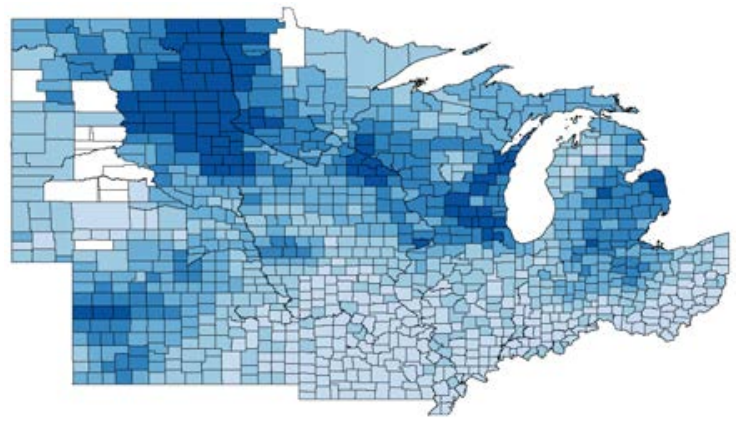

Farmland in barley, 1940

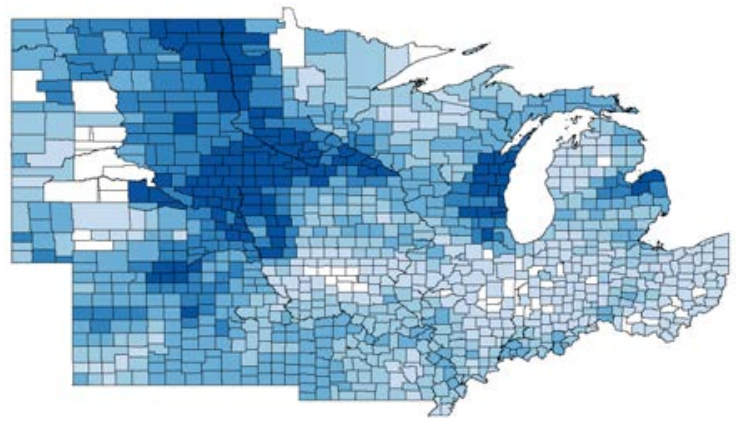

Farmland in barley, 1950

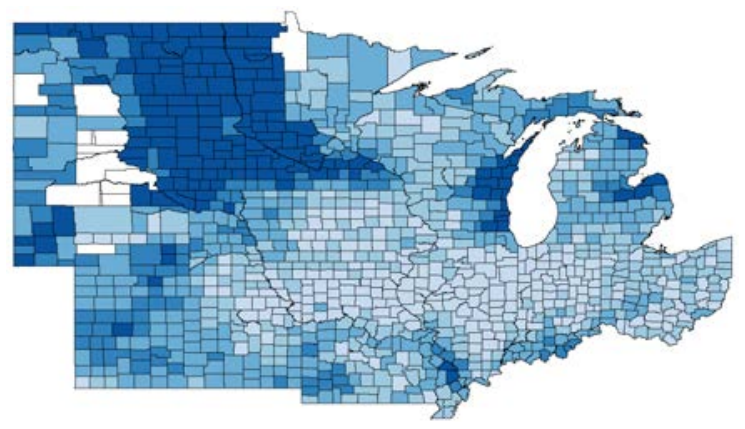

Notes: Map shows the percent of farmland planted in barley from 1910 to 1950, with darker colors indicating greater concentrations. Data from 1910 to 1950 Census of Agriculture. 
Figure B.11: Percent of farmland in rye, 1910-1950

Farmland in rye, 1910

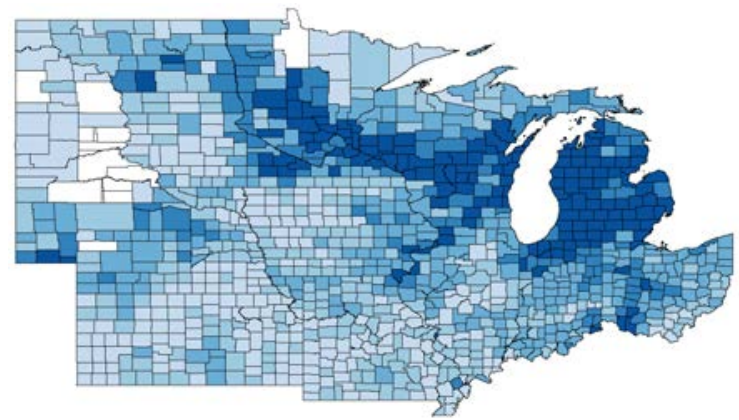

Farmland in rye, 1930

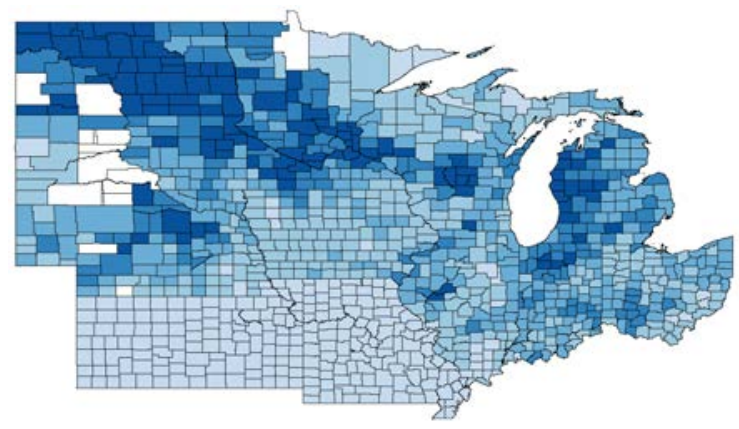

Farmland in rye, 1920

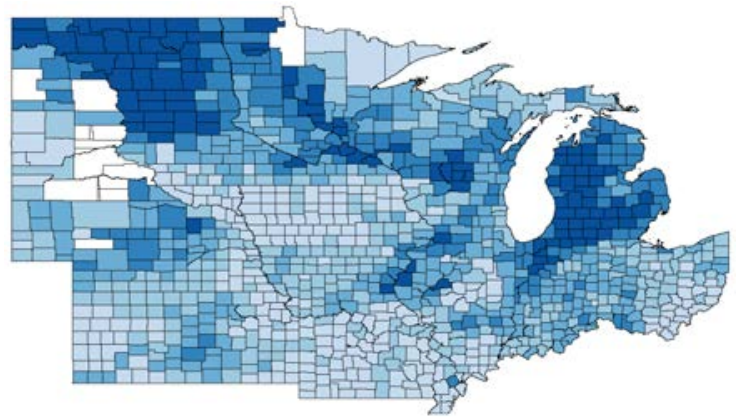

Farmland in rye, 1940

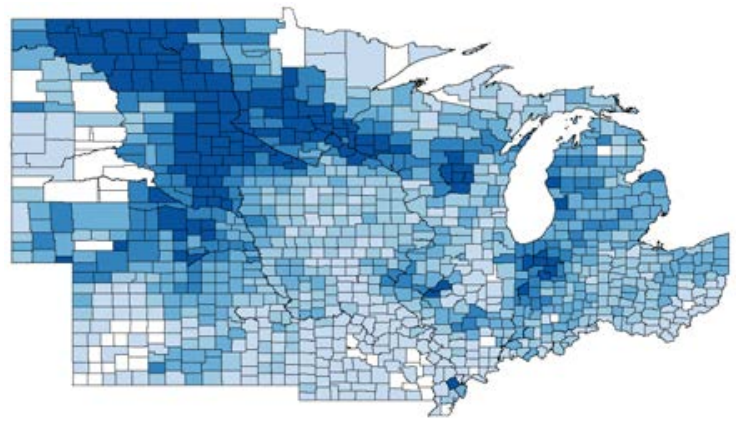

Farmland in rye, 1950

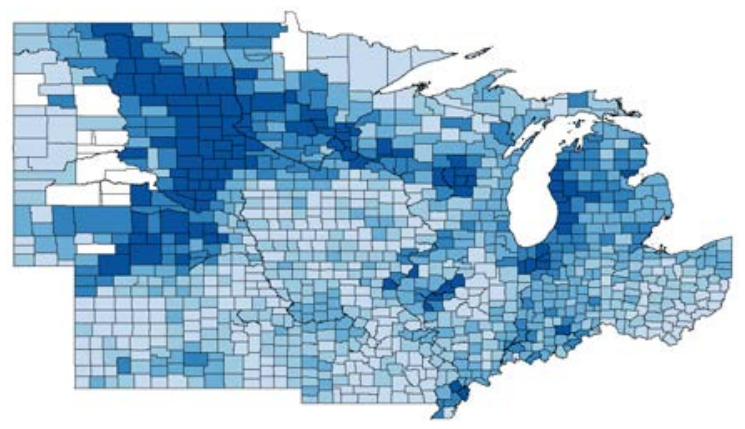

Notes: Map shows the percent of farmland planted in rye from 1910 to 1950, with darker colors indicating greater concentrations. Data from 1910 to 1950 Census of Agriculture. 
Figure B.12: Percent of farmland in hay, 1910-1950

Farmland in hay, 1910

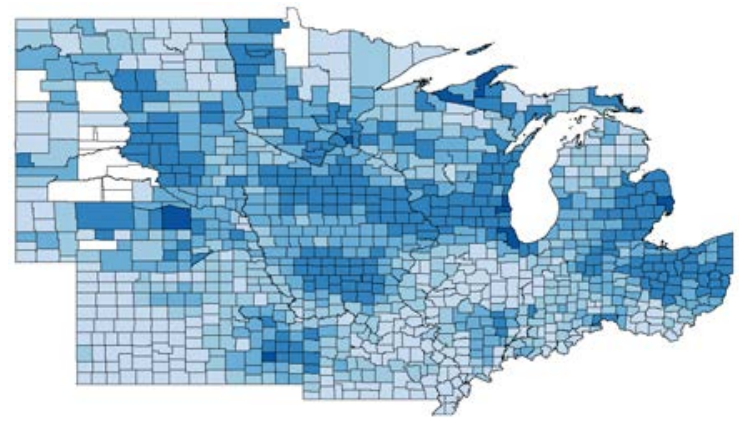

Farmland in hay, 1930

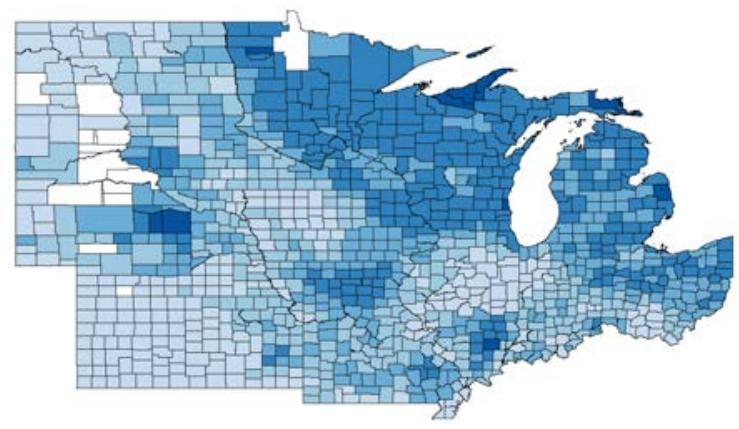

Farmland in hay, 1920

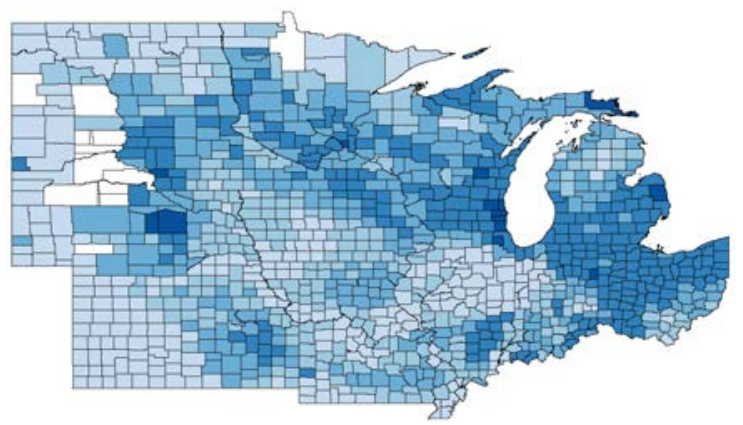

Farmland in hay, 1940

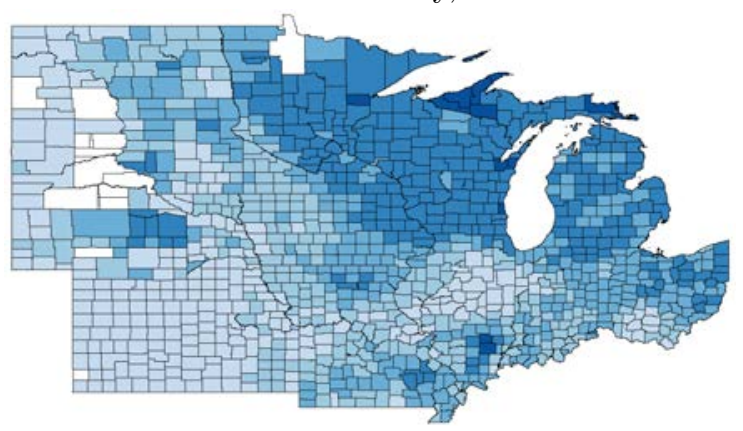

Farmland in hay, 1950

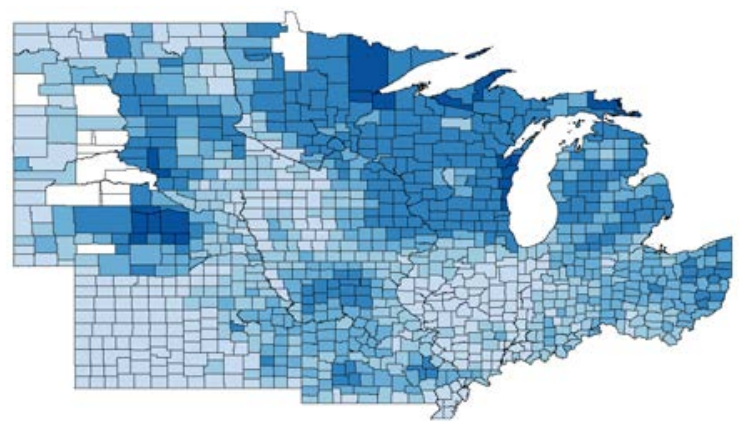

Notes: Map shows the percent of farmland planted in hay from 1910 to 1950, with darker colors indicating greater concentrations. Data from 1910 to 1950 Census of Agriculture. 


\section{B.3 Farm Population, Pre- and Post-WW2}

Tables B.2 and B.3 provide a window into changes in Midwest farm populations at the state level (the most disaggregated level available) over the sample period. The first table focuses on the inter-war period. Farm populations declined modestly over this period, with most of the reduction taking place in the Great Plains (ND, SD, NE, KS) between 1930 and 1940.

The second table shows farm population in the 1940s, which declined precipitiously during World War II, mirroring the national trend. During the war, the Midwest farm population declined 21\%, with state-level changes ranging from $-15 \%$ in Iowa to $-24 \%$ in Michigan. The proximate cause of the decline was the war effort, which mobilized adult males into other sectors: the 1950 Census of Agriculture notes that "a rapid loss of farm population occurred during World War II because of the demand for manpower in industry and in the military services."

Table B.2: Farm Population (thousands), State Totals, 1920-1940

\begin{tabular}{lrrrrr}
\hline \hline State & $\mathbf{1 9 2 0}$ & $\mathbf{1 9 3 0}$ & $\mathbf{1 9 4 0}$ & $\begin{array}{c}\text { Pct. Chg. } \\
\mathbf{1 9 2 0 - 3 0}\end{array}$ & $\begin{array}{c}\text { Pct. Chg. } \\
\mathbf{1 9 3 0 - 4 0}\end{array}$ \\
\hline IA & 991 & 981 & 931 & -0.01 & -0.05 \\
$\mathrm{IL}$ & 1107 & 1002 & 979 & -0.09 & -0.02 \\
$\mathrm{IN}$ & 914 & 815 & 816 & -0.11 & 0.00 \\
$\mathrm{KS}$ & 742 & 709 & 607 & -0.04 & -0.14 \\
$\mathrm{MI}$ & 856 & 785 & 871 & -0.08 & 0.11 \\
$\mathrm{MN}$ & 903 & 898 & 915 & -0.01 & 0.02 \\
$\mathrm{MO}$ & 1219 & 1118 & 1125 & -0.08 & 0.01 \\
$\mathrm{ND}$ & 398 & 398 & 328 & 0.00 & -0.18 \\
$\mathrm{NE}$ & 588 & 587 & 498 & 0.00 & -0.15 \\
$\mathrm{OH}$ & 1149 & 1016 & 1089 & -0.12 & 0.07 \\
$\mathrm{SD}$ & 364 & 391 & 307 & 0.07 & -0.21 \\
$\mathrm{WI}$ & 927 & 883 & 883 & -0.05 & 0.00 \\
\hline \hline
\end{tabular}

Table B.3: Farm Population (thousands), State Totals, 1940-1950

\begin{tabular}{lrrrrr}
\hline \hline State & $\mathbf{1 9 4 0}$ & $\mathbf{1 9 4 5}$ & $\mathbf{1 9 5 0}$ & $\begin{array}{c}\text { Pct. Chg. } \\
\mathbf{1 9 4 0 - 4 5}\end{array}$ & $\begin{array}{c}\text { Pct. Chg. } \\
\mathbf{1 9 4 5 - 5 0}\end{array}$ \\
\hline IA & 931 & 792 & 790 & -0.15 & 0.00 \\
IL & 979 & 759 & 773 & -0.22 & 0.02 \\
IN & 816 & 656 & 671 & -0.20 & 0.02 \\
KS & 607 & 480 & 445 & -0.21 & -0.07 \\
MI & 871 & 663 & 703 & -0.24 & 0.06 \\
MN & 915 & 731 & 746 & -0.20 & 0.02 \\
MO & 1125 & 855 & 869 & -0.24 & 0.02 \\
ND & 328 & 270 & 255 & -0.18 & -0.06 \\
NE & 498 & 404 & 393 & -0.19 & -0.03 \\
OH & 1089 & 842 & 870 & -0.23 & 0.03 \\
SD & 307 & 254 & 254 & -0.17 & 0.00 \\
WI & 883 & 720 & 733 & -0.18 & 0.02 \\
\hline \hline
\end{tabular}




\section{Alternative Dependent Variables}

The specifications in the paper estimate linear models for the fraction of farms in a county reporting a tractor. This appendix repeats the exercise for alternative definitions of diffusion.

The next check replaces diffusion with the log-odds ratio: if diffusion follows a logistic pattern in the explanatory variables, then the log-odds ratio will be linear in these variables. Though Griliches (1957) demonstrates that diffusion follows a logistic pattern over time, it is not ex-ante obvious that it does so in other variables - but in the event that it does, the results in Table C.1 lay to rest any concerns that the results in the paper are driven by mismeasurement of the dependent variable, as the patterns persist for the log-odds measure.

As discussed in the paper, the focal definition also imposes an assumption of perfect indivisibility, despite evidence to the contrary of cooperative ownership (Myers 1921) and custom work (Gilbert 1930). To ensure that the results are not sensitive to this assumption, in Table C.2 I re-estimate these regressions defining diffusion as the number of tractors per 100 acres of county farmland. The regressions for 1925-1930 are estimated on a sample excluding the Plains states (North and South

Dakota, Kansas, and Nebraska), where farmland was expanding rapidly at the time. The results are qualitatively similar to those in the body of the paper.

Tables C.3 to C.5 provide further checks on the main results, estimating specifications with Conley (1999) standard errors, which allow for spatial correlation in the error term that declines linearly in distance up to a fixed radius from the unit of observation. The tables set the cutoff radius to 20, 50, and 100 miles (respectively) from county centroids. Though the standard errors increase with the cutoff distance, the results continue to hold at the widest radius. 


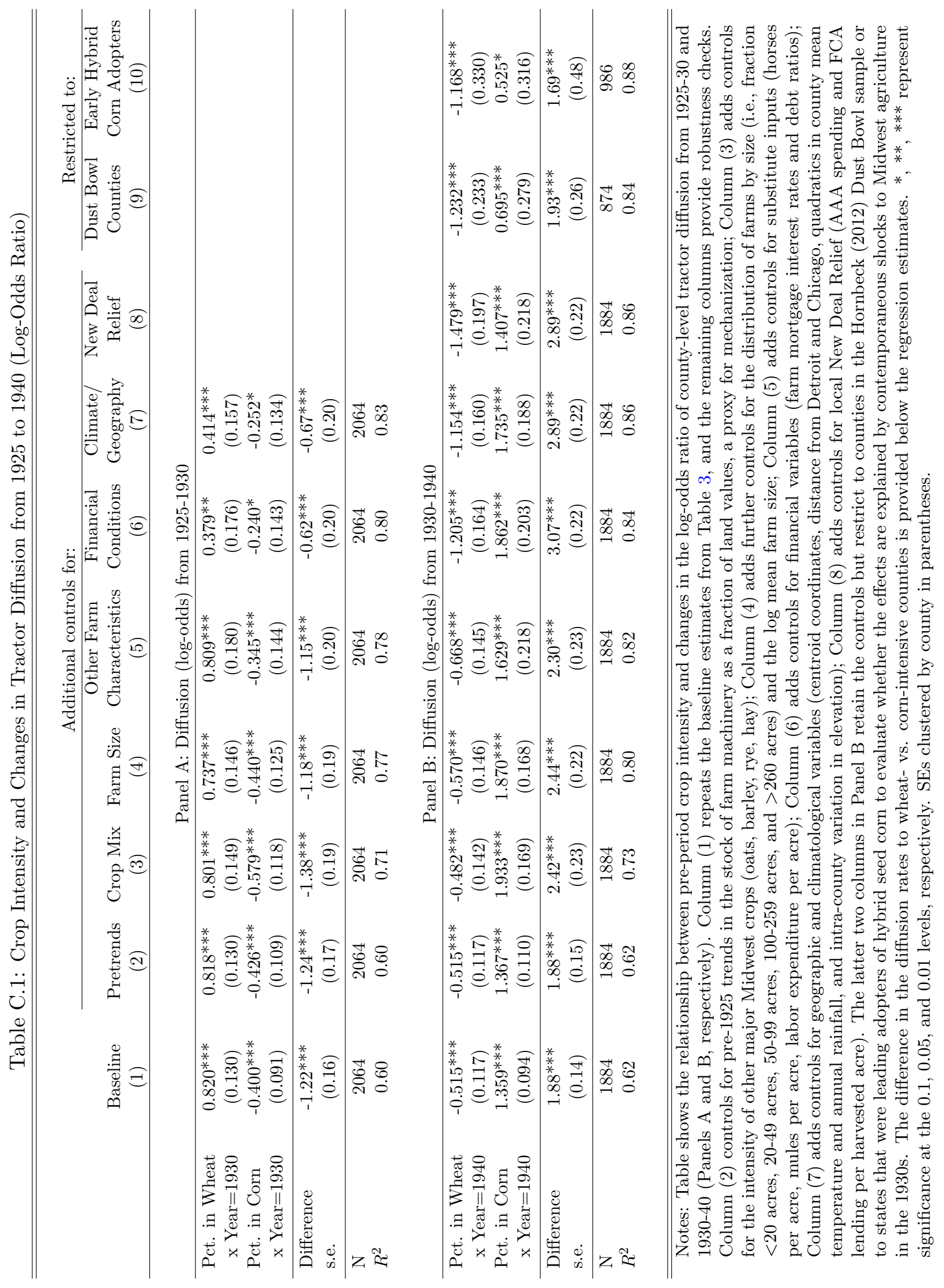




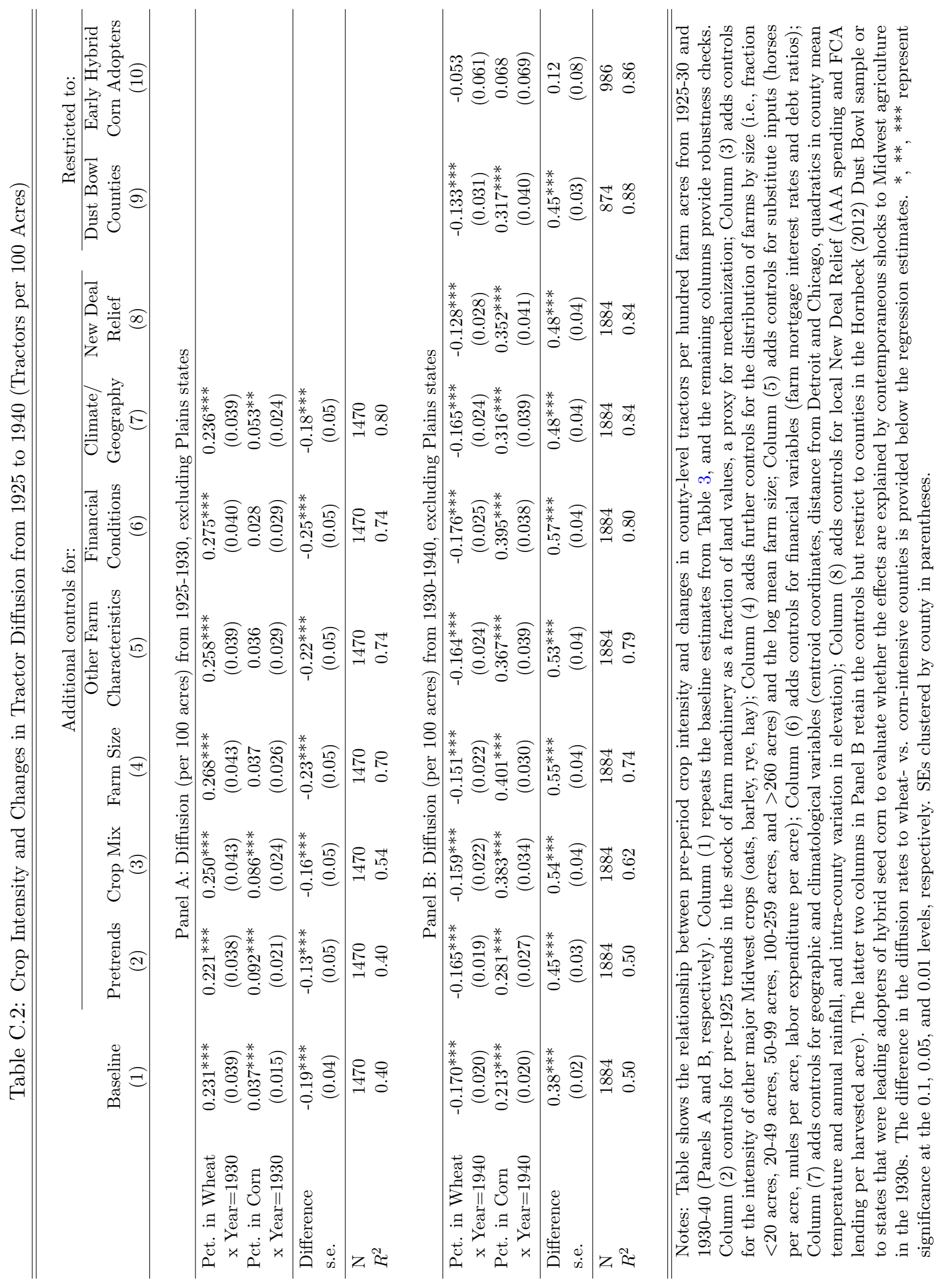




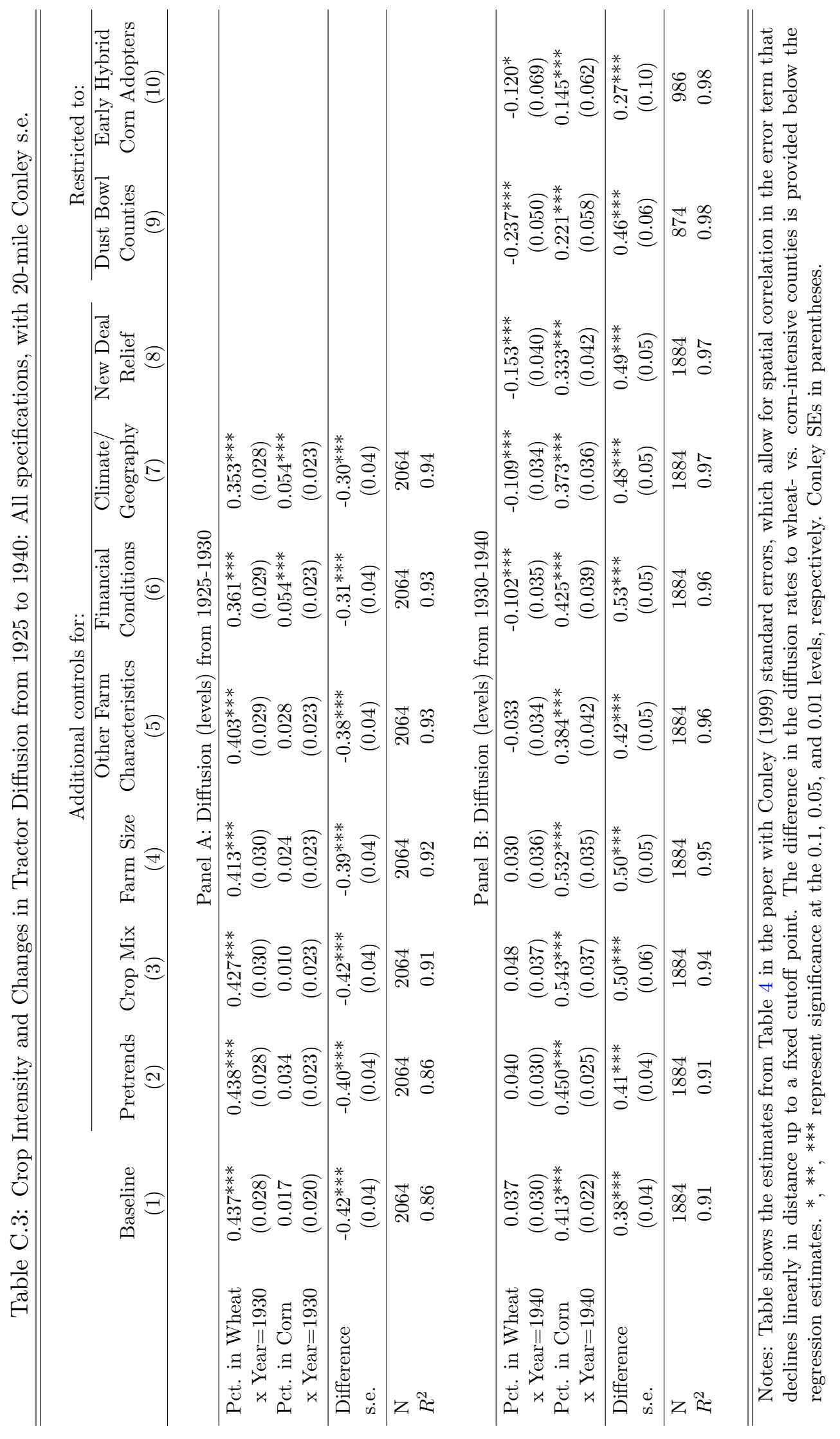




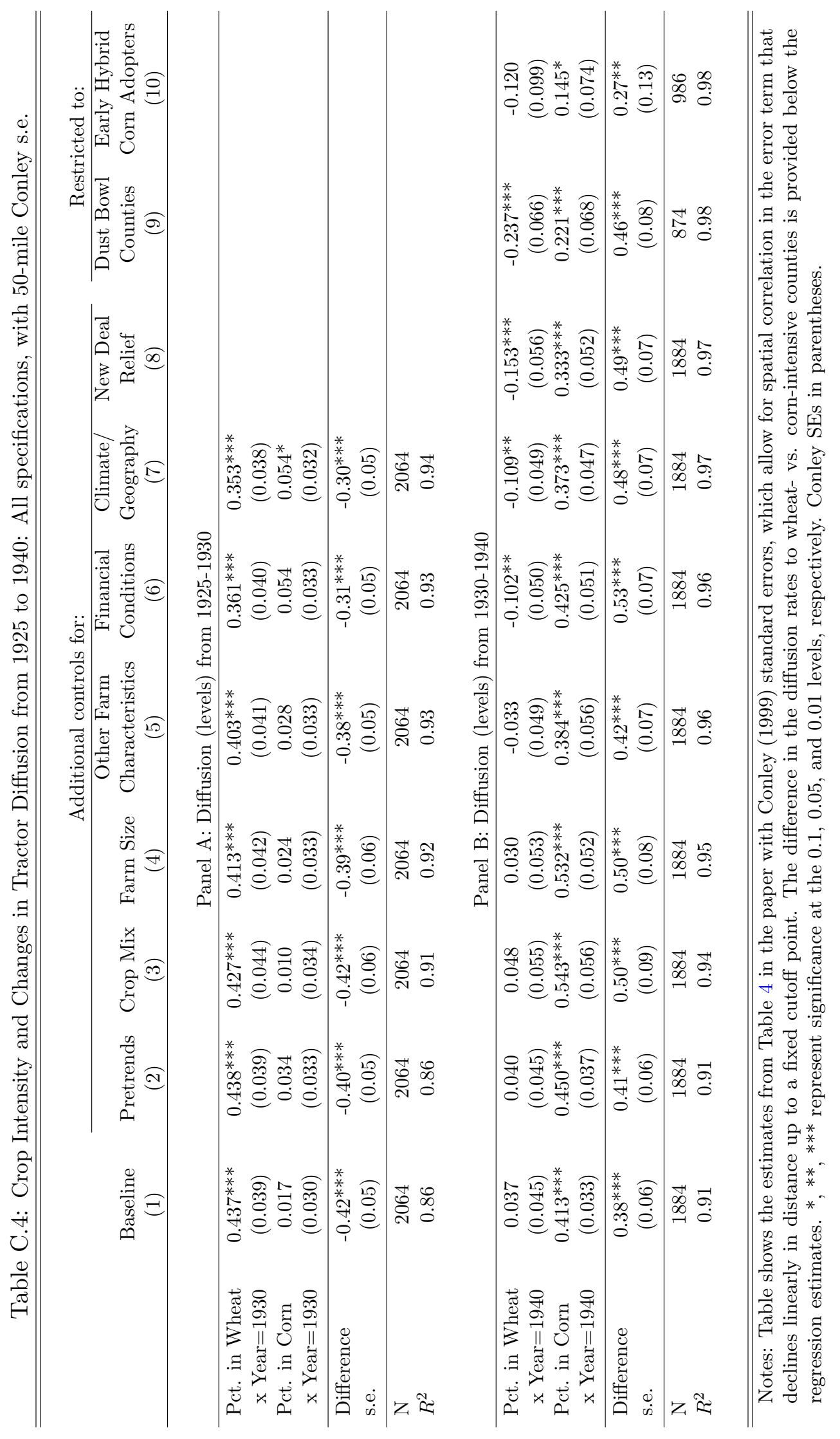




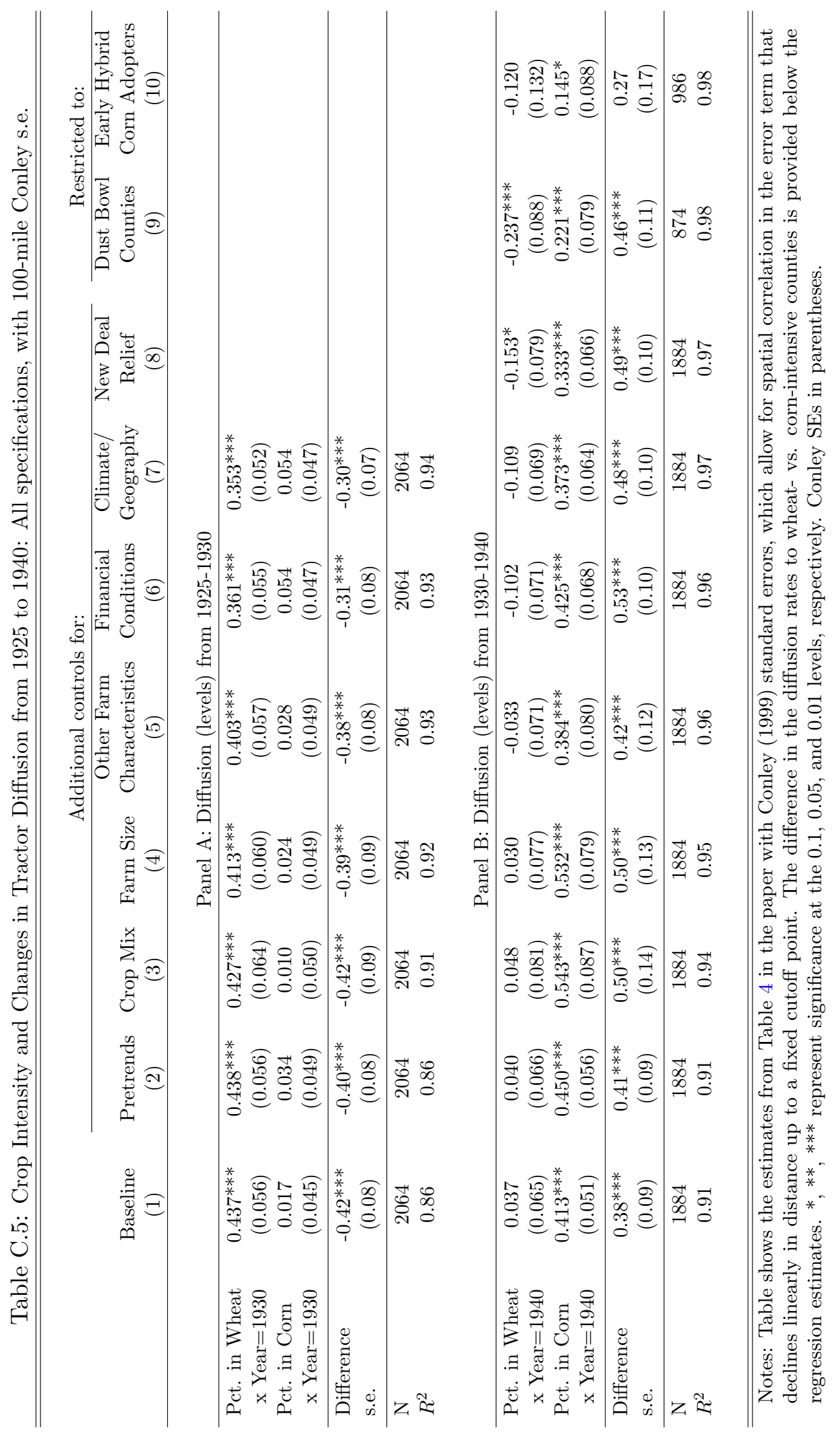




\section{Proofs of Propositions}

Before proving the propositions, it is useful to reiterate the core features and assumptions of the model, to have the details handy. Each sector $a \in\{1,2\}$ has a market size of $M$. The fraction of potential users in sector $a$ adopting the focal technology is:

$$
D_{a}=F\left(\left(z_{g}+z_{a}\right) T_{a}\right), \text { with } F^{\prime}(x)>0, F^{\prime \prime}(x)<0, F(0)=0 \text { and } \lim _{x \rightarrow \infty} F(x)=1
$$

Note that because the focal technology and its complements are perfect complements, demand from sector $a$ for each is identical. The total R\&D cost for the focal technology through time $t$ is the sum of the costs for developing each quality:

$$
C_{1}\left(z_{1, t}\right)+C_{2}\left(z_{2, t}\right)+C_{g}\left(z_{g, t}\right)
$$

where $C_{1}=C_{2}=C_{z}, C_{g}=\lambda C_{z}$ with $\lambda>1$; and $C_{z}(0)=C_{z}^{\prime}(0)=0, C_{z}^{\prime}(x)>0$ for $x>0$, and $C_{z}^{\prime \prime}(x)>0$. The complements have similar costs $\Gamma_{1}\left(T_{1, t}\right)$ and $\Gamma_{2}\left(T_{2, t}\right)$, where $\Gamma_{1}=\Gamma_{2}=\Gamma_{T}$, and $\Gamma_{T}$ is increasing convex, with derivative of zero at the origin.

In words, the demand curve in each sector is an increasing, concave function of quality originating at zero and asymptoting at $M(100 \%$ diffusion $)$. Note that the demand curve could be rewritten to be S-shaped and the same results would obtain, provided that demand initially grows more quickly than costs (otherwise no $R \& D$ will occur). The cost curve for each quality is an increasing, convex function that originates at zero with initially flat derivative.

Fixing a functional form is not necessary to proving the propositions, nor directly useful. However, example demand and cost functions that meet these conditions are:

$$
F\left(\left(z_{g}+z_{a}\right) T_{a}\right)=\frac{\left(z_{g}+z_{a}\right) T_{a}}{\left(z_{g}+z_{a}\right) T_{a}+1} \quad \text { and } \quad C_{a}\left(z_{a, t}\right)=\frac{1}{2}\left(z_{a, t}\right)^{2}
$$

Treating the quality parameters $z \in\left\{z_{1}, z_{2}, z_{g}\right\}$ and $T \in\left\{T_{1}, T_{2}\right\}$ as state variables, and denoting the possible increment to each one as $\delta_{z}$ or $\delta_{T}$, returns to R\&D are:

$$
\begin{aligned}
z_{1}, z_{2}: \Pi_{z_{1}}\left(\delta_{z} \mid \mathbf{z}, \mathbf{T}\right) & =\underbrace{M \cdot\left[F\left(\left(z_{g}+z_{a}+\delta_{z}\right) T_{a}\right)-F\left(\left(z_{g}+z_{a}\right) T_{a}\right)\right]}_{\text {Incremental benefit }}-\underbrace{\left[C_{a}\left(z_{a}+\delta_{z}\right)-C_{a}\left(z_{a}\right)\right]}_{\text {Incremental cost }} \\
z_{g}: \Pi_{z_{g}}\left(\delta_{z} \mid \mathbf{z}, \mathbf{T}\right) & =M \sum_{a=1,2}\left[F\left(\left(z_{g}+z_{a}+\delta_{z}\right) T_{a}\right)-F\left(\left(z_{g}+z_{a}\right) T_{a}\right)\right]-\left[C_{g}\left(z_{g}+\delta_{z}\right)-C_{g}\left(z_{g}\right)\right] \\
T_{1}, T_{2}: & \Pi_{T_{a}}\left(\delta_{T} \mid \mathbf{z}, \mathbf{T}\right)=M \cdot\left[F\left(\left(z_{g}+z_{a}\right)\left(T_{a}+\delta_{T}\right)\right)-F\left(\left(z_{g}+z_{a}\right) T_{a}\right)\right]-\left[\Gamma_{a}\left(T_{a}+\delta_{T}\right)-\Gamma_{a}\left(T_{a}\right)\right]
\end{aligned}
$$

And their FOCs are as follows:

$$
\begin{aligned}
z_{1}, z_{2}: & \Pi_{z_{a}}^{\prime}\left(\delta_{z} \mid \mathbf{z}, \mathbf{T}\right)=M \cdot F^{\prime}\left(\left(z_{g}+z_{a}+\delta_{z}\right) T_{a}\right) T_{a}-C_{a}^{\prime}\left(z_{a}+\delta_{z}\right)=0 \\
z_{g}: & \Pi_{z_{g}}^{\prime}\left(\delta_{z} \mid \mathbf{z}, \mathbf{T}\right)=M \cdot \sum_{a=1,2} F^{\prime}\left(\left(z_{g}+z_{a}+\delta_{z}\right) T_{a}\right) T_{a}-C_{g}^{\prime}\left(z_{g}+\delta_{z}\right)=0 \\
T_{1}, T_{2}: & \Pi_{T_{a}}^{\prime}\left(\delta_{T} \mid \mathbf{z}, \mathbf{T}\right)=M \cdot F^{\prime}\left(\left(z_{g}+z_{a}\right)\left(T_{a}+\delta_{T}\right)\right)\left(z_{g}+z_{a}\right)-\Gamma_{a}^{\prime}\left(T_{a}+\delta_{T}\right)=0
\end{aligned}
$$


Proposition 1. The Path of Product Development.

The focal technology will develop in the order of (i) $z_{1}$, (ii) $z_{g}$, and (iii) $z_{2}$. As such, it will develop as an application-specific technology before it becomes a general-purpose technology.

\section{Proof:}

By assumption, we have initial values of $z_{1,0}=z_{2,0}=z_{g, 0}=0, T_{1,0}=T>0$, and $T_{2,0}=0$.

The key elements of the proof are the following four observations:

1. $\mathrm{R} \& \mathrm{D}$ in $z_{2}$ requires that $T_{2}>0$ to be profitable

2. R\&D in $T_{2}$ requires that $z_{2}>0$ or $z_{g}>0$ to be profitable

3. $\mathrm{R} \& \mathrm{D}$ in $z_{g}$ requires that $T_{1}>0$ or $T_{2}>0$ to be profitable

4. $\mathrm{R} \& \mathrm{D}$ in $z_{1}$ requires that $T_{1}>0$ to be profitable

From these four observations it immediately follows that if $z_{2}$ is ever advanced, must be developed after $T_{2}$, which in turn must be developed after $z_{g}$, which will necessarily be developed because $T_{1}>0$ at time $t=0$. The question remains as to which of $z_{1}$ or $z_{g}$ will receive investment first, but because in the first period $T_{2}=0$, and $C_{g}\left(\delta_{z}\right)>C_{1}\left(\delta_{z}\right)$ for all $\delta_{z}>0$, investment in $z_{1}$ strictly dominates. The sequence of $\mathrm{R} \& \mathrm{D}$ is thus as follows:

$$
T_{1} \longrightarrow z_{1} \longrightarrow z_{g} \longrightarrow T_{2} \longrightarrow z_{2}
$$

More explicitly, in the first period, the returns to R\&D in the focal technology are:

$$
\begin{aligned}
& z_{1}: \Pi_{z_{1}}\left(\delta_{z} \mid \mathbf{z}_{t=0}, \mathbf{T}_{t=0}\right)=M \cdot F\left(\delta_{z} T\right)-C_{1}\left(\delta_{z}\right) \\
& z_{2}: \Pi_{z_{2}}\left(\delta_{z} \mid \mathbf{z}_{t=0}, \mathbf{T}_{t=0}\right)=0-C_{2}\left(\delta_{z}\right) \\
& z_{g}: \Pi_{z_{g}}\left(\delta_{z} \mid \mathbf{z}_{t=0}, \mathbf{T}_{t=0}\right)=M \cdot F\left(\delta_{z} T\right)-C_{g}\left(\delta_{z}\right)
\end{aligned}
$$

First, observe that because (i) $F(0)=C_{z}(0)=0$, and (ii) $F^{\prime}(x)>0, \forall x \geq 0$, and $\lim _{x \rightarrow 0} C_{z}^{\prime}(x)=0$ (by assumptions over the shape and position of the cost and demand curves):

$$
\forall z_{0} \geq 0 \text { and } \lambda \geq 1, \exists \varepsilon>0 \text { such that } F^{\prime}\left(z_{0}+\varepsilon\right)>C_{g}^{\prime}(\varepsilon)=\lambda C_{z}^{\prime}(\varepsilon)
$$

In words: because demand is increasing-concave in quality, with a positive derivative everywhere, while costs are increasing-convex, with zero derivative at zero, there will always be profit attainable from increasing quality from zero (provided the necessary complement exists).

Because $C_{g}\left(\delta_{z}\right)=\lambda C_{1}\left(\delta_{z}\right)>C_{1}\left(\delta_{z}\right)$ for all $\delta_{z}>0, z_{1}$ will be developed first, and will increase to the level $z_{1}=\delta_{z}^{*}$ which solves the FOC. After the first period, we have:

$$
z_{1, t=1}>0, z_{2, t=1}=0, z_{g, t=1}=0, T_{1, t=1}>0, T_{2, t=1}=0
$$


In the second period, the firm developing the complements has the opportunity to perform R\&D in $T_{1}$ and $T_{2}$. The FOCs for each of $T_{1}, T_{2}$ are:

$$
\begin{array}{ll}
T_{1}: & \Pi_{T_{1}}^{\prime}\left(\delta_{T} \mid \mathbf{z}_{t=1}, \mathbf{T}_{t=1}\right)=M \cdot F^{\prime}\left(z_{1, t=1}\left(T_{1, t=1}+\delta_{T}\right)\right) z_{1, t=1}-\Gamma_{1}^{\prime}\left(T_{1, t=1}+\delta_{T}\right)=0 \\
T_{2}: & \Pi_{T_{2}}^{\prime}\left(\delta_{T} \mid \mathbf{z}_{t=1}, \mathbf{T}_{t=1}\right)=0-\Gamma_{1}^{\prime}\left(\delta_{T}\right)=0
\end{array}
$$

Note that at this stage, the maximization problem for $T_{1}$ may either have an interior solution or a corner solution at $\delta_{T}=0$, and which of the two is the case depends on the precise form of the diffusion and cost functions, in particular how quickly the diffusion curve flattens and how quickly costs grow. Incrementing $T_{2}$ will never be profitable here.

If $T_{1}$ increments, it may increase the returns to additional $z_{1}$ in the next period (again, depending on precise functional form; in the example diffusion function given above, the cross-partial of profits w.r.t. $z_{1}$ and $T_{1}$ is positive at low values, when $T_{1}\left(z_{g}+z_{1}\right)<1$, and negative at high values, when $\left.T_{1}\left(z_{g}+z_{1}\right)>1\right)$. Whether this dynamic occurs is non-essential, because the asymptoting of the diffusion curve at the limit implies the returns to each will eventually be exhausted, after which either $z_{2}$ or $z_{g}$ will develop. For the present purposes, I will treat this dynamic as playing out in period $t=2$, such that by $t=3$,

$$
\begin{aligned}
& M \cdot F^{\prime}\left(z_{1, t=2} T_{1, t=2}\right) T_{1, t=2}=C_{1}^{\prime}\left(z_{1, t=2}\right) \\
& M \cdot F^{\prime}\left(z_{1, t=2} T_{1, t=2}\right) z_{1, t=2}=\Gamma_{1}^{\prime}\left(T_{1, t=2}\right)
\end{aligned}
$$

At the end of the second period, we thus have:

$$
z_{1, t=2}>0, z_{2, t=2}=0, z_{g, t=2}=0, T_{1, t=2}>0, T_{2, t=2}=0
$$

In the third period, the FOCs for each of $z_{1}, z_{2}, z_{g}$ are:

$$
\begin{array}{ll}
z_{1}: & \Pi_{z_{1}}^{\prime}\left(\delta_{z} \mid \mathbf{z}_{t=2}, \mathbf{T}_{t=2}\right)=M \cdot F^{\prime}\left(\left(z_{1, t=2}+\delta_{z}\right) T_{1, t=2}\right) T_{1, t=2}-C_{1}^{\prime}\left(z_{1, t=2}+\delta_{z}\right)=0 \\
z_{2}: & \Pi_{z_{2}}^{\prime}\left(\delta_{z} \mid \mathbf{z}_{t=2}, \mathbf{T}_{t=2}\right)=0-C_{2}^{\prime}\left(\delta_{z}\right)=0 \\
z_{g}: & \Pi_{z_{g}}^{\prime}\left(\delta_{z} \mid \mathbf{z}_{t=2}, \mathbf{T}_{t=2}\right)=M \cdot\left[F^{\prime}\left(\left(z_{1, t=2}+\delta_{z}\right) T_{1, t=2}\right) T_{1, t=2}+0\right]-C_{g}^{\prime}\left(\delta_{z}\right)=0
\end{array}
$$

At this juncture, the optimal $\delta_{z}$ for each of $z_{1}$ and $z_{2}$ is zero (in the former case, because marginal returns are exhausted; in the latter case, because returns are negative). However there are returns to be realized by incrementing $z_{g}$, which develops next.

At the end of the third period, we thus have:

$$
z_{1, t=3}>0, z_{2, t=3}=0, z_{g, t=3}>0, T_{1, t=3}>0, T_{2, t=3}=0
$$


In the fourth period, the FOCs for each of $T_{1}, T_{2}$ are:

$T_{1}: \quad \Pi_{T_{1}}^{\prime}\left(\delta_{T} \mid \mathbf{z}_{t=1}, \mathbf{T}_{t=1}\right)=M \cdot F^{\prime}\left(\left(z_{g, t=3}+z_{1, t=3}\right)\left(T_{1, t=3}+\delta_{T}\right)\right)\left(z_{g, t=3}+z_{1, t=3}\right)-\Gamma_{1}^{\prime}\left(T_{1, t=3}+\delta_{T}\right)=0$

$T_{2}: \Pi_{T_{2}}^{\prime}\left(\delta_{T} \mid \mathbf{z}_{t=1}, \mathbf{T}_{t=1}\right)=M \cdot F^{\prime}\left(z_{g, t=3} \delta_{T}\right) z_{g, t=3}-\Gamma_{1}^{\prime}\left(\delta_{T}\right)=0$

Now that the focal technology is productive in sector $2, \mathrm{R} \& \mathrm{D}$ in $T_{2}$ becomes profitable, $T_{2}$ will increment from zero. A similar feedback loop may play out as before, and is non-essential. We can treat this dynamic as playing out in period $t=4$, such that by $t=5$,

$$
\begin{aligned}
& M \cdot F^{\prime}\left(\left(z_{g, t=4}+z_{1, t=4}\right) T_{1, t=4}\right) T_{1, t=4}=C_{1}^{\prime}\left(z_{1, t=4}\right) \\
& M \cdot\left[F^{\prime}\left(\left(z_{g, t=4}+z_{1, t=4}\right) T_{1, t=4}\right) T_{1, t=4}+F^{\prime}\left(\left(z_{g, t=4}+0\right) T_{2, t=4}\right) T_{2, t=4}\right]=C_{g}^{\prime}\left(z_{g, t=4}\right) \\
& M \cdot F^{\prime}\left(\left(z_{g, t=4}+z_{1, t=4}\right) T_{1, t=4}\right)\left(z_{g, t=4}+z_{1, t=4}\right)=\Gamma_{1}^{\prime}\left(T_{1, t=4}\right) \\
& M \cdot F^{\prime}\left(\left(z_{g, t=4}+0\right) T_{2, t=4}\right)\left(z_{g, t=4}+0\right)=\Gamma_{2}^{\prime}\left(T_{2, t=4}\right)
\end{aligned}
$$

At the end of the fourth period, we thus have:

$$
z_{1, t=3}>0, z_{2, t=3}=0, z_{g, t=3}>0, T_{1, t=3}>0, T_{2, t=3}>0
$$

In the next period, the FOCs for each of $z_{1}, z_{2}, z_{g}$ are:

$$
\begin{gathered}
z_{1}: \quad \Pi_{z_{1}}^{\prime}\left(\delta_{z} \mid \mathbf{z}_{t=4}, \mathbf{T}_{t=4}\right)=M \cdot F^{\prime}\left(\left(z_{g, t=4}+z_{1, t=4}+\delta_{z}\right) T_{1, t=4}\right) T_{1, t=4}-C_{1}^{\prime}\left(z_{1, t=4}+\delta_{z}\right)=0 \\
z_{2}: \quad \Pi_{z_{2}}^{\prime}\left(\delta_{z} \mid \mathbf{z}_{t=4}, \mathbf{T}_{t=4}\right)=M \cdot F^{\prime}\left(\left(z_{g, t=4}+\delta_{z}\right) T_{1, t=4}\right) T_{1, t=4}-C_{2}^{\prime}\left(\delta_{z}\right)=0 \\
z_{g}: \quad \Pi_{z_{g}}^{\prime}\left(\delta_{z} \mid \mathbf{z}_{t=4}, \mathbf{T}_{t=4}\right)=M \cdot\left[F^{\prime}\left(\left(z_{g, t=4}+z_{1, t=4}+\delta_{z}\right) T_{1, t=4}\right) T_{1, t=4}\right. \\
\left.+F^{\prime}\left(\left(z_{g, t=4}+\delta_{z}\right) T_{2, t=4}\right) T_{2, t=4}\right]-C_{g}^{\prime}\left(\delta_{z}\right)=0
\end{gathered}
$$

At this juncture, the optimal $\delta_{z}$ for each of $z_{1}$ and $z_{g}$ are zero, because the marginal returns are exhausted. However there are returns to be realized by incrementing $z_{2}$, which develops last. 
Although outside the scope of this paper, this proposition can also be obtained when complements are initially available in both sectors, i.e. $T_{1,0}>0$ and $T_{2,0}>0$, if one of the following is true:

1. Sectors 1 and 2 have heterogeneous market sizes $M_{1}$ and $M_{2}$

2. $z_{1}$ and $z_{2}$ have different cost functions, $C_{1} \neq C_{2}$

3. $T_{1}$ and $T_{2}$ have different initial values, $T_{1,0} \neq T_{2,0}$

In this case, because $T_{2,0}>0, z_{2}$ is a candidate to develop in the first period, in addition to $z_{1}$ and $z_{g}$ as before. Between $z_{1}$ and $z_{2}$, the more advantaged of the two (i.e., that with the larger market size, lower R\&D cost, or higher-quality complement) will develop first. Without loss of generality, suppose that $z_{1}$ is the more advantaged of the two. To be advantaged over $z_{g}$, which will yield the greatest raw benefits because it diffuses to both sectors, it must be the case that $C_{g}=\lambda C_{1}$ is sufficiently greater than $C_{1}$ so as to make $z_{g}$ initally unattractive. However, $z_{g}$ will develop next if sufficiently cheap so as to be more attractive than $z_{2}$.

Formally, in the first period, the returns to incrementing each of $z_{1}, z_{2}, z_{g}$ by $\delta_{z}$ is:

$$
\begin{aligned}
& z_{1}: \Pi_{z_{1}}\left(\delta_{z} \mid \mathbf{z}_{t=0}, \mathbf{T}_{t=0}\right)=M_{1} \cdot F\left(\delta_{z} T_{1}\right)-C_{1}\left(\delta_{z}\right) \\
& z_{2}: \Pi_{z_{2}}\left(\delta_{z} \mid \mathbf{z}_{t=0}, \mathbf{T}_{t=0}\right)=M_{2} \cdot F\left(\delta_{z} T_{2}\right)-C_{2}\left(\delta_{z}\right) \\
& z_{g}: \Pi_{z_{g}}\left(\delta_{z} \mid \mathbf{z}_{t=0}, \mathbf{T}_{t=0}\right)=M_{1} \cdot F\left(\delta_{z} T_{1}\right)+M_{2} \cdot F\left(\delta_{z} T_{2}\right)-C_{g}\left(\delta_{z}\right)
\end{aligned}
$$

If (i) $M_{1}>M_{2}, C_{1}=C_{2}$, and $T_{1}=T_{2}$, then $z_{1}$ is more profitable than $z_{2}$. The same is true if either (ii) $M_{1}=M_{2}, C_{1}<C_{2}$, and $T_{1}=T_{2}$, or (iii) $M_{1}=M_{2}, C_{1}=C_{2}$, and $T_{1}>T_{2}$.

For $z_{1}$ to be more attractive than $z_{g}$, we need that:

$$
\begin{aligned}
M_{1} \cdot F\left(\delta_{z} T_{1}\right)-C_{1}\left(\delta_{z}\right) & >M_{1} \cdot F\left(\delta_{z} T_{1}\right)+M_{2} \cdot F\left(\delta_{z} T_{2}\right)-C_{g}\left(\delta_{z}\right) \\
-C_{1}\left(\delta_{z}\right) & >M_{2} \cdot F\left(\delta_{z} T_{2}\right)-C_{g}\left(\delta_{z}\right) \\
C_{g}\left(\delta_{z}\right) & >M_{2} \cdot F\left(\delta_{z} T_{2}\right)+C_{1}\left(\delta_{z}\right)
\end{aligned}
$$

Suppose this condition holds, and that $z_{1}$ initially increments to $z_{1}^{*}$, and suppose $T_{1}$ is subsequently unchanged. For $z_{g}$ to then be more attractive than $z_{2}$, we need that:

$$
\begin{gathered}
M_{1} \cdot\left[F\left(\left(z_{1}^{*}+\delta_{z}\right) T_{1}\right)-F\left(z_{1}^{*} T_{1}\right)\right]+M_{2} \cdot F\left(\delta_{z} T_{2}\right)-C_{g}\left(\delta_{z}\right)>M_{2} \cdot F\left(\delta_{z} T_{2}\right)-C_{2}\left(\delta_{z}\right) \\
M_{1} \cdot\left[F\left(\left(z_{1}^{*}+\delta_{z}\right) T_{1}\right)-F\left(z_{1}^{*} T_{1}\right)\right]-C_{g}\left(\delta_{z}\right)>-C_{2}\left(\delta_{z}\right) \\
M_{1} \cdot\left[F\left(\left(z_{1}^{*}+\delta_{z}\right) T_{1}\right)-F\left(z_{1}^{*} T_{1}\right)\right]+C_{2}\left(\delta_{z}\right)>C_{g}\left(\delta_{z}\right)
\end{gathered}
$$


Proposition 2. R\&D spillovers (complementors' rents from own R\&D).

If developers can earn rents on the contemporaneous, incremental sales of complements generated by their own REDD, then firms would invest more heavily in RED in each period.

\section{Proof:}

The proposition will be shown for $\mathrm{R} \& \mathrm{D}$ in $z_{1}$, as the results generalize to $z_{2}, z_{g}, T_{1}$, and $T_{2}$. Suppose the firm developing the focal technology earns $\theta>0$ per unit of the complement sold as a result of its own R\&D. The R\&D profit function is then:

$$
\Pi_{z_{1}}\left(\delta_{z} \mid \mathbf{z}, \mathbf{T}\right)=M \cdot(1+\theta) \cdot\left[F\left(\left(z_{g}+z_{1}+\delta_{z}\right) T_{1}\right)-F\left(\left(z_{g}+z_{1}\right) T_{1}\right)\right]-\left[C_{1}\left(z_{1}+\delta_{z}\right)-C_{1}\left(z_{1}\right)\right]
$$

The FOC is in turn:

$$
\Pi_{z_{1}}^{\prime}\left(\delta_{z} \mid \mathbf{z}, \mathbf{T}\right)=M \cdot(1+\theta) \cdot F^{\prime}\left(\left(z_{g}+z_{1}+\delta_{z}\right) T_{1}\right) T_{1}-C_{1}^{\prime}\left(z_{1}+\delta_{z}\right)=0 \quad,
$$

where the solution $\delta_{z}^{* *}$ satisfies

$$
\frac{C_{1}^{\prime}\left(z_{1}+\delta_{z}^{* *}\right)}{F^{\prime}\left(\left(z_{g}+z_{1}+\delta_{z}^{* *}\right) T_{1}\right) T_{1}}=M \cdot(1+\theta)
$$

whereas in the absence of rents from complements, the solution $\delta_{z}^{*}$ satisfied

$$
\frac{C_{1}^{\prime}\left(z_{1}+\delta_{z}^{*}\right)}{F^{\prime}\left(\left(z_{g}+z_{1}+\delta_{z}^{*}\right) T_{1}\right) T_{1}}=M
$$

Combining these expressions, we have that:

$$
\frac{C_{1}^{\prime}\left(z_{1}+\delta_{z}^{* *}\right)}{C_{1}^{\prime}\left(z_{1}+\delta_{z}^{*}\right)} \cdot \frac{F^{\prime}\left(\left(z_{g}+z_{1}+\delta_{z}^{*}\right) T_{1}\right) T_{1}}{F^{\prime}\left(\left(z_{g}+z_{1}+\delta_{z}^{* *}\right) T_{1}\right) T_{1}}=(1+\theta)>1
$$

Because $F^{\prime \prime}(x)<0$ and $C_{1}^{\prime \prime}(x)>0$,

$$
\delta_{z}^{* *}>\delta_{z}^{*}
$$




\section{E Scope in the Diffusion of Hybrid Corn}

Griliches' (1957) foundational study of the diffusion of hybrid seed corn provides another clear example of the distinction between scale and scope in diffusion. Griliches demonstrates that local diffusion of hybrid corn follows an S-curve over time, and shows that it can be closely fitted by a logistic function parametrized by three arguments: one characterizing when diffusion begins, another characterizing the rate at which it proceeds - what this paper terms scope and scale, respectively - and a third which defines the ceiling, if diffusion settles at a value of less than 100 percent. Subsequent research on diffusion, however, typically does not distinguish between them. The key insight that is often overlooked, as it relates to the present paper, is that the diffusion of hybrid corn required seed varieties adapted to local growing conditions.

Because product development often proceeds from specific- to general-purpose variants, as in the model in Section 6, diffusion may even follow the characteristic S-curve not only within applications, but also across them. This in fact appears to have been the case for hybrid corn: for any fixed level

of diffusion, and in particular for lower levels indicating availability of locally-adapted varieties, the number of states that had surpassed that level of diffusion forms an S-shape over time (Figure E.2), much as diffusion within individual states followed an S-curve (Figure E.1, reproducing Griliches' Figure 1). Note that discerning this S-curve requires diffusion data at relatively high frequency, which is available for hybrid corn, and with data only available at 5- to 10-year intervals for tractors, there are not enough datapoints to draw the analogous curves. 
Figure E.1: Reproduction of Griliches (1957) Fig. 1:

Percent of corn acreage planted to hybrids

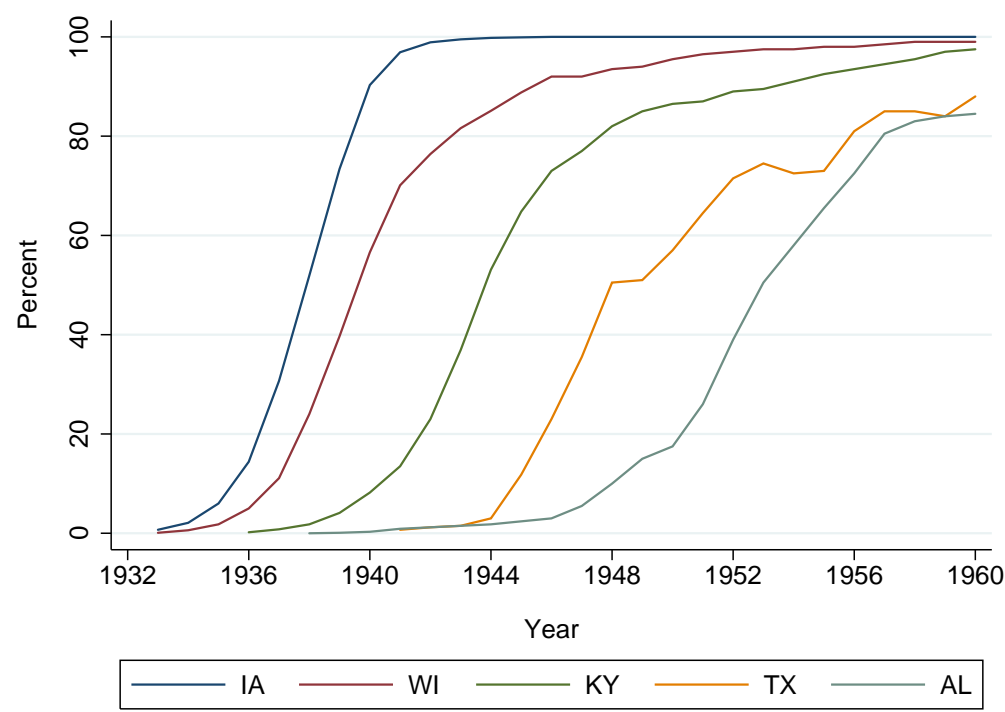

Notes: Figure shows the characteristic S-shaped hybrid corn diffusion curve for each of Iowa, Wisconsin, Kentucky, Texas, and Alabama, reproducing Figure 1 of Griliches (1957). Data from USDA Agricultural Statistics.

Figure E.2: Distribution of states, by year at which given level of hybric corn diffusion attained
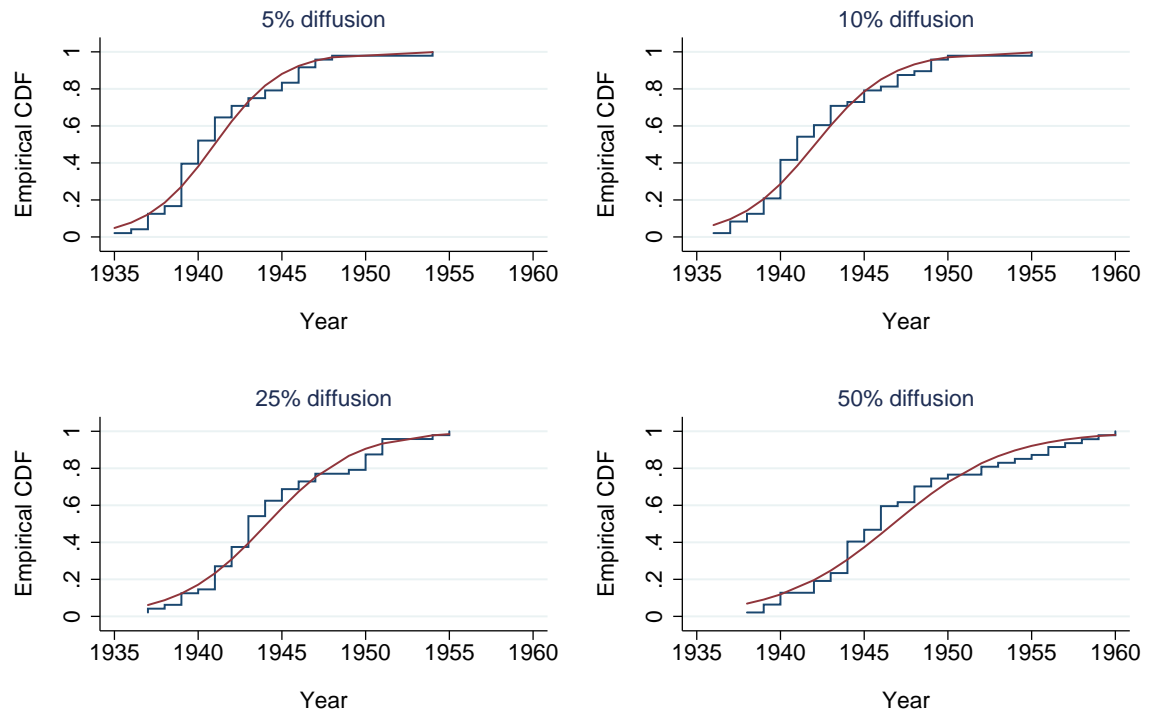

\section{Empirical CDF — Fitted logistic}

Notes: Figure shows the distribution of U.S. states by the year at which they attain a given level of hybrid corn diffusion, measured as the percentage of corn acreage planted to hybrids. Data from USDA Agricultural Statistics. 


\section{F Details of Labor Savings Calculations}

Starting point: U.S. labor savings from tractorization in $\mathbf{1 9 4 4}$

(1) 1,700 Labor savings from tractorization, 1944 (millions of hours) Cooper-Barton-Brodell (1947)

Calculation: Subset of U.S. labor savings in 1944 from Midwest

(2) 1,169,154 Farms in Midwest with tractors, 1945

(3) 2,002,662 Farms in U.S. with tractors, 1945

(4) $58.4 \% \quad$ Midwest share of adopting farms, 1945 Midwest share of labor savings, 1944 (millions of hours)

(Assumes labor savings constant across mechanized farms.

(5) $992.46 \quad$ Note that this is likely to be a lower bound, as labor savings should be relatively larger in the Midwest, where the crop mix is more amenable to mechanization.)

Calculation: Added labor savings in 1930 under counterfactual Calculated: $(2) /(3)$

(6) $11.4 \% \quad$ Increase in diffusion from 1925-30, actual

(7) $25.6 \%$ Resulting diffusion in 1930, actual

(8) 0.4351 Diffusion in 1930 (actual) : Diffusion in 1945

(9) $431.86 \quad$ Multiplied by 1944 Midwest labor savings

(10) $431.86 \quad$ Midwest labor savings in 1930, actual (millions of hours)

(11) $18.0 \% \quad$ Increase in diffusion from 1925-30, c.f.

(12) $32.2 \% \quad$ Resulting diffusion in 1930, c.f.

(13) $\quad 0.5470 \quad$ Diffusion in 1930 (c.f.) : Diffusion in 1945

(14) $542.85 \quad$ Multiplied by 1944 Midwest labor savings

(15) $542.85 \quad$ Midwest labor savings in 1930, c.f. (millions of hours)

(16) $110.99 \quad$ Increase in labor savings in counterfactual (millions of hours)

U.S. Ag Census (1930)

U.S. Ag Census (1930)

U.S. Ag Census (1930, 1945)

Calculated: $(5) *(8)$

Repeated from above

U.S. Ag Census (1930)

U.S. Ag Census (1930)

U.S. Ag Census $(1930,1945)$

Calculated: $(5) *(13)$

Repeated from above

Calculated: (15)-(10)

Calculation: Added labor savings in 1930 as fraction of hired labor

(17) $136.04 \quad$ Days of labor employed in Midwest agriculture, 1930 (millions)

(18) $1,088.35 \quad$ Hours of labor employed in Midwest agriculture, 1930 (millions)

(19) $10.2 \% \quad$ Labor savings as a percent of hired labor

Calculation: Gross value of added labor savings, at prevailing market wages

(20) 55,496 Increase in labor savings in counterfactual (FTEs)

(Assumes FTE works $2000 \mathrm{hrs} / \mathrm{yr}$, or 50 weeks at $40 \mathrm{hrs} / \mathrm{wk}$ )

(21) $0.845 \quad$ Fraction of non-farm labor in manufacturing

(22) $1437 \quad$ Average wage in Midwest manufacturing

(23) $67.35 \quad$ Increase in output, manufacturing (million $\$ \mathrm{~s}$ )

(24) $0.155 \quad$ Fraction of non-farm labor in wholesale

(25) $1854 \quad$ Average wage in Midwest wholesale

(26) $15.97 \quad$ Increase in output, wholesale (million \$s)

(27) $83.32 \quad$ Sum: Value of labor savings (million \$s)

Calculation: Gross value, rel. to 2014 Midwest agricultural output

(28) $11.44 \quad$ Inflating factor: 1930 to 2014

(29) $952.97 \quad$ Value of labor savings, 2014 dollars (millions)

(30) 80,606 Agricultural GDP in Midwest, 2014 (millions)

(31) $1.2 \% \quad$ Labor savings as percent of current regional output
U.S. Ag Census (1930)

Calculated: $(17)^{*} 8$

Calculated: $(16) /(18)$

Calculated: $(16) / 2000$

U.S. Pop Census (1930)

U.S. Pop Census (1930)

Calculated: $(20)^{*}(21) *(22)$

U.S. Pop Census (1930)

U.S. Pop Census (1930)

Calculated: $(20) *(24) *(25)$

Calculated: $(23)+(26)$

BEA GNP Price Deflator Calculated: $(27)^{*}(28)$ BEA GDP by State tables Calculated: $(29) *(30)$ 